DOE/JPL-1060-77/1

Distribution Category UC-62

(ITASA-CR-155427) PROJECTION OF

N78-15568

DISTRIBUTED-COLLECTOR SOLAR-THERMAL ELECTRIC

POWER PLANT ECONOMICS TO YEARS 1990-2000.

(Jet Propulsion Iab.) $90 \mathrm{p} \mathrm{HC} \mathrm{A05/MF} \mathrm{A01}$

CSCI 10B G3/44 57815 .

Thermal Power Systems

Research and Development Project

\title{
Projection of Distributed-Collector Solar-Thermal Electric Power Plant Economics to Years 1990-2000
}

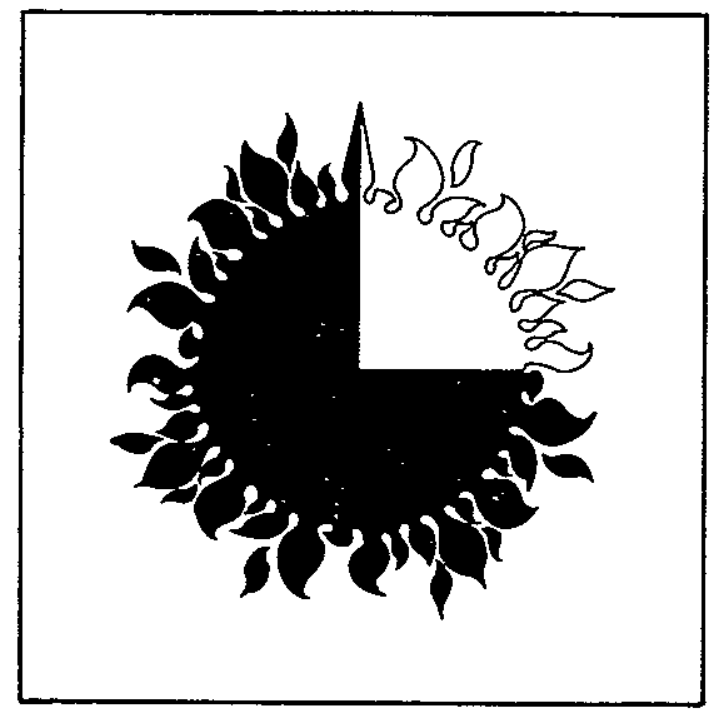

Prepared for

Department of Energy

by

Jet Propulsion Laboratory

California Institute of Technology

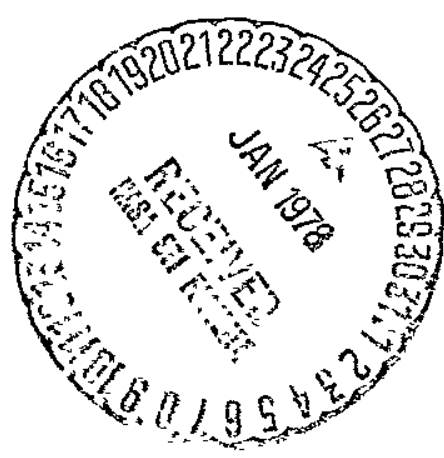

- Pasadena, California

(JPL PUBLICATION 77-79) 
Printed in the United States of America Available from

National Technical Information Service

U.S. Department of Commerce

5285 Port Royal Road

Springfield, VA 22161

Price: Printed Copy $\$ 6.00$ : Microfiche $\$ 3.00$ 


\begin{tabular}{|c|c|}
\hline 1. Report No. JPL Pub. $77-79$ & 3. Recipient's Catalog No. \\
\hline \multirow{2}{*}{$\begin{array}{l}\text { 4. Title and Subtitle } \\
\text { Projection of Distributed-Collector Solar-Therma1 } \\
\text { Electric Power Plant Economics to Years 1990-2000 }\end{array}$} & $\begin{array}{l}\text { 5. Report Date } \\
\text { December } 1977\end{array}$ \\
\hline & 6. Performing Organization Code \\
\hline $\begin{array}{l}\text { 7. Author(s) } \\
\text { T. Fujita/N. E1 Gabalawi/G. Herrera/R. H. Turner }\end{array}$ & 8. Performing Organization Report No. \\
\hline \multirow{3}{*}{$\begin{array}{l}\text { 9. Performing Organization Name and Address } \\
\text { JET PROPULSION LABORATORY } \\
\text { California Institute of Technology } \\
\text { 4800 Oak Grove Drive } \\
\text { Pasadena, California } 91103\end{array}$} & 10. Work Unif No. \\
\hline & $\begin{array}{c}\text { 11. Contract or Grant No. } \\
\text { NAS 7-100 }\end{array}$ \\
\hline & 13. Type of Report and Period Covered \\
\hline \multirow{2}{*}{$\begin{array}{l}\text { 12. Sponsoring Agency Name and Address } \\
\text { NATIONAI AERONAUTICS AND SPACE ADMINISTRATION } \\
\text { Washington, D.C. } 20546\end{array}$} & JPL Publication \\
\hline & 14. Sponsoring Agency Code \\
\hline
\end{tabular}

15. Supplementary Notes

16. Abstract

A preliminary comparative evaluation of distributed-collector solar thermal power plants has been undertaken by projecting power plant economics of selected systems to the 1990-2000 time frame. The selected systems include: (1) fixed orientation (non-tracking) collectors with concentrating reflectors and vacuum tube absorbers, (2) one-axis tracking linear concentrators including parabolic trough and variable slat designs, and (3) two-axis tracking parabolic dish ystems including concepts w1th small heat engine-electric generator assemblies at each focal point as well as approaches having steam generators at the focal point with pipeline collection to a central power conversion unit.

Comparisons are presented primarily in terms of energy cost (mills/kWe hr) and capitol cost over a wide range of operating load factors. Sensitivity of energy costs for a range of efficiency and cost of major subsystems/components is presented to delineate critical technological development needs. The baseline central receiver or poer tower systems using state-of-the-art $1000^{\circ} \mathrm{F}$ steam Rankine technology is used as a reference case for making comparisons of the selected distributed collector systems.

17. Key Words (Selected by Author(s)) Energy Production and Conversion Systems Analysis
18. Distribution Statement

Unclassified - UnIimited
19. Security Classif. (of this report) Unclassified
20. Security Classif. (of this page)

Unclassified
21. No. of Pages 89
22. Price 


\section{HOW TO FILL OUT THE TECHNICAL REPORT STANDARD TITLE PAGE}

Make items 1, 4, 5, 9, 12, and 13 agree with the corresponding information on the report cover. Use all capital letters for title (item 4). Leave items 2, 6, and 14 blank. Complete the remaining items as follows:

3. Recipient's Catalog No. Reserved for use by report reciptents.

7. Author(s). Include corresponding information from the report cover. In addition, list the affiliation of an author if it differs from that of the performing organization.

8. Performing Organization Reporf No. Insert if performing organization wishes to assign this number.

10. Work Unit No. Use the agency-wide code (for example, 923-50-10-06-72), which uniquely identifies the work unit under which the work was authorized. Non-NASA performing organizations will leave this blank.

11. Insert the number of the contract or grant under which the report was prepared.

15. Supplementary Notes. Enter information not included elsewhere but useful, such as: Prepared in cooperation with... Translation of (or by)... Presented at conference of... To be published in...

16. Abstract. Include a brief (not to exceed 200 words) factual summary of the most significant information contained in the report. If possible, the abstract of a classified report should be unclassified. If the report contains a significant bibliography or literature survey, mention it here.

17. Key Words. Insert terms or short phrases selected by the author that identify the principal subjects covered in the report, and that are sufficiently specific and precise to be used for cataloging.

18. Distribution Statement. Enter one of the authorized statements used to denote releasability to the public or a limitation on dissemination for reasons other than security of defense information. Authorized statements are "Unclassified-Unlimited," "U.S. Government and Contractors only," "U.S. Government Agencies only, "and "NASA and NASA Contractors only."

19. Security Classification (of report). NOTE: Reports carrying a security classification will require additional markings giving security and downgrading information as specified by the Security Requirements Checklist and the DoD Industrial Security Manual (DoD 5220.22-M).

20. Security Classification (of this page). NOTE: Because this page may be used in preparing announcements, bibliographies, and data banks, it should be unclassified if possible. If a classification is required, indicate separately the classification of the title and the abstract by following these items with either "(U)" for unclassified, or "(C)" or "(S)" as applicable for classified items.

21. No. of Pages. Insert the number of pages.

22. Price. Insert the price set by the Clearinghouse for Federal Scientific and Technical Information or the Government Printing Office, if known. 
DOE/JPL-1060-77/1

Distribution Category UC-62

\section{Thermal Power Systems}

Research and Development Project

\section{Projection of Distributed-Collector Solar-Thermal Electric Power Plant Economics to Years 1990-2000}

T. Fujita

N. El Gabalawi

G. Herrera

R. H. Turner

December 1977

Prepared for

Department of Energy

by

Jet Propulsion Laboratory

California institute of Technology

Pasadena, Calıfornı

(JPL PUBLICATION 77-79) 
This document was prepared by the Jet Propulsion Laboratory, Calıforna Institute of Technology, for the Department of Energy, Division of Solar Energy under an Interagency Agreement with the Natıonal Aeronautıcs and Space Adminıstratıon

This report was prepared as an account of work sponsored by the United States Government Nelther the United States nor the United States Department of Energy, nor any of their employees, nor any of their contractors, subcontractors, or their employees, makes any warranty, express or implied, or assumes any legal liabılity or responsibility for the accuracy, completeness or usefulness of any information, apparatus, product or process disclosed, or represents that its use would not infringe privately owned rights 
FOREWORD

The primary objective of this study is to project power plant economics for optional distributed-collector solar-thermal power stations to the 1990-2000 time frame. The present report summarizes the major results which essentially update and extend prior work:

"An Initial Comparative Assessment of Orbital and Terrestrial Central Power Systems", Final Report No. 900-780, prepared by R. Caputo, Jet Propulsion Laboratory, NASA, March 1977.

The above report contains detailed explanatıons of the economic methodology along with assumptions regarding factors such as differential inflation rates for solar systems. This report also projects the performance and costs of central solar power plants ( 100 MWe rating) to the year 2000. Included in these power plants are the central receiver and two-axis tracking distributed-collector parabolic dish systems. The present report considers two additional distributed-collector systems, namely one-axis tracking, linear systems and fixed, non-tracking systems. The non-distrubuted collector, central receiver, system is included for reference purposes. The present study also analyzes size effects by considering a range of plant ratings from 0.1 MWe to 1000 MWe.

As a basis for the present report, the status of solar power plant technology has been surveyed and assessed with primary emphasis placed on concentrator costs. The updated data base from this activity serves as the input to the economic projections presented in this report. 


\section{ACKNOWLEDGEMENTS}

Mr. Richard Caputo of JPL was responsible for inituating the study effort. He also provided guidance and support during all phases of the study. His invaluable contribution is gratefully acknowledged.

During the course of the study, the authors interfaced with the Solar Thermal Power group at JPL who raised specific questions that helped define the detailed contents of this study. This interaction is gratefully acknowledged since it enabled the effort to maximally support the planning activities to the extent possible within the scope of the study.

The cooperation and support of specialists from both industry and research laboratories in providing inputs to the data base is especially appreciated. The support of the solar concentrator manufacturers, as detailed in the Appendix $A$ of this report, was particularly useful.

The support of Shozo Murakami in handling the report preparation and publication, and the diligent work of Mary Lou Downey, Gerilynn Abracosa, Peggy Panda, Pamela Uttke, and Laurel Flinn in typing the report is gratefully acknowledged.

The authors wish to particularly acknowledge the support provided by Mr. Martin Gutstein, Advanced Technology Branch, DOE Thermal Power Systems.

This report summarizes the work sponsored by DOE, Division of Solar Energy under the Interagency Agreement, EX-76-A-29-1060, with NASA. 


\begin{abstract}
A prelimanary comparative evaluation of distributed-collector solar thermal power plants has been undertaken by projecting power plant economics of selected systems to the 1990-2000 time frame. The selected systems include: (1) flxed orientation (non-tracking) collectors with concentrating reflectors and vacuum tube absorbers, (2) one-axis tracking linear concentrators including parabolic trough and variable slat designs, and (3) two-axis tracking parabolic dish systems including concepts with small heat engine-electric generator assemblies at each focal point as well as approaches having steam generators at the focal point with pipeline collectıon to a central power conversıon unit.

Compaxisons are presented pximarily in terms of energy cost (mills/kWe $\mathrm{hr}$ ) and capital cóst over a wide range of operating load factors. Sensitivity of energy costs for a range of efficiency and cost of major subsystems/components is presented to delineate critical technological development needs. The baseline central recelver or power tower systems using state-of-the-art $1000^{\circ} \mathrm{F}$ steam Rankine technology is used as a reference case for making comparisons of the selected distributed collector systems.
\end{abstract}




CONTENTS

I. INTRODUCTION . . . . . . . . . . . . . . . . I-I

A. STUDY BASTS . . . . . . . . . . . . . . 1-1

B. SUMMARY ................. I-3

II. SELECTED SYSTEMS ... . . . . . . . . . . . . . . . 2-1

A. FIXED ORIENTATION VEE-TROUGH . . . . . . . . . . . 2-1

B. SINGLE-AXIS LINEAR CONCENTRATORS ......... . 2-3

C. TWO-AXIS PARABOLIC DISH CONCENTRATORS . . . . . . 2-5

D. BASELINE CENTRAL RECEIVER . . . . . . . . . . . 2-7

III. SUBSYSTEMS/COMPONENTS DATA BASE . . . . . . . . . . . 3-I

A. DISTRIBUTED COLLECTORS .............. . . 3-1

1. Advanced Fixed Orzentation Collectors ..... . 3-4

2. Parabolic Trough ............. . . 3-5

3. Variable slat .. . . . . . . . . 3-6

4. Central Receiver Heliostats . . . . . . . 3-6

5. Point Focusing Dish . . . . . . . . . 3-6

B. ENGTNES/POWER GENERATION SYSTEMS . . . . . . . . . . . 3-7

C. ENERGY STORAGE . . . . . . . . . . . . . 3-10

D. ENERGY TRANSPORT . . . . . . . . . . . . . . . 3-12

IV. COMPARISON OF SELECTED SYSTEMS . . . . . . . . . . . . 4-1

A. APPROACH . . . . . . . . . . . . . . . . . 4-1

1. Performance Simulatıon ........... . 4-1

2. Economic Methodology .............. . 4-2

3. Example of Procedure . . . . . . . . . . 4-3

B. COMPARATIVE ECONOMICS . . . . . . . . . . . 4-6

C. SIZE EFFECTS . . . . . . . . . . . . . . 4-9 
CONTENTS (contd)

D. SYSTEM SENSITIVITIES . . . . . . . . . . . 4-14

E. SUBSYSTEM SENSITIVITIES . . . . . . . . . . . 4 4-17

-

1. Collector Subsystem . . . . . . . . . 4-17

2. Eñergy Coñversıon Subsystem .. . . . . . . 4-17

3. Energy Storage Subsystem ........... . 4-17

4. Energy Transport Subsystem . . . . . . . . . 4-22

5. Operation and Maıntenance Costs . . . . . . 4-22

v. CONCLUSTONS ................... . . . 5-1

VI. RECOMMENDATIONS . . . . . . . . . . . . . . 6-1

REFERENCES ....................... . . . . . . .

APPENDIXES

A. DISTRIBUTED COLLECTOR SURVEY . . . . . . . . . . A A-1

B. ISSUES INVOLVED IN DETERMINATION 


\section{FIGURES}

1-1. Comparative Energy Costs for 100 MWe P1ants . . . . . . 1-5

2-1. Vee-Trough - Organıc Fluıd Transport . . . . . . . . 2-2

2-2. Parabolic Trough - Steam Transport . . . . . . . . 2-4

2-3. Variable Slats-Steam Transport . . . . . . . . . . 2-4

2-4. Parabolic Dish-Steam Transport . . . . . . . . . 2-6

2-5. Parabolic Dish-E1ectric Transport . . . . . . . . . . 2-6

2-6. Central Receiver Solar Thermal-Electric Power PIant . . . 2-7

4-1. Solar Plant System Simulation Computer Code . . . . . . 4-2

4-2. Parabolic Dish-Electric Plant Performance . . . . . . . 4-4

4-3. Parabolic Dish-Electric System Characteristics . . . . . 4-7

4-4. Parabolic Dish-Electric Capital and Energy Costs . . . 4-7

4-5. Solar PIant Energy Costs ............ . . 4-8

4-6. Solar Plant Capital Costs . . . . . . . . . . . . 4-8

4-7. Effect of Plant Size ............... 4-10

4-8. System Sensıtivity Comparıson . . . . . . . . . . . 4-14

4-9. System Sensitivities: Central Receiver and $\ldots$ 4-16

4-10. System Sensitivities: One-Axis and Two-Axis
Distributed Systems . . . . . . . . . . . . 4-16

4-II. Sensitivity to Collector Cost . . . . . . . . . . 4-18

4-12. Sensitivity to Collector Effictency . . . . . . . . . 4-18

4-13. Sensitivity to Energy Conversion Cost: 4-19

Rankine Cycle Systems . . . . . . . . . . . . 4-19

4-14. Sensitivity to Energy Conversion Cost:

4-1.5. Sensitivity to Energy Conversion Efficiency:
Rankine Cycle Systems . . . . . . . . . . . 4-20

4-16. Sensitivity to Energy Conversion Efficiency:
Parabolic Dish-Electric System . . . . . . . . 4-20

4-17. Sensitıvity to Engıne Life:

Parabolic Dish-Electric System . . . . . . . . . . 4-21 
FIGURES (contd)

4-18. Sensıtivity to Storage Cost . . . . . . . . . . . 4-21

4-19. Sensitivity to Storage Throughput Efficıency . . . . . . 4-22

4-20. Sensitivity to Transport Cost............. . . 4-23

4-21. Sensitivity to Transport Efflciency . . . . . . . . 4-23

4-22. Sensitivity to Operatıon and Maintenance Cost . . . . . 4-24

A-1. Cylindrical Concentrator . . . . . . . . . . . A-3

A-2. Solar Concentrators . . . . . . . . . . . . . $\mathrm{A}-5$

A-3. Parabolic Trough Concentrator and Performance Data . . . A-6

A-4. Parabolic Concentrator Test Site . . . . . . . . . . A-8

A-5. Parabolic Trough Concentrator and Performance Computations A-9

A-6. Fixed Mirror Solar Concentrators . . . . . . . . . A-12

A-7. Parabolıc Trough Concentrator and Performance Data . . . A-13

A-8. Parabolic Trough Concentrator . . . . . . . . . A-15

A-9. Linear Focus Solar Concentrator and Performance Data . . A-17

A-10. Point Concentrator Collector . . . . . . . . . . A-19

A-11. Reflector Mirror Layout . . . . . . . . . . . A-20

B-1. Projection of New Plant Installation . . . . . . . . B-2

B-2. Payback of R\&D Energy Costs . . . . . . . . . . . B-3

TABLES

2-1. Systems Considered . . . . . . . . . . . . 2-2

3-1. Solar Subsystem Performance Data . . . . . . . . . 3-2

3-2. Solar Subsystem Direct Cost Data . . . . . . . . . 3-3

4-1. Capital Cust Breakdown, 100 MWe Plant . . . . . . . 4-12

4-2. Energy Cost Breakdown, 100 MWe Plant . . . . . . . 4-12

4-3. Capital Cost Breakdown, 10 MWe Plant . . . . . . . . 4-13

4-4. Energy Cost Breakdown, 10 MWe Plant . . . . . . . . . 4-13 


\section{SECTION 1}

\section{INTRODUCTION}

\section{A. STUDY BASIS}

Solar-thermal power plants are comprised of either central receiver or distributed-collection systems (Refs. 1 through 7). In the central receiver system, a large field of reflecting mirrors (hellostats) is used to concentrate energy on a tower-mounted receivex (Ref. 7). The energy transport from the field is optical. For distributed-collection systems, thermal energy is concentrated at a multiplicity of distrubuted locations throughout the large collecting field (Ref. 4). The distributed thermal energy can be directly collected and transported (e.g., as steam or hot water) to a central location for energy conversion.

Alternatively, the thermal energy can be used to drive a chemical reaction and the resulting chemical products can be transported to a central location where the chemical reaction can be reversed to recover thermal energy for power generation. Finally, the distributed thermal energy can be used to druve heat engune-generator units on or near the collectors to generate electrucity. Thls energy can be collected via electrical collection networks. The present study pertains to these types of distrubuted systems, with the central receiver systems included for reference purposes.

A major factor in the viabllity of distributed systems is the performance and cost of collectors and, therefore, a large number of design approaches are being pursued. These designs can be classified according to the following three basic types:

Type

Fixed orientation Single-axis tracking Two-axis tracking
Approximate Temperature Range $\left(\sim^{\circ} F\right)$

200-500

$500-900$

$900-2500$

For fixed orientation (non-tracking) systems, early designs are characteruzed as flat plate collectors which develop maximum operating temperatures of $\sim 200^{\circ} \mathrm{F}$ without the use of concentrating mirror surfaces (Ref. 1). Higher temperatures are possible via the use of concentrators (Ref. 2), but concentrators block a portion of the Insolation over the day, and have limited capability to concentrate energy. This blockage problem is partıcularly sıgnificant for these non-tracking systems. Thus, the use of concentrators involves basic trade-offs which must be assessed for each application.

For single-axıs trackıng, a single-curvature reflectıng surface is used to concentrate solar energy on a linear receiver. The reflecting surface is articulated about one-axis to minimlze blocklng problems and increase concentration. The reflecting surface may be a parabolic trough or a series of flat mirrox strips which can be individually articulated so that each strip mirror reflects energy on the linear receiver as the sun orientation varies (Ref. 3). 
The two-axis tracking, distributed collector, system is associated with compound-curvature reflecting surfaces (e.g., parabolic dishes) which concentrate energy on an aperture that approaches a point (Ref. 4). Two-axis tracking minimizes blocking, and eliminates the off-angle (cosine) losses of fixed- and one-axis tracking systems. This maximizes the amount of solar energy captured per unit area of collector surface. Two-axis-tracking also provides potential-for highex concentration ratios and higher temperatures.

Proceeding from the fixed orientation to the sungle-axis tracking and finally to the two-axls trackıng system, collector performance Improves while the temperature level also rises. For power systems, hlgher temperatures provide an advantage in that highex thermal to mechanical energy conversion efficlencies are achievable. This trend of increasing performance with more sophisticated collection systems is accompanied by increasing costs per unit of collector area and the possible need for additional technology development.

The primary purpose of the present study is to determine which types of distributed-collection solar energy systems are most attractive for commercial electric generation. This study will be accomplished by comparing performance and costs of the distributed solar-thermal power systems employing the three basic types of collectors previously described. Comparisons will be based on projections of energy costs to the year 2000. Uncertalnties in the data base will be delineated via sensitivity analyses at the system and subsystem/component level.

Within the limitations of the study, conclusıons are dxawn concerning the relative viabllity of different distributed-collection system approaches and recommendations for future work are offered. Some of the major 1imitations or bounds on the study are that it does not treat total energy or cogeneration systems, integration of solar systems into bulldings, socio-environmental or social costs except those reflected in projections of utility bus-bar costs, and aspects of total utility grid reliability in terms of introducing solar power plants. Many of these factors are common to all systems considered in this report and, hence, it is believed that comparative results will not be significantly affected.

It is noted that the present study uses insolation data from Inyokern (CA), representative of the solar-intensive regions of the Southwest. For other sutes, lower insolation levels coupled with higher fractions of diffuse insolation would degrade performance, particularly for high concentration ratio tracking systems which relay on direct insolation. When considering locations where the diffuse component is large, the effect would be to improve the relative rankıng of the non-tracking, low concentration ratio compared to the tracking or higher concentration ratıo systems. 


\section{B. SUMMARY}

As guidance for the planning of solar-thermal R\&D activities, a preliminary comparatıve eváluation of distrıbuted-collector solarthermal power plants was undertaken. This evaluation involved the projection of power plant economics to the 1990-2000 time frame for the following selected distributed-collector power plants:

- Fixed (non-tracking), Vee-trough, reflector/vacuum tube absorber system operating at a temperature of $\sim 350^{\circ} \mathrm{F}$ and using organic Rankine conversıon.

- One-axis trackıng, linear concentrator systems involving steam Rankine conversion with (I) parabolic txough concentrator at $650^{\circ} \mathrm{F}$, and (2) variable slat concentrators at $850^{\circ} \mathrm{T}$.

- Two-axis tracking, parabolıc dısh concentrator systems involving (1) central steam Rankıne conversion at $\sim 1000^{\circ} \mathrm{F}$, and (2) dish-mounted, heat engine-generator sets (Stirlıng and Brayton) at operating temperature of $1500^{\circ} \mathrm{F}$.

The baseline, steam-Rankine, central receiver system was also included for reference purposes. The study effort first focused on upgrading JPL's previous data base (unit costs and efficiencies of subsystems/components) to reflect the current status of development in both industry and Government Laboratories. Most of the current activities in the industry have been focused on one-axis tracking systems. Nominal cost and performance estımates, including uncertainty ranges, have been estimated by synthesizing data obtained from a survey of thls work and past studies. A comparatıve analysis of the two-axis trackang heliostat (for the central receiver) and parabolic dish concentrating systems versus the single-axis tracking system indicated that the more complex structure and tracking mechanisms of the heliostat would result in higher costs on a unit area basis than the one-axis tracking systems surveyed. Further, it was concluded that the parabolic dish would be more costly than the heliostat on a unit area basis since it requires curved mirror surfaces and additional structure to support a receiver at the focal point.

Based on this comparative analysis, collector system costs were estimated for the selected systems. Data concerning energy conversion, energy storage, and energy transport were based on values projected in prior studies. During this study, available data for these subsystems were reviewed in the light of on-going activities and development status as the basis for estimating uncertainty ranges in both cost and efficiency for each subsystem.

Using the nominal values for estimated performance and cost, the dish-electric system provided the lowest capital and energy costs, while also exhibiting essentially uniform performance and cost over a wide range of plant sizes due to uts inherent modularity. The two-axis 
tracking dish-steam and one-axis tracking systems were comparable in performance and costs. The energy cost of the reference central receiver was lower than these systems, but higher than the dish-electric system for power plant sizes greater than 10 MWe.

When the systems are compared on the basis of the combined effects of all the subsystem uncertainties, the energy cost ranges of the systems exhıbit considerable overlap. Thus, it is not possible to totally rule out any candidate. However, fixed orientation systems appear to have conslderably less promise for strictly electric power applications and it is recommended that they not be pursued for this application. Fixed systems show promise for other applications that are not considered in this study.

If fixed orientation systems are removed from consideration, the basıc comparison involves one-axis and two-axis tracking systems. Oneaxis tracking systems have inherently lower collection efflclencies and achieve lower temperatures than the two-axis systems. However, oneaxis tracking collector subsystems comprised of reflector, receiver, and tracking unit have lower cost on a unit aperture area basis than the two-axis trácking collectors. Two-axıs systems generally achieve higher conversion efficiencies due to higher temperatures and, therefore, require a smaller collector field for a given plant rating. The present study indicates that the increased efficiency and reduction in field size afforded by the two-axis dish-electric systems will more than offset its higher collector cost on a unit area basis. Nominal costs for the one-axis variable slat system are compared to the dish-steam and dish-electric systems in Figure 1. The baseline central receiver is also shown for reference purposes.

As shown in Figure $1-1$, collectors account for $\approx 50 \%$ of the energy cost. The dish-electric system assumes use of stirling engines having a rated efficiency of $42 \%$ at $1500^{\circ} \mathrm{F}$. The dish-steam system, involving pipeline transport of steam to a central power conversion unit, is based on the use of $920^{\circ} \mathrm{F}$ steam to achieve a rated efficiency of $35 \%$. The variable slat system employs $850^{\circ} \mathrm{F}$ steam for a $30 \%$ rated efficiency, while the reference central receiver uses $950^{\circ} \mathrm{F}$ steam to achieve a rated efficiency of $36 \%$. The low relative cost of the collectors for the dish-electric system is primarily due to the high conversion efficiency of the Stirling engine resulting in a substantially smaller collector field. Efficient electrical transport at $94 \%$ efficiency for the dish-electric system as compared to $87 \%$ for the dish-steam transport system also contributes significantly to the collector field cost differentıal.

Although the dish-steam system has a conversion efficiency that is higher than the variable slat system, its nominal energy cost is slightly higher. This indicates that the efficiency advantage of the dish-steam over the variable slat system is essentially offset by the lower costs per unit area of one-axis varlable slat collectors. The baseline central receiver, which assumes the use of available steam Rankine technology with no reheat, has lower nominal energy costs than either the dish-steam or variable slat system. 


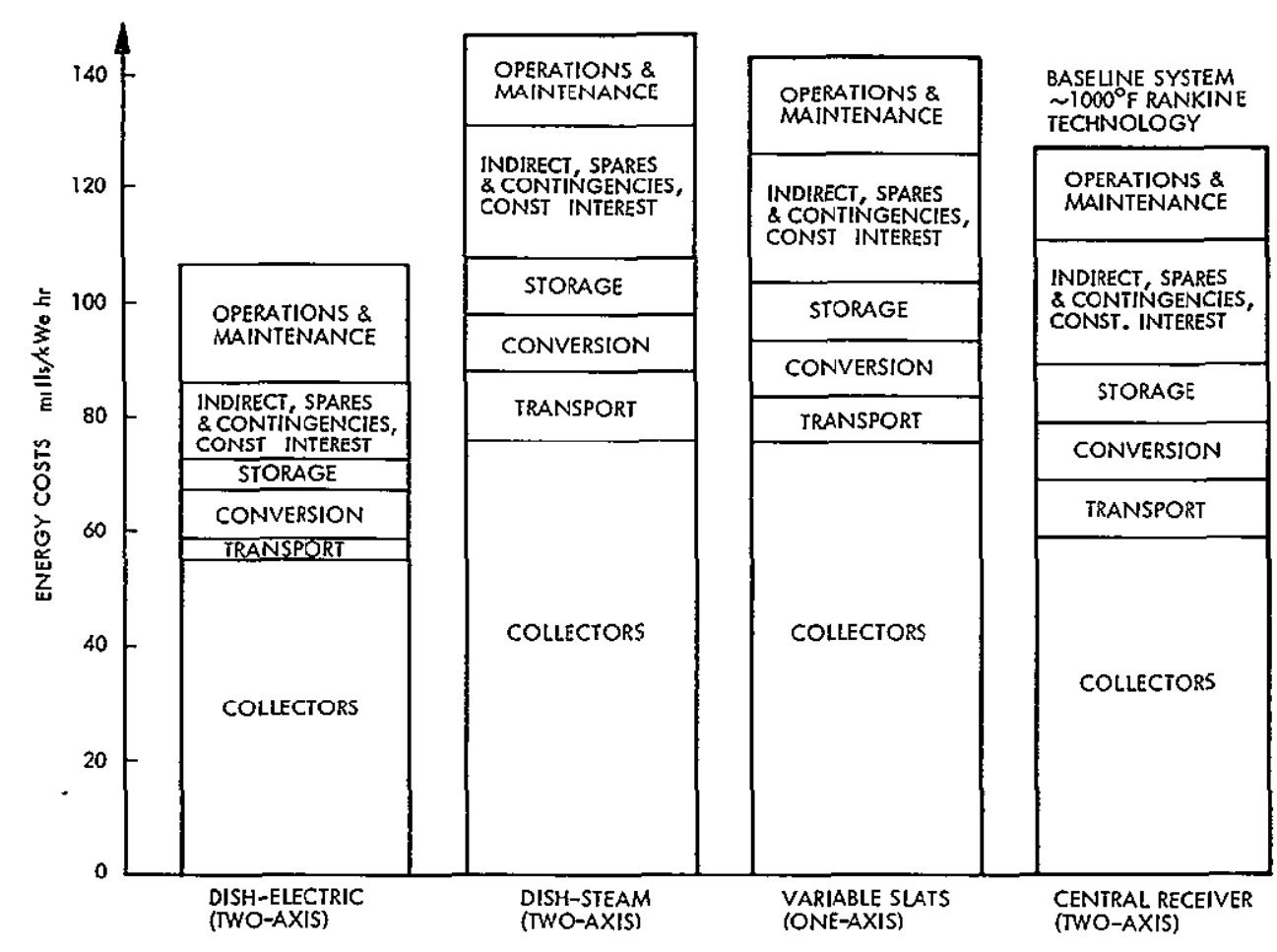

Figure 1-1. Comparative Energy Costs for 100 MWe Plants (Annual Load Factor $=0.55 ; 1975$ Dollars; Year 2000 Startup)

The baseline central recelver system in the 100 MWe plant size range appears to be preferable when existing Rankine technology is employed. Higher temperature advanced technology systems such as the dish-electrıc system using $1500^{\circ} \mathrm{F}$ Stirling engine technology are needed to achieve improvements over the baselıne. High temperature advanced technology central receiver systems are expected to provide substantial improvements over the baseline, but consideration of advanced central receiver concepts was outside of the scope of this study, which was specifically focused on distrubuted-collector systems.

For small dispersed power applications ( 1 to 50 MWe), the inherently more modular systems, such as the dish-electric system, have advantages particularly in the lower end of the power range. The energy cost of central receivex or power towex approaches tend to increase as plant size decreases since a greater number of heliostat facets per unit power and/or curvature of the facets are required. Also, as power rating decreases, Rankine steam turbine efficiencies decrease while costs per unit power increase. The energy cost of dishelectric systems is essentially invariant to size with only a small increase with decreasing size due to the indirect costs that comprise a larger fraction of small plant costs. 
Thus, It has been concluded that the most promising distributed collector system, particularly for small power applications, is the dish-electric system. However, this system has the greatest uncertainties and requires more technology development than the other systems. Thus, for a balanced R\&D program, it is suggested that this system be pursued as a downstream target while one-axis tracking and dish-steam systems are simultaneously developed for near term systems. These near term systems could be implemented for some applications while also serving as a backup for the dish-electrıc system. Thus type of approach minımızes developmental risks.

An examination of subsystem sensitivities indicates that collector costs are a dominant parameter. The overall system efficlency involving a.11 the subsystems from collectors to energy conversion is also a powerful cost driver since higher efficiencies allow use of a smaller, and hence, less costly collector field for a given power plant rating. These sensitivity results indicate that cost reduction activities should emphasize the collector system while the advanced technology should concentrate on zmproving efficiencles of components such as receivers and engines. 
SECTION II

SELECTED SYSTEMS

As shown in Table 2-1, the systems considered in this study involve the three basic types of distributed collectors and, for reference purposes, the baseline central receiver system. For one-axis tracking, the design approach of parabolic trough and linear variable slat collectors are included; whereas for two-axis tracking, the options of steam pipeline or electrical transport of energy within the collector field are considered. Enexgy conversion and storage are via Rankine systems with sensible heat thermal storage for all systems except for the parabolic dish-electric system which employs small dish-mounted heat engines (Brayton or Stirling) and batteries for storage.

\section{A. FIXED ORIENTATION VEE-TROUGH}

As indicated in Ref. I, fixed orientation (non-tracking) flat plate collector systems without concentrators are not competitive with tracking and concentrating systems for solar thermal electric power production. Performance of fixed orientation collector systems can be markedly improved via the addition of concentrators such as, e.g., flat Vee-trough or compound parabolic (CPC), reflectors, where the reflector is coupled with a vacuum tube thermal receiver (Ref. 2). For good yearround performance, the Vee-trough reflectors can be asymmetrically designed and reversed only twice a year, at March and September equinoxes. This approach is considered to be economlcally equivalent to the CPC reflector, but this comparison should be subjected to a detailed analysis to verify the assumed similarity.

As the collection temperature increases, receiver efficiency decreases while the Rankine cycle performance improves. Thus, there exists an optimum overall system efficiency and associated temperature. For the asymmetric Vee-trough system, the optimum system performance occurs at a temperature of $\simeq 177^{\circ} \mathrm{C}\left(350^{\circ} \mathrm{F}\right)$. For this temperature, organic Rankine cycle power conversion systems are deemed to be appropriate (Ref. 2).

The Vee-trough electric power generation system, depicted in Figure 2-1, was analyzed in Ref. 2 and found to have about double the energy cost of the baseline central receiver system. Therefore, the system was deemed to be unattractive for central station power. For these reasons, further analysıs of this system was not conducted and the results from Ref. 2 are used in this study for completeness.

Since operation and maintenance (O\&M) difficulty and cost are considered to be low due to the simple tracking scheme (semi-annual reflector adjustment), fixed systems such as the Vee-trough may have viable roles for applications (other than central power production) where availability of skilled labor for maintenance is poor. Possible roles include on-site or community level systems for electrical power, 
Table 2-1. Systems Considered

\begin{tabular}{|c|c|c|c|}
\hline COLLECTOR TYPE & $\begin{array}{c}\text { ENERGY } \\
\text { TRANSPORT }\end{array}$ & STORAGE & ENERGY CONVERSION \\
\hline $\begin{array}{l}\text { DISTRIBUTED SYSTEMS } \\
\text { - FIXED-"V" TROUGH } \\
\text { - 1-AXIS } \\
\text { - PARABOLIC TROUGH } \\
\text { - VARIABLE SLATS } \\
\text { - 2-AXIS } \\
\text { - PARABOLIC DISH } \\
\text { - PARABOLIC DISH }\end{array}$ & $\begin{array}{l}\text { ORGANIC } \\
\text { FLUID } \\
\text { STEAM } \\
\text { STEAM } \\
\text { STEAM } \\
\text { ELECTRIC }\end{array}$ & $\begin{array}{l}\text { SENSIBLE } \\
\text { THERMAL } \\
\text { SENSIBLE } \\
\text { THERMAL } \\
\\
\text { SENSIBLE } \\
\text { THERMAL } \\
\text { ADVANCED } \\
\text { BATTERY }\end{array}$ & $\begin{array}{l}\text { ORGANIC RANKINE } \\
\text { CENTRAL STEAM RANKINE } \\
\text { CENTRAL STEAM RANKINE } \\
\text { CENTRAL STEAM RANKINE } \\
\text { SMALL HEAT ENGINE } \\
\text { MOUNTED ON DISH }\end{array}$ \\
\hline $\begin{array}{l}\text { CENTRAL RECEIVER } \stackrel{ }{*} \\
\bullet \text { HELIOSTAT (2-AXIS) }\end{array}$ & OPTICAL & $\begin{array}{l}\text { SENSIBLE } \\
\text { THERMAL }\end{array}$ & CENTRAL STEAM RANKINE \\
\hline
\end{tabular}

*INCLUDED FOR REFERENCE ONLY

$\approx$ FIXED SYSTEM CONSIDERED WITHOUT STORAGE

ORIGINAL PAQT

OF POOR QUATHTII

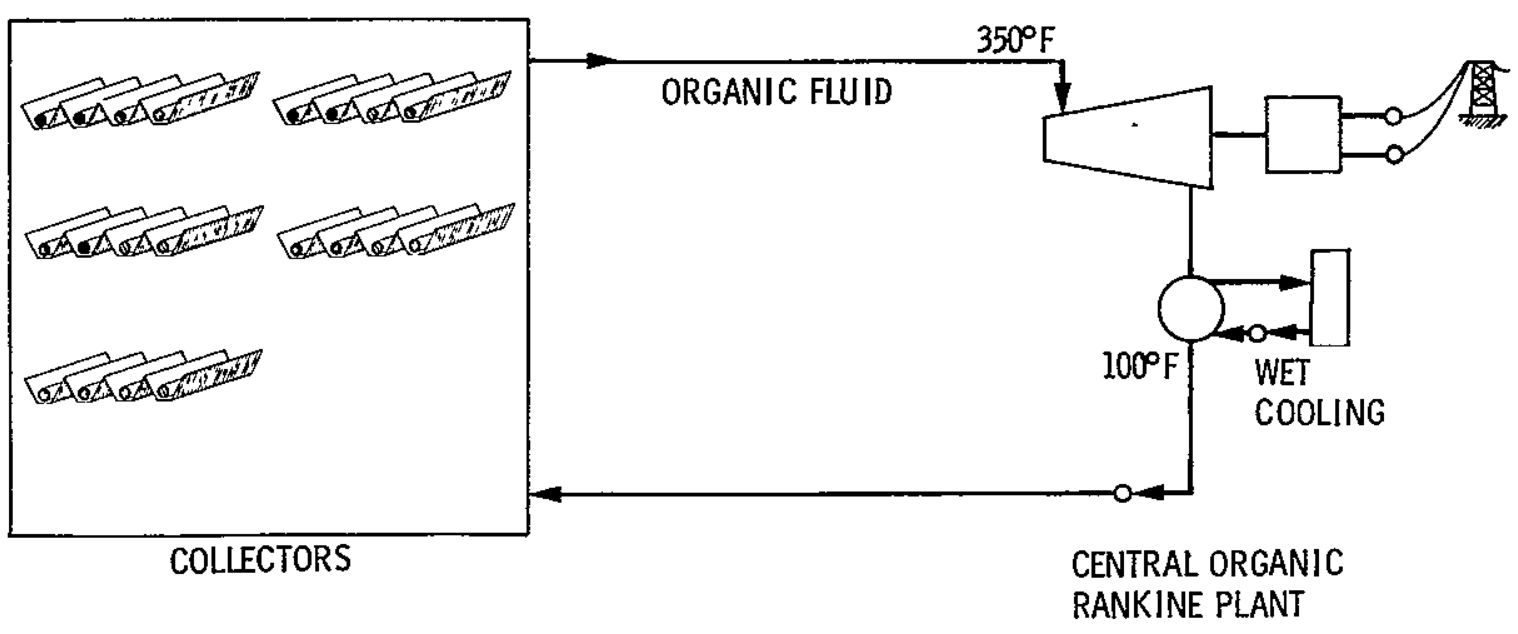

Figure 2-1. Vee-Trough - Organic Fluid Transport 
and power for irrigation pumping at remote locations. This class of collector may also be considered for druving air conditioning systems or for total energy, or industrial applications where the "thermal" energy portion is significant. Consideration of these aspects is not within the scope of the present study.

\section{B. SINGLE-AXIS LINEAR CONCENTRATORS}

Linear concentrator development activity is focused on two generic design approaches; the paraboluc trough and variable slat. A preliminary assessment of these concentrators (Ref. 3) indicates that temperatures up to $\simeq 450^{\circ} \mathrm{C}\left(842^{\circ} \mathrm{F}\right)$ can be achieved and that overall power plant efficiencies of 12 to $18 \%$ are possible.

As shown by the survey of current distributed collector developments in Appendix A, the preponderance of private industrial activity is in the intermediate temperature range $\left(500^{\circ} \mathrm{F}-900^{\circ} \mathrm{F}\right)$ involving the parabolic trough and variable slat collector systems. These systems are candidates for small on-site applications and may even be competıtive with higher temperature two-axis tracking systems for central power, if one-axis collectors can be made at substantially lower costs than two-axis systems (such as parabolic dishes and hellostats).

The selected parabolic trough and variable slat power plants are depicted on Figs. 2-2 and 2-3, respectively. Both systems are based on steam transport, which appears preferable to pressurized hot water systems (Ref. 3). Fluids such as Therminol 66 are also candidates, but additional evaluation ragarding problems such as safety and fluld stability at high temperatures is required.

For parabolic trough designs (Fig. 2-2), since the concentrating surface rotates as-one piece, there are practical limitations on size from both structural and insolation blocking considerations. To achieve the desired concentration ratıos withın size constraints, concentrating surfaces have relatively high rim angles which tend to preclude the use of cavity receivers. Thus, vacuum-jacketed tube receivers having lesser performance and greater losses with increasing temperatures are generally employed.

For varıable slat designs (Fıg. 2-3), strip mirrors are individually articulated to concentrate energy on a linear receiver. The strip mirrors can be located in a curved plane having an effectively low rim angle. This allows the use of a longer focal length with the reflected insolation converging toward the receiver within a sufficiently small angle to allow the use of a cavity recelver.

Since the cavity recexver design has inherently lower losses than the vacuum-jacketed tube receiver at higher temperatures, the strip mirror approach is associated with higher temperatures and greater efficiencies than the parabolic trough. As shown on Figs. 2-2 and 2-3, the steam temperatures for the selected systems are $650^{\circ} \mathrm{F}$ for the parabolic trough and $850^{\circ} \mathrm{F}$ for the variable slat arrangement. These temperatures correspond to the maximum overall system efficiency. 


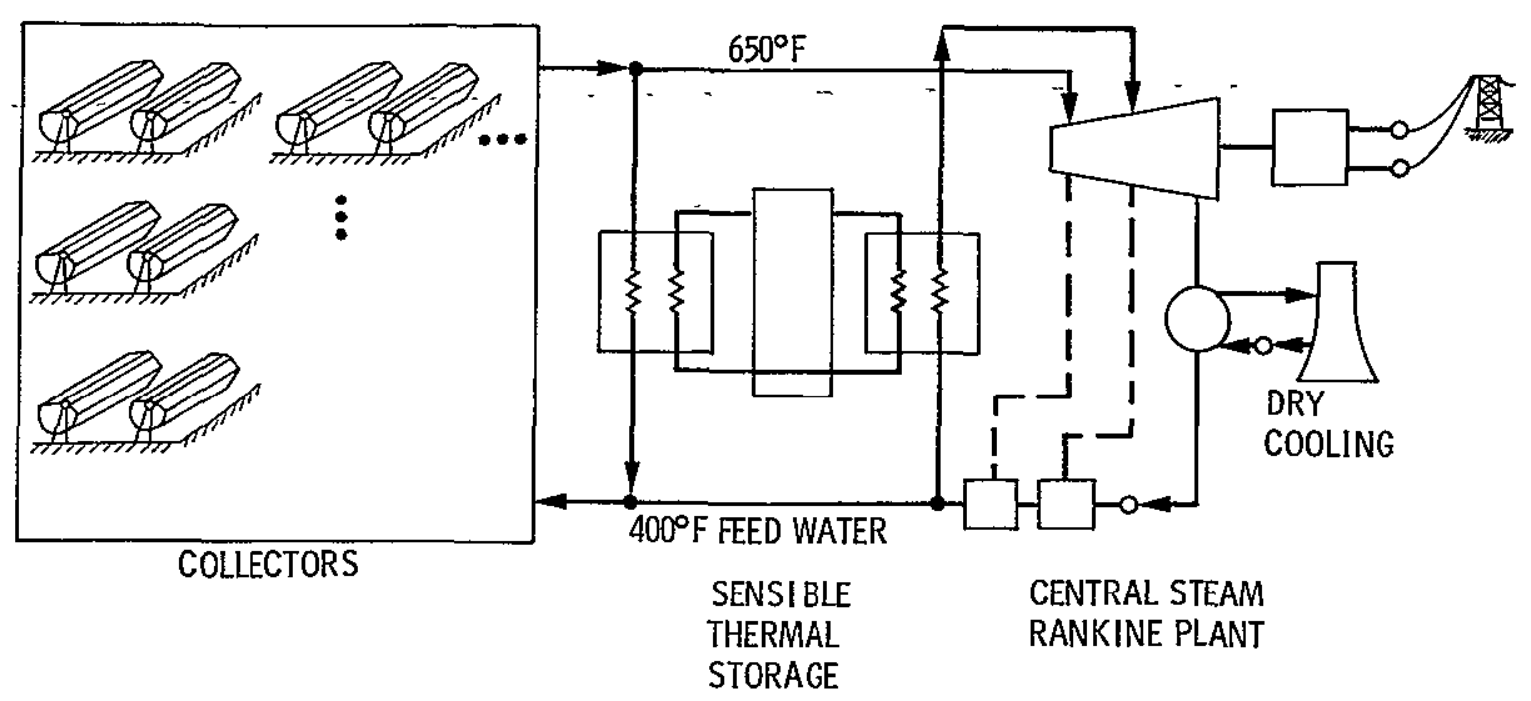

Figure 2-2. Parabolic Trough - Steam Transport

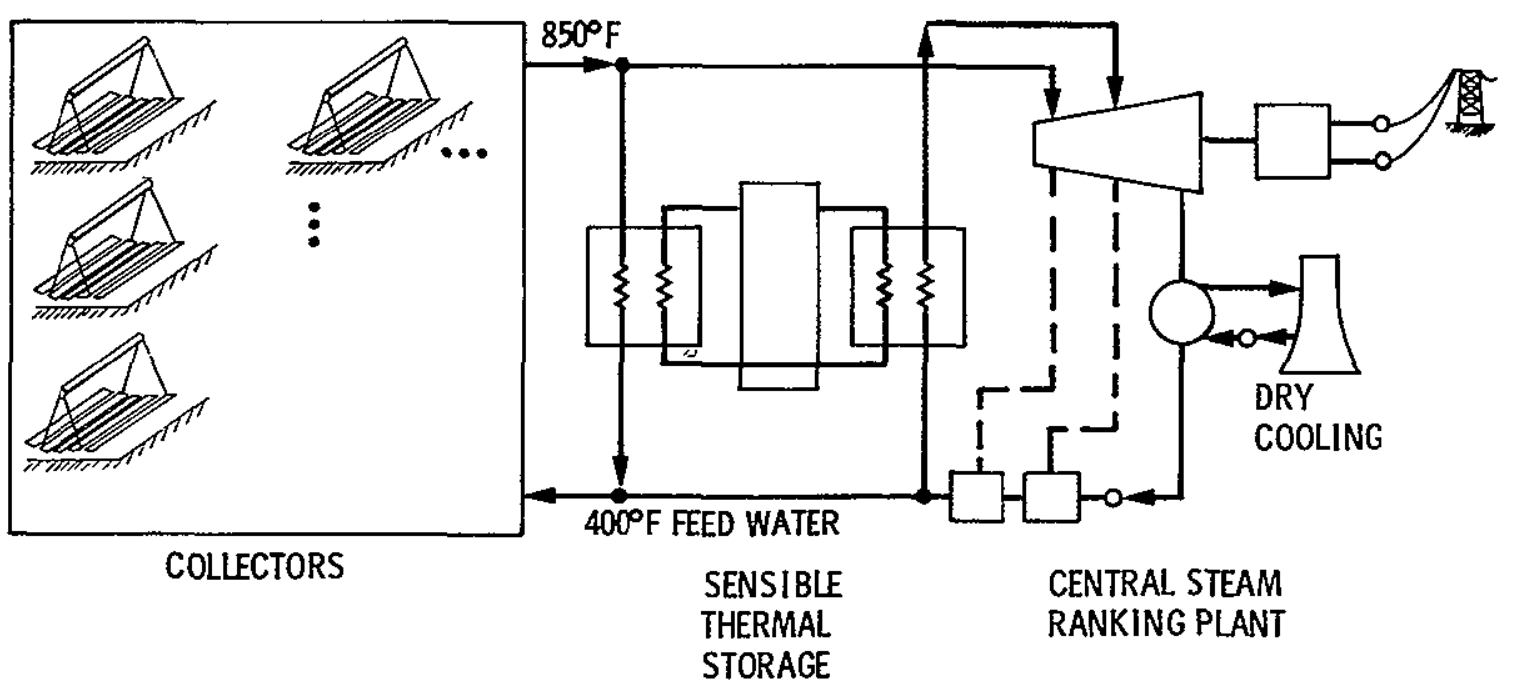

Figure 2-3. Variable Slats - Steam Transport 
For both the parabolic trough and variable slat systems, energy conversion is accomplished via a central steam Rankine plant with dry cooling tower. The present study is based on the use of dry cooling towers since it is expected that implementation of these systems will ultimately requixe dry cooling (particularly in the arid Southwest). A sensible heat thermal storage system is used and the feedwater temperature $15400^{\circ} \mathrm{F}$ (see Figs. 2-2 and 2-3).

\section{TWO-AXIS PARABOLIC DISH CONCENTRATORS}

The two selected parabolic dish power plant options of using steam transport and electric transport are shown on Figs. 2-4 and 2-5, respectively. For the stean transport system (Fig. 2-4), steam is generated via receivers mounted at the focal point of each dish. This steam is transported via insulated pipelines to a central steam Rankine plant with dry cooling towers. The dish collector field is arranged so that saturated steam is generated in the outer portion of the field with superheat occurring in the inner portion closest to the central power plant. The system generates superheated steam at $1000^{\circ} \mathrm{F}$ and 1450 psi. Due to transport losses, the steam arrives at the power plant with a temperature of $920^{\circ} \mathrm{F}$ and a pressure of $1400 \mathrm{psi}$. The feedwater temperature is $400^{\circ} \mathrm{F}$ and energy storage is accomplished by a sensible heat thermal system (Ref. 4).

In earliex parabolic dish studies, (Refs. 5, 6, and 7), the steam system was not pursued since it was shown to have lesser potential than dish-electric or advanced dish-chemical transport systems. The dishsteam system was selected for the present study since it is a more nearer term system using conventional power-plant energy conversion technology; i.e., it is the distributed-collection counterpart of the baseline central receiver system.

The dish-chemical systems (Ref. 7) are based on using solar-thermal energy to drive a reversible endothermic chemical reaction. The chemical products of the reaction (either gases or liquids) are transported and stored. When energy is required, the stored chemicals are reacted to release heat, which in turn drives an energy conversion system such as the central steam Rankine plant. Recent studies (Refs. 8 and 9) indicate that chemical systems may be competitive when large quantities of energy must be stored, and that considerable research work is required before technical feasibility can be established. For these reasons, the chemical system is deleted from the present study. It requires an in-depth assessment in the context of advanced technology systems; this task is beyond the scope of the present study.

In the dish-electric systems studied in Refs. 6 and 7, a small heat engine-generator is mounted at the focal point of each dish (Fig. 2-5). For the near term, Brayton cycle gas turbine systems can -be used as the engine-generator, and in the far term, advanced high temperature Brayton and Stirling engine systems are primary candidates. The technology for advanced Brayton systems appears to be further developed, but Stırling engines are undergoing extensive development for automotive applications. If this automotive development is successfully 


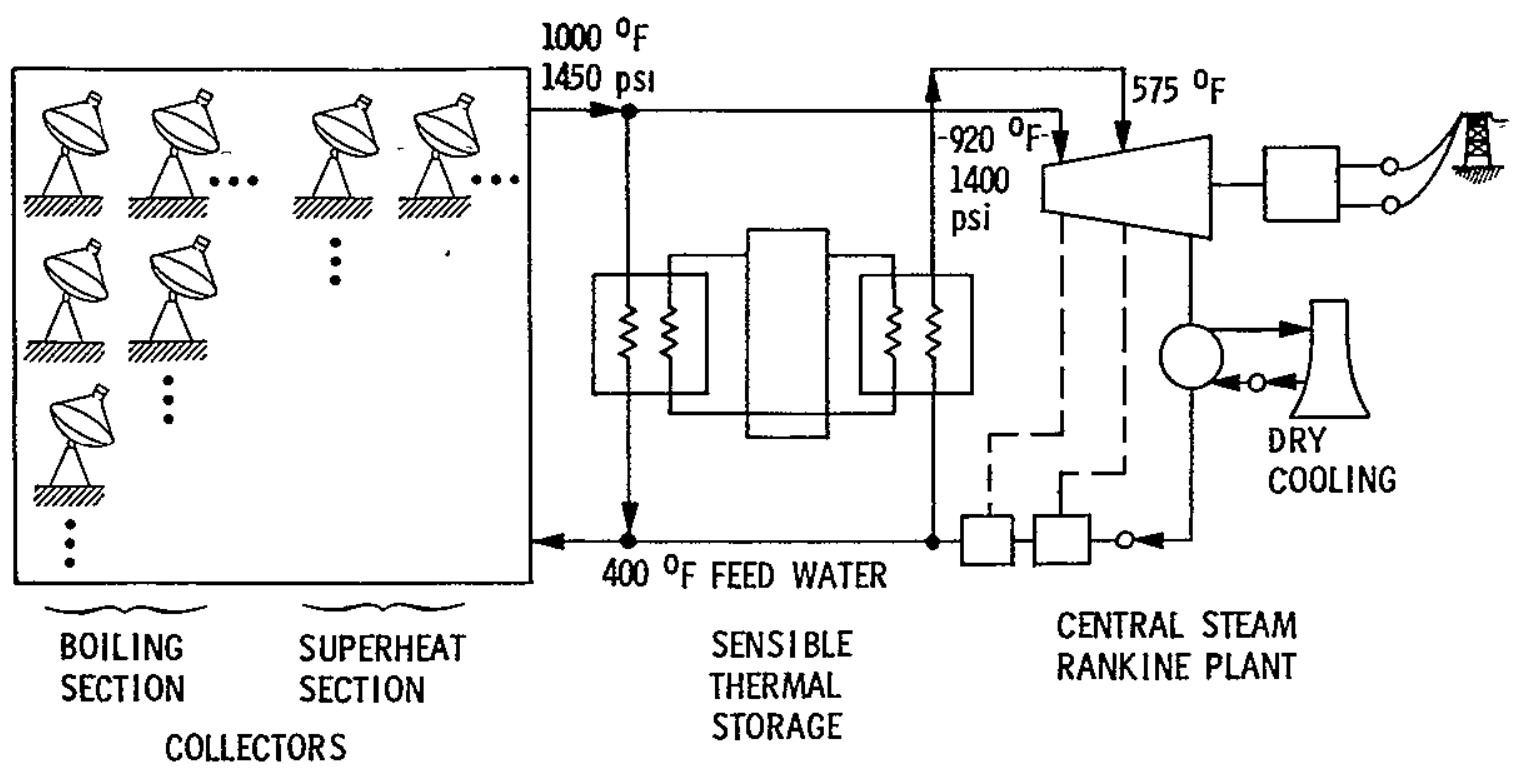

Fıgure 2-4. Parabolic Dish-Steam Transport

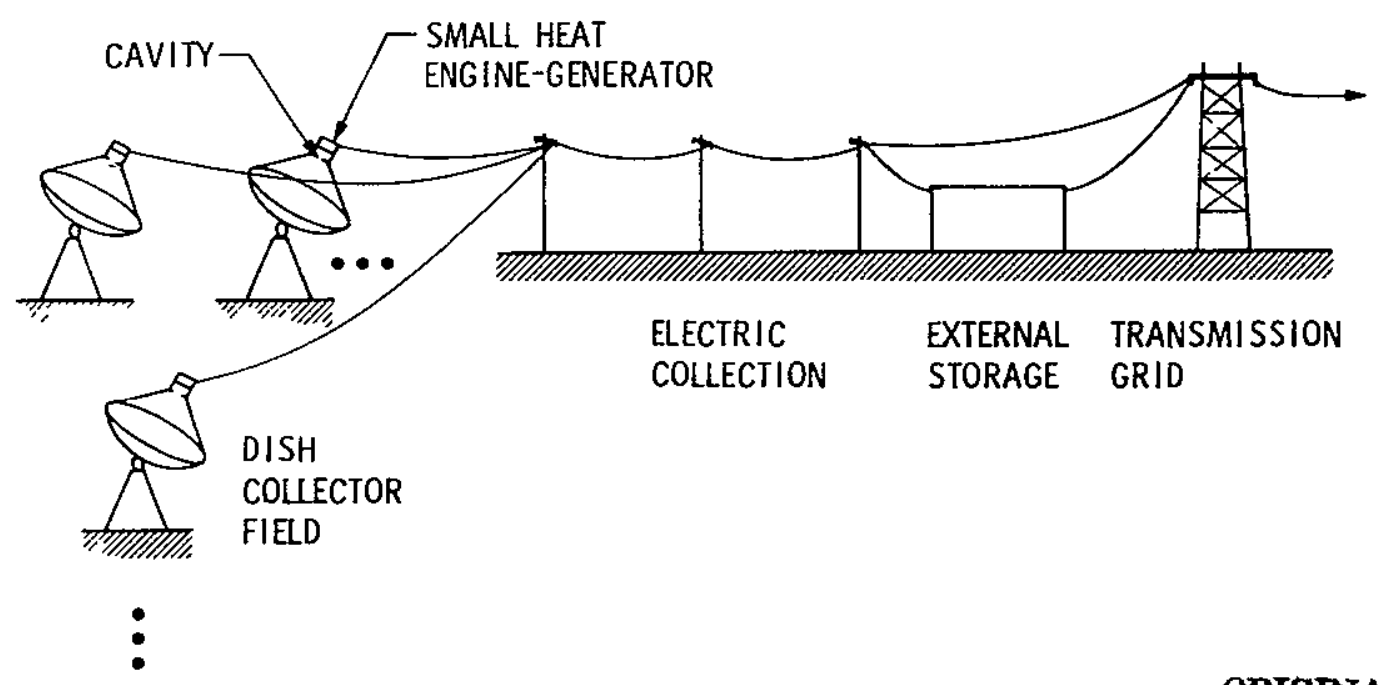

ORIGINAL PAGE IS

Figure 2-5. Parabolic Dish-Electric Transport

OF POOR QUAATTY 
accomplished, highly efficient ( $40 \%$ ) Stirling engines will be available on a low-cost volume production basis. Therefore, the present study concentrates on the Stirling engine system with the advanced Brayton as a backup. In addition to the automotive crankshaft Stirling, there are concepts presently under development, such as the linear free piston Stirling, which could prove to be more efficient and/or less costly.

\section{BASELINE CENTRAL RECEIVER}

The baseline central receiver system depicted in Fig. 2-6 is included for reference purposes only. A field of two-axis tracking heliostats focuses insolation on a tower-mounted receiver; i.e., energy is optically transported from the collector field. For the baseline system, the working fluid is steam and a Rankine power plant is used for energy conversion. Steam generated in the tower-mounted receiver is transported via pipelines to the bottom of the tower where the Rankine plant is located. The system employs dry cooling towers and sensible heat thermal storage. Selected steam conditions (Fig. 2-6) are compatible with existing component technology. These steam conditions are close to those used in current central receiver designs. Early central receiver plants may be based on wet cooling systems, but dry cooling towers are assumed in this study since it is felt that dry cooling will generally be required for commexcial plants, particularly when located in the solar-intensive but arid Southwest.

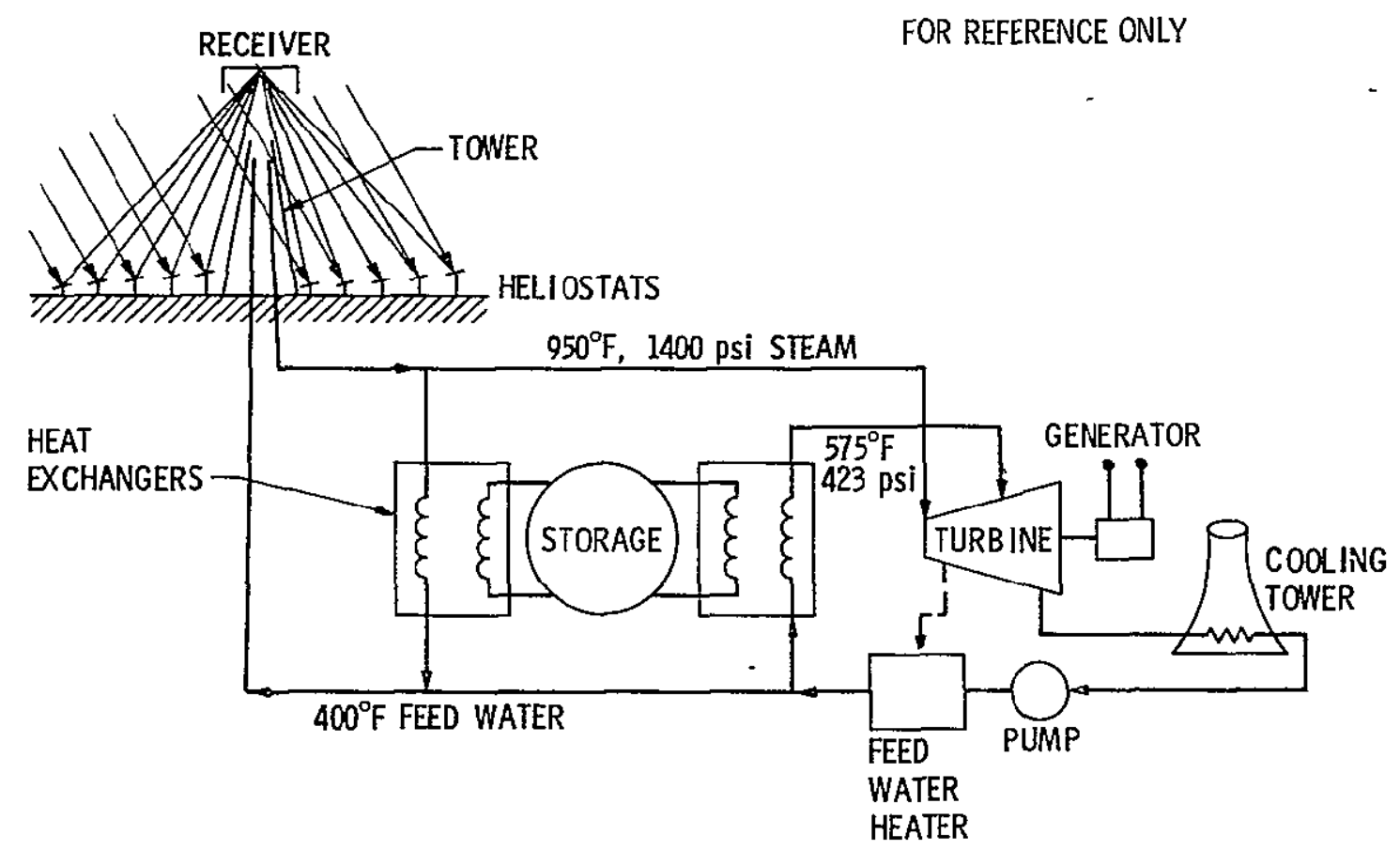

Figure 2-6. Central Receiver Solar Thermal-Electric Power Plant 
SECTION III

SUBSYSTEMS/COMPONENTS DATA BASE

The selected solar thermal power plant systems are comprised of the following four basic subsystems:

- Collectors--concentrators, receivers, tracking mechanisms, structures, and controls.

- Energy Transport--pipelines or electrical collection networks with associated control systems.

- Energy Storage--sensible heat thermal storage or advanced batteries.

- Energy Conversion--steam or organic Rankine cycles, open or closed-cycle Brayton, or Stirling engines.

The performance and cost data bases for these subsystems are summarized in Tables $3-1$ and $3-2$, respectively. Th1s data reflects the updating of material in Refs. 6 and 7 which synthesized information developed as part of earlier comparative assessment studies. The synthesis process has identified promising candidate subsystems and projected unit cost and performance levels achievable by the 1990-2000 time frame. Inputs from industrial specialists and laboratory researchers have been used as the basis for forecasting technology advances. The updating has basically Involved a survey to Identify changes in the data base since Refs. 6 and 7. Results of this survey activity are summarızed below.

\section{A. DISTRIBUTED COLLECTORS}

One of the key ingredients in the evaluation of distributed solar power systems is the projection of eventual commerical cost and performance of various types of collectors. The types of equipment considered to represent classes of equipment are:

1) Advanced "fixed" collector using asymmetrical Vee-trough reflectors and vacuum absorber tube.

2) Continuous surface parabolic trough linear concentrating collector with vactum tube receiver.

3) Variable slat linear concentrating collector with pyrex tube cavity receiver.

4) Parabolic dish point concentrating collector with cavity receiver. 
Table 3-1. Solar Subsystem Performance Data

- PLANT RATING: $100 \mathrm{MWe}$

\begin{tabular}{|c|c|c|c|c|c|c|c|}
\hline \multirow{4}{*}{$\begin{array}{l}\text { MAJOR } \\
\text { SUBSYSTEM }\end{array}$} & \multicolumn{7}{|c|}{ EFFICIENCIES } \\
\hline & \multirow{3}{*}{$\begin{array}{c}\text { FIXED } \\
\text { VEE } \\
\text { TROUGH }\end{array}$} & \multicolumn{2}{|c|}{$1-A X I S$} & \multicolumn{4}{|c|}{ 2-AXIS } \\
\hline & & \multirow{2}{*}{$\begin{array}{l}\text { PARABOLIC } \\
\text { TROUGH }\end{array}$} & \multirow{2}{*}{$\begin{array}{l}\text { VARIABLEE } \\
\text { SLATS }\end{array}$} & \multirow{2}{*}{$\begin{array}{l}\text { DISH } \\
\text { STEAM }\end{array}$} & \multicolumn{2}{|c|}{ DISH ELECTRIC } & \multirow{2}{*}{$\begin{array}{l}\text { CENTRAL } \\
\text { RECEIVER }\end{array}$} \\
\hline & & & & & STIRLING & BRAYTON & \\
\hline COLLECTORS $^{(1)}$ & $0.34^{(2)}$ & 0.42 & 0.54 & 0.79 & 0.70 & 0.70 & $0.65^{(3)}$ \\
\hline (FLUID TEMP, ${ }^{0} \mathrm{C}$ ) & (177) & (350) & (450) & (537) & (810) & $(810)$ & $(510)$ \\
\hline ENERGY TRANSPORT (4) & 0.95 & 093 & 0.92 & 0.87 & 0.94 & 0.94 & $0.95^{(5)}$ \\
\hline $\begin{array}{l}\text { STORAGE THROUGHPUT } \\
\text { ENERGY CONVERSION }\end{array}$ & $-(6)$ & 0.80 & 0.80 & 0.80 & $0.75^{(7)}$ & $0.75^{(7)}$ & 0.80 \\
\hline - TURBINE/ENGINE & 0.20 & 0.27 & 0.30 & 0.35 & 0.42 & 0.35 & 0.36 \\
\hline - NET SUBSYSTEM $(9)$ & 0.19 & 0.24 & 027 & 0.31 & 0.36 & 0.30 & 0.32 \\
\hline
\end{tabular}

(I) COMB INED EFFECT OF CONCENTRATOR AND RECEIVER INSTANTANEOUS EFFICIENCIES BASED ON NOON, NORMAL INSOLATION

(2) ANNUAL AVERAGE EFFICIENCY BASED ON CONCENTRATION RATIO OF 3, PEAK EFFICIENCY IS $43 \%$ TWICE A YEAR

(3) BOTTOM OPEN CAVITY RECEIVER

(4) INCLUDES HEAT LEAK AND PUMPING POWER

(5) INCLUDES SMALL OPTICAL TRANSPORT LOSS (1\% ABSORPTION PER $1000 \mathrm{ft}$ LINE-OF-SIGHT) AND THERMAL TRANSPORT LOSS INSIDE TOWER

(6) FIXED SYSTEM CONSIDERED WITHOUT STORAGE

(7) INCLUDES INVERTERS

(8) RANKINE SYSTEM EXCEPT FOR DISH ELECTRIC

(9) INCLUDES EFFECT OF DRY COOLING EXCEPT FOR VEE-TROUGH, AUXILIARY POWER, GENERATOR, etc.

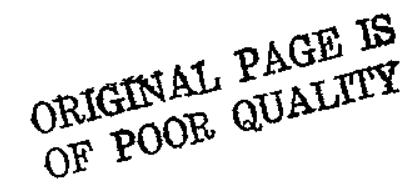


Table 3-2. Solar Subsystem Direct Cost* Data

- plant RATING 100 MWe

- yeAR 2000 PLANT STARTUP

- LOAD FACTOR 0.55

\begin{tabular}{|c|c|c|c|c|c|c|c|}
\hline \multirow[b]{4}{*}{ MAJOR SUBSYSTEMS $\star$} & \multicolumn{7}{|c|}{ TYPE OF PLANT } \\
\hline & FIXED & \multicolumn{2}{|c|}{$1-A X I S$} & \multicolumn{4}{|c|}{$2-A \times I S$} \\
\hline & \multirow{2}{*}{$\begin{array}{c}\text { VEE } \\
\text { TROUGH }\end{array}$} & \multirow{2}{*}{$\begin{array}{c}\text { PARABOLIC } \\
\text { TROUGH }\end{array}$} & \multirow{2}{*}{$\begin{array}{l}\text { VARIABLE } \\
\text { SLATS }\end{array}$} & \multirow{2}{*}{$\begin{array}{l}\text { DISH } \\
\text { STEAM }\end{array}$} & \multicolumn{2}{|c|}{ DISH ELECTRIC } & \multirow{2}{*}{$\begin{array}{l}\text { CENTRAL } \\
\text { RECEIVER }\end{array}$} \\
\hline & & & & & STIRLING & BRAYTON & \\
\hline \multicolumn{8}{|l|}{ COLLECTORS $^{(1)}$} \\
\hline - CONCENTRATORS, $\$ / \mathrm{m}^{2}$ & 28 & 103 & 130 & 182 & 182 & 182 & 145 \\
\hline - RECEIVERS, $\$ / \mathrm{m}^{2}$ & 35 & 26 & 41 & 7.6 & 11.5 & 115 & $25(2)$ \\
\hline ENERGY TRANSPORT, \$/kWe & 100 & 185 & 185 & 305 & 77 & 77 & \\
\hline ENERGY STORAGE ${ }^{(3)}$, \$/kWe hr & - & 60 & 60 & 60 & 45 & 45 & 60 \\
\hline ENERGY CONVERSION, \$/KWe & 250 & 250 & 250 & 250 & $102^{(4)}$ & $121^{(5)}$ & 250 \\
\hline $0 \& M \cos T^{(6)}, 10^{6} \$ / y r$ & 064 & 29 & 31 & 29 & $37^{(7)}$ & 2.9 & 29 \\
\hline
\end{tabular}

* diREct cost does Not INClude spares AND CONTINGENCY, INDIRECT COST, OR INTEREST DURING CONSTRUCTION

* * BASED ON EARLY ESTIMATES - CONSIDERED OPTIMISTIC COMPARED TO OTHER SYSTEMS

(1) COSTS NORMALIZED TO CONCENTRATOR APERTURE AREA. DIAMETER $=36 \mathrm{ft}$ FOR DISH SYSTEMS

(2) INCLUDES TOWER STRUCTURE, RECEIVER, AND PIPING TRANSPORT IN TOWER, \$/kWe

(3) STORAGE COST NORMALIZED TO RATED STORAGE OUTPUT POWER OF 70\% PLANT RATING

(4) INCLUDES STIRLING ENGINE COST OF 42 \$/kWe PLUS GENERATOR, STARTER, SWITCHGEAR, etc

(5) INCLUDES BRAYTON ENGINE COST OF 61 \$/kWe PLUS GENERATOR, STARTER, SWITCHGEAR, etc

(6) FIRST YEAR AVERAGE COST WITHOUT INFLATION AND CLEANING - LEVELIZED COSTS OVER $30 \mathrm{yr}$ PLANT LIFE ARE APPROXIMATELY 3 TIMES HIGHER DUE TO INFLATION

(7) INCLUDES COST OF ENGINE REPLACEMENT EVERY 5 years FOR STIRLING/15 YEARS FOR BRAYTON 
Although many design variations are possible, these types of collectors are believed to represent a wide range of potential distributed-collector systems.

Past studies (see Ref. 6) have predicted the performance and eventual commercial cost of these collector systems and include the heliostat for the central receiver solar plant as a reference point. Since there is increasing activity related to these types of collectors, a survey has been conducted to review more recent development. A description of this survey is contained in Appendix A. Several types of collectors are being installed at the total energy solar facility at Albuquerque, N.M., at the 5 MWe central receiver test facility, and at the irrigation project at Gila Bend, Arizona. The collectors are still prototype devices or low production items, and little or no performance data is as yet available.

This survey, as well as recent cost estimates submitted to Sandia Albuquerque, have been used along with the previous studies to estimate the cost and performance of various collector subsystems. These data are shown in Tables 3-1 and 3-2 and represent the authors' best judgement at this time. They are not definitıve estımates since detailed mass production cost estimates were not made based on specific designs and production processes.

In general, these cost estimates are higher than previous studies and highlight the need for an aggressive R\&D program that can lead to less expensive subsystem costs, particularly in the collector area.

\section{Advanced Fixed Orientation Collectors}

As described previously, this device uses "Vee" shaped reflectors which are asymmetrical so that by adjusting (reversing) the position of the reflector $t \bar{w} i \overline{c e}$ a year, the annual performance is ennanced while preserving simplicity of design. A tubular vacuum receiver containing a tube and a fin absorber plate with a selective coating is used. The design achieves minimum system cost at about $350^{\circ} \mathrm{F}$ when coupled to a Rankine power plant.

The performance is based on detailed calculations (Ref. 2) and a verification test program is in progress. At the optimum temperature $\left(350^{\circ} \mathrm{F}\right)$ and concentration ratio $(\mathrm{CR}=3)$, the annual average efficiency is estimated to be $34 \%$, while the peak annual efficiency is $43 \%$. The cost projection is heavily dependent on the cost of the vacuum absorber tube. The Corning design having a copper tube and fin with a glass to metal seal is considered. Prototype costs are greater than $\$ 25 / \mathrm{ft}^{2}$ of absorber area, and the manufacturer is predicting eventual costs of $\$ 10 / \mathrm{ft}^{2}$. This cost is believed to be optimistic at this time, but it is used to determine if this approach can be competitive. The reflective surface is considered to cost $\$ 0.50 / \mathrm{ft}^{2}$ of reflector surface and is based on aluminized plastic on a steel or aluminum sheet metal substrate. The structural framing including concrete pads are considered to cost $\$ 15 /$ ft $^{2}$ of frame area. Shipping and assembly are considered to be about $\$ 0.60 / \mathrm{ft}^{2}$ (see Ref. 2 for details). 
For a concentration ratio of 3 , these cost estimates are shown in Table 3-2 based on the aperture area for the concentrator and receiver parts of the subsystem. The total collector direct cost is $\$ 63 / \mathrm{m}^{2}$ of aperture area using the $\$ 10 / \mathrm{ft}^{2}$ absorber tube cost.

The CPC design is believed to be similar in that it is an advanced "fixed" flat plate system. As the concentration ratio (CR) is increased, the annual number of concentrating surface adjustments must increase; e.g., onIy 2 adjustments are needed for $C R=3$, while 12 are required for $\mathrm{CR}=5$. This increases performance but it also appears to require a more complicated tracking system than reflector reversal. A careful review of the CPC performance and cost characterustics should be conducted to explore these issues in more detall and check the present conclusion that the CPC is about as cost effective as the asymmetric Vee-trough approach.

\section{Parabolic Trough}

The understanding of the performance of continuous surface parabolic trough linear concentrators was obtained primarily from the experience and technology developed by the University of Minnesota and Honeywe11. Visits to Acurex, Del Mfg. and Hexcel served to point out the wide range of system designs, quality of equipment, operating and performance characteristics, etc. The rough estimates of cost provided by these three companies were evaluated and compared with earlier estimates (Ref. 3).

Based on this information, a range of cost estimates has been derived for a parabolic trough that could achleve a noon time efficiency of $42 \%$ at an optimum operating temperature of $350^{\circ} \mathrm{C}\left(660^{\circ} \mathrm{F}\right)$. Off-angle effects will reduce the efficiency at other sun times considered in the hour-by-hour system simulation. The eventual mass production cost estimate is $\$ 103 / \mathrm{m}^{2}$ for the concentrator part of the collector which is made up of supporting structure (steel and concrete), reflecting surface and supports, tracking mechanism, shıpping, and fleld assembly.

The receiver cost, as shown in Table $3-2$, is projected to be $\$ 26 / \mathrm{m}^{2}$ of concentrator aperture area and is based on a vacuum tube receiver wath coating. The total collector cost 1 s then $\$ 129 / \mathrm{m}^{2}$. Prototype collectors are being sold at this price now, but they do not have the performance indicated nor have their commercial lifetime capability been demonstrated, particularly in the context of withstanding severe environments such as wind and hail.

However, this price is based on prototype production without benefit of potential mass production cost improvements. Thus, the judgement is made that future mass production-costs for a suitably longlived commercial item with improved pexformance will be the same as current prototype costs. 
The basis for projecting the performance of the variable slat linear concentrator is the work done by Prof. Francia at the University of Marseille in the sixties and to some extent, the later work at Sheldahl and Itek companies. The noon instantaneous performance of $54 \%$ is estimated to occur at $450^{\circ} \mathrm{C}$ for optimum system operation even though somewhat higher performance was achieved (see Ref. 2).

A range of costs has been determined using the rough cost information from Sheldahl and Itek along with earlier studies. It is believed that the slat concentrator costs are higher by about $30 \%$ than for the parabolic troughs due to the uncreased mechanical complexity, increased number of reflector facets, and greater accuracy requirements. The receiver cost is also considered to be due more to higher temperatures $\left(450^{\circ} \mathrm{C}\right)$. The total collector cost is $\$ 171 / \mathrm{m}^{2}$ versus $\$ 129 / \mathrm{m}^{2}$ for the parabolic trough and is about $1 / 3$ more.

The same reservations expressed earlier exist here in that no detajled mass production-cost estimates have been performed on a specific design.

\section{CentraI Receiver Heliostats}

The baseline central receiver solar power plant collector is included in the study as a reference for the distributed systems. The estimate of the performance is based on earlier studies (see Refs. 6 and 10) which compare three system contractor approaches. The nominal efficiency is stated as $65 \%$ based on a 360-degree field using a bottom open cavity receiver.

The cost prediction is based primarily on the earlier projection for the one-axis tracking systems. The heliostat is a two-axis tracking system that (for most present designs) has a single structural support member with high cantilevered loads. The two-axis tracking system is more complex than one-axis, and the aiming requirements are much more stringent for a 1000:1 concentration ratio system versus a 20:1 system. This combination of effects and the use of limited cost data from the central recelver program lead us to estimate that the heliostat should be about $25 \%$ more costly than the average of the one-axis tracking systems. The mass production-cost estimate is then $\$ 145 / \mathrm{m}^{2}$ as compared to $\$ 116 / \mathrm{m}^{2}$, which is the average cost for the one-axis collectors.

Early prototypes for use in the 5 MWe test facılity provided by the Martin Company cost approximately $\$ 340 / \mathrm{m}^{2}$ for several hundred heliostats. The DOE goal is in the $\$ 60 / \mathrm{m}^{2}$ to $\$ 80 / \mathrm{m}^{2}$ range.

5. Point Focusing Dish

The performance and cost estimates for the two-axis tracking 
point focusing dish has the greatest uncertainty associated with it. The device is similar in complexity to the two-axis tracking heliostat except that the heliostat will probably have a flat surface. Further, the point-focusing dish introduces the additional factors of reflector surface curvature and receiver mounting on the collector. Smaller mirror facets may be necessary and this would increase fabrication complexity.

Current microwave antenna (parabolic dish) costs are between $\approx \$ 650 / \mathrm{m}^{2}$ and $\approx \$ 1100 / \mathrm{m}^{2}$ based on limited production ( $<100$ per year) and on more stringent surface and aiming requirements than axe necessary for heat collection. A near term approach is to adapt these antennas to meet solar collection requirements. One solar concentration dish is being installed at the Albuquerque total energy facility by Raytheon with early cost estimates between $\$ 540 / \mathrm{m}^{2}$ and $\$ 650 / \mathrm{m}^{2}$.

Based primarily on the previous cost estimates and earlier studies (see Ref. 6), the concentrator part of the dish collector (everything besides the receiver) is estimated to be $25 \%$ more than the heliostat and nearly $60 \%$ more than the average of the one-axis linear concentrating collectors. Thus, the mass produced cost of the concentrator part of the dish is estimated to cost $\$ 182 / \mathrm{m}^{2}$ versus $\$ 145 / \mathrm{m}^{2}$ for the heliostat.

The receiver cost is estimated to vary depending on the temperature level, type of fluid, pressure level and fabrication materials used. The receiver cost varies from about $\$ 8 / \mathrm{m}^{2}$ to $\$ 12 / \mathrm{m}^{2}$ of aperture area. The lower cost is for a steam system at $1000^{\circ} \mathrm{F}$, while the higher cost pertains to a gas at $1500^{\circ} \mathrm{F}$. Thus, the total collector cost is about $\$ 192 / \mathrm{m}^{2}$ for a mass produced point focusing dish.

The performance estimate is based on earlier studies (see Refs. 4 and 7) and limited experimental data carried out at JPL. This data includes a room temperature calorimeter test conducted with a $81 \%$ to $83 \%$ efficlency for a niñe facet (16 in. x $16 \mathrm{kn}$. each) mirror on a two-axis tracking structure. This structure used back silvered glass attached to a spherically curved foamed glass substrate. Based on this, the nominal collector efficiency is estimated to be $70 \%$ and $79 \%$ based on $1500^{\circ} \mathrm{F}$ and $1000^{\circ} \mathrm{F}$ fluid exit temperature, respectively.

These estimates of the combination of nominal performance and cost for the selected collectors have uncertannty associated with them. Upper and lower bound estimates are shown in Section IV in connection with an investigation of subsystem sensitivities. These bounds represent extreme best/worst limits in each axea.

\section{B. ENGINES/POWER GENERATION SYSTEMS}

Engine types for solar applications were. furst Identified (Ref. 11) and then subdıvided into availabılity classes shown below: 


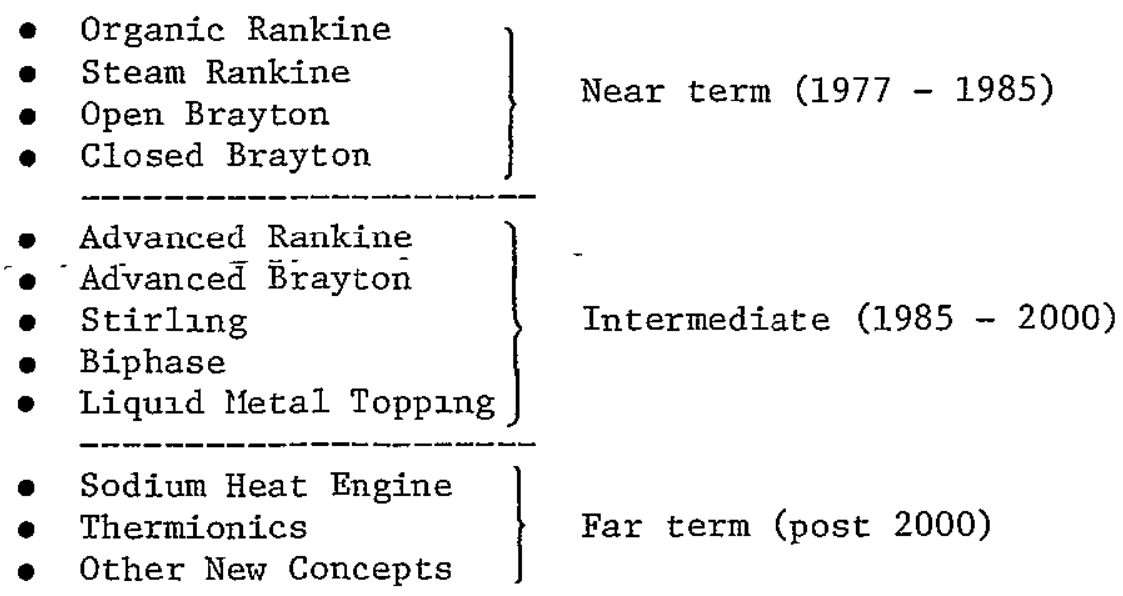

Near term engines are either in production or are proceeding successfully through development/demonstration phases. The intermediate class of engines encompasses advances to Brayton and Rankine systems, primarily involving higher temperature designs having greater efficiency. This class also includes Stirling and Biphase engines which are currently in early stages of development. Far term engines include those in the laboratory research stage and new concepts.

The near term engines are used in current baseline or alternative systems. The intermediate term engines are expected to reach a sufficient level of technological maturity so that they will be avallable for use in commercial power plants during the 1990-2000 period, which is the primary focus of this study.

Far term engines could reach the large scale feasibility demonstration stage during 1990-2000 and it is expected that those which show promise will be developed to the point of commercial implementation in the period after the year 2000. It is possible that some developments such as Thermionic conversion systems could be accelerated by factors such as their use in spacecraft propulsion systems (Ref. 17), but considerable progress toward achievement of higher efficiencies and reliable operation is required before these systems can be considered as viable candidates for terrestrial power applications.

The organic Rankine system Is suitable for low temperatures and applications include fixed collector solar power systems, waste heat recovery, and bottoming cycles for conventional power stations. Emphasis on energy conservation has recently stimulated developmental activities. Cost and performance projections based on these activities are summarizeci in Ref. 11. For the present study, the only system employing organic Rankine cycles is the fixed-collector Vee-trough power plant treated in Ref. 2. Only a 100 MWe system is considered and, for this size, the same unit cost as a conventional steam Rankine plant is employed for a large size organic Rankine power plant.

Steam Rankine power plants for ratings greater than 10 MWe are well-developed commercial systems. They operate at temperatures of $\sim 1000^{\circ}$ resulting from design optimizations involving cost and 
performance tradeoffs. The steam Rankine systems employed in this study are based on this proven technology.

Advanced stean Rankine systems could involve new high temperature materials which would enable higher temperature operation. The cost of such new materials must be such that a net economic gain accrues. Other approaches include the addıtion of high temperature topping cycles and/ or low temperatures bottoming cycles to a conventional steam Rankine cycle. In-depth evaluations of these options is beyond the scope of the present study.

For the advanced Brayton and Stirling engines, a review of recent developmental activities confirmed cost and efficiency projections employed in Refs. 6 and 7. These projections are based on successful completion of development activities. The data of Table 3-1 corresponds to cycle temperatures of $\sim 1500^{\circ} \mathrm{F}$. It is expected that solar receiver/engine systems could be developed without incurring major materials problem if temperatures are limited to this level. Therefore, these systems could reasonably be expected to be developed to a commercial status in the 1990-2000 time period. In the near term, existing open and closed cycle Brayton engines developed for non-solar application could be adapted to the solar system with some decrease in performance as compared to Table 3-1. Near term costs will also be higher than the Table 3-2 costs which are predicted on high volume production ( $10^{5}$ to $10^{6}$ units per year) in the 1990-2000 time frame. The use of high temperature materials (e.g., ceramics) for both the receiver and heat engine components would allow higher temperatures and greater efficlencles, but it is less likely that these systems will reach a stage of development where they could be commercially implemented by 1990. Therefore, this high temperature possibility is not considered in this study.

The Biphase engine development is based on cycles where liquid and vapor phases are separated so that power can be efficiently extracted from each phase. This cycle is potentially advantageous for use with two-phase geothermal power systems (Ref. 12). High temperature Biphase systems involving liquid metals are also possible. Development of such high temperature concepts is in the early research stage and these high temperature systems are considered to be far term possibilities.

In the intermediate term, Biphase engines represent an alternative to organic Rankine cycles. At the present early stage of development, it is not possible to quantitatively determine the relative merits of the Biphase and organic Rankine systems (Ref. 12). Since it appears that the Biphase will be comparable to the organic Rankine system, a separate estimate for the Biphase system is not included in this study.

Liquid metal topping cycles (Ref. 31), involving mercury and potassium, have been pursued for space applications and a substantial technology base has been developed. Based on this work, it appears that liquid metal topping cycles could be implemented in the intermediate term. At present, costs for these systems are uncertaln (e.g., mercury is expensive and has a historically unstable price structure.) and there are problems such as toxicity, contamination, materials compatibility for potassium systems, turbine erosion, etc. In view of the nature of 
these problems, a systematic evaluation of liquid metal cycles is considered to be beyond the scope of the present study.

Thermionic power systems involving the direct conversion of heat to electrical energy are potentialiy applicable to a wide spectrum of terrestrial power and space propulsion systems (Ref. 13). Terrestrial application- activities have been focused primarily on high temperature topping cycles for fossil fuel power plants. The possibility of thermionic topping for solar thermal power systems has been explored in a preliminary manner (Refs. 14 through 16). The key problem is the development of thermionic diodes that can achieve conversion efficiencies of 20 or $30 \%$ (Ref. 13).

Thermionic systems involve high temperatures $\left(\sim 1400^{\circ} \mathrm{C}\right)$ and associated advanced materials technology. Consequently, these systems are in an early development stage. Since thermionic technology involves highly advanced technology, it is judged to be a far term candidate and is not included in the present study based on commexcially available technology in the 1990-2000 period.

The Sodium Heat Engine (SHE) Is an advanced concept that is in the early laboratory research stage (Ref. 18). Work on this concept was initiated by Ford Motor Co. (Ref. 19) and additional research is underway at Calıfornia Institute of Technology (Ref. 18). This work is directed toward attaining a better understanding of the basic mechanism as a basis for estimating performance characteristics. Until this step Is accomplished, detail design and cost activities have been deferred. In view of this very early development stage, the SHE is considered to be a far term system and is not included in the present study.

With regard to the engine data given in Tables 3-1 and 3-2, It is noted these values are nominal estimates subject to a range of uncertainty. The effect of-this uncertainty is examined as part of the subsystem sensitivity evaluation in Section IV.

\section{ENERGY STORAGE}

As shown in Ref. 20, use of thermal storage systems is particularly advantageous for solar thermal power plants. If thermal storage is interposed between the collector field and energy conversion system, the storage can absorb insolation variations and thereby allow a more uniform level of energy input to the conversion system. In particular, the conversion system can now be sized to match this storage-buffered input energy level as opposed to being sized to accept peak insolation levels. This results in reduced conversion system capital costs which, at least, partially offsets the cost of the storage system.

Based on the assessment of thermal storage systems in Ref. 21, sensible heat thermal storage systems were selected for the comparative assessment study of Ref. 6 . The survey of thermal storage systems undertaken as part of the present study tends to confirm that sensible heat systems are the most likely candidates for commercial implementation in the 1990-2000 time period. Latent heat or phase change storage 
systems offer higher energy density storage and may, therefore, potentially be less costly. However, they require considerably more technological development regarding problems such as the long-term stability of eutectic salt mixtures, tube life, and operation and maintenance considerations.

The values for thermal storage as presented in Table $3-1$ and $3-2$ axe, therefore, the same as used in Refs. 6 and 7 ; i.e., the estimated cost and performance of sensible heat systems have not changed. The estimates pertain to large storage systems capable of providing six hours of power at a level of 70 MWe when coupled to a conventional steam Rankine power plant. Such systems are still in the early development stage and the cost and performance values shown are based on projections and judgements. It is expected that unit costs of thermal storage systems will increase as the size of the system decreases, since these systems employ containment vessels which are more economical when sizes are large. Analysis of these economies of scale is not possible within the scope of this study and a constant unit cost with size is employed.

For the dish-electric system, a small heat engine/generator is coupled directly to the receiver mounted at the focal point of the dish. This arrangement avouds the use of flexible lines to transport heat from the focal point to a ground-based conversion system. Location of a thermal storage system at the focal point will increase welght and size to the point where much of the advantage of the compact focal-point mounted system will be lost. Therefore, inclusion of thermal storage for dish-electric systems is not considered in the present study.

Instead, electrical energy from each of the dish-mounted engine/ generators is collected and stored at a central location. As discussed in Ref. 22, electrical energy can be stored via mechanical, chemical, and electromagnetic pathways. The mechanical approach includes pumped hydro, compressed air, and flywheels, while the chemical approach encompasses batteries and hydrogen energy systems. The electromagnetic route involves direct storage of electrical energy in superconducting magnets.

Pumped hydro, compressed air, and lead-acid batteries are nearterm candidates. Pumped hydro and compressed air systems require particular terrain and geology which tends to 11mit their applicatıon. Lead-acid batteries have lower energy densities as compared to advanced concepts. Flywheels tend to be competitive only for short duration storage. Hydrogen systems require development of advanced electrolyzerfuel cell systems and appear to be advantageous when certain utility operating conditions exist. Electromagnetic systems require advanced technology development which offers high efficlency, but costs are highly uncertain.

The survey conducted as part of this study indicates that considerable effort is being expended under DOE and EPRI sponsorship to develop energy storage systems. With regard to projections of performance and cost, the latest and most authoritative source is considered to be the extensive assessment of energy storage systems prepared by the Public 
Service Electric Gas Company (Ref. 23). This study identifies a set of candidates and infers that it is premature to select any one system. In fact, all of the systems could be implemented depending on application specıfic circumstances.

For the comparative assessment study (Ref : 6)) the- advanced battery system was selected along with pumped hydro as a baseline external energy storage system, since pumped hydro is the only storage system presently in utility service. This advanced battery system was also employed in the present study and the data in Tables 3-1 and 3-2 corresponded to nominal estimates within the range of advanced battery cost and performance in Ref. 23. The battery system was chosen since there is an extensive DOE/EPRI development program underway centered around the use of a large scale Battery Energy Storage Test (BEST) facility, which is to be operational in the 1980s. Batteries will be particularly attractive since they can be easily located at dispersed locations and have rapid response characteristics.

Even if advanced batteries do not attaun projected performance and cost goals, other candidate storage systems are being pursued. Therefore, it appears likely that at least one system having performance and costs in the range of values projected for the battery will be available in the 1990-2000 time frame. The effect of performance and cost uncertainties associated with energy storage systems is discussed in Section IV.

\section{ENERGY TRANSPORT}

For distributed-collector concepts, energy is transported from the collector field either by pipelines or electric wires. For systems selected in this study, pipeline transport involves steam and organic fluids. No new studies regarding transport system design and associated optimizations have been uncovered by the data base survey. Hence, the analysis and estımates employed in the comparative assessment study of Ref. 6 are used in this study.

For pipeline systems, the analysis procedure for distributeddish (or point focusing) systems is given in Ref. 24. This basic procedure was extended to encompass linear concentrator systems as part of the present study. The analysis was based on a square field arrangement, where 8480 linear collectors (1000 $\mathrm{ft}^{2}$ each) were required for a $100 \mathrm{MWe}$ plant (Ref. 25).

For electrical collection involved in the parabolic dish-electric system, the basis for estimating costs and performance is given in Ref. 4. The collection network analysis Includes both low and high voltage transformers, capacitors, circult breakers, and cables. 
SECTION IV

COMPARISON OF SELECTED SYSTEMS

In this section, the data base of the previous section is used as the basic input for a comparative evaluation of the selected systems. The approach employed in making the comparison is first described in terms of the basic methodology and assumptions. Then the economics of the selected systems are compared over a range of operating load factors for a fixed 100 MWe plant rating. The effect of varying the plant size is next investigated for a fixed plant load factor of 0.55 . System sensitivities to variations in the data base are then delineated to show the impact of uncertainties in cost and performance projections. These sensitivities are also presented on an individual subsystem/ component level to show the relative importance of uncertainties associated with each data input.

\section{A. APPROACH}

This study uses the basic approach developed in the comparative assessment study of Ref. 6 . This approach is first briefly summarized and then illustrated by an example of the basic procedures.

\section{Performance Simulation}

The first step in the approach is to simulate the basic performance of the selected power plants. This involves the development of a computer simulation code based on an analysis of the collector field as a function of factors such as concentrator geometry/optics, solar tracking characteristics, surface reflectivities, and receiver heat losses. These factors are reflected in the nominal collector system efficiency given in Table 3-1. The efficiencies of the other system components as shown on Table 3-1 are then combined with collector efficiency characteristics to determine how much of the collected energy is converted to electricity. Off-angle effects on the collector performance, off-load effects on the engine efficiency, auxiliary power, and five modes of operation (normal, low insolation, intermittent clouds, night using storage, and standby) are considered.

The use of this basic system simulation code to determine system performance is illustrated on Fig. 4-1. Inputs to the code comprise weather conditions or insolation and the electric demand of the utility grid. For this study, hourly direct insolation data for one year from Inyokern, CA., are employed. The utility demand was set for baseload operation; i.e., the grid requested that the plant deliver rated power continuously. Under these conditions, the computer simulation control logic would allow the plant to operate and deliver rated power to the maximum extent possible within constraints of plant design characteristics. That is, the plant would delfver rated power during periods of 


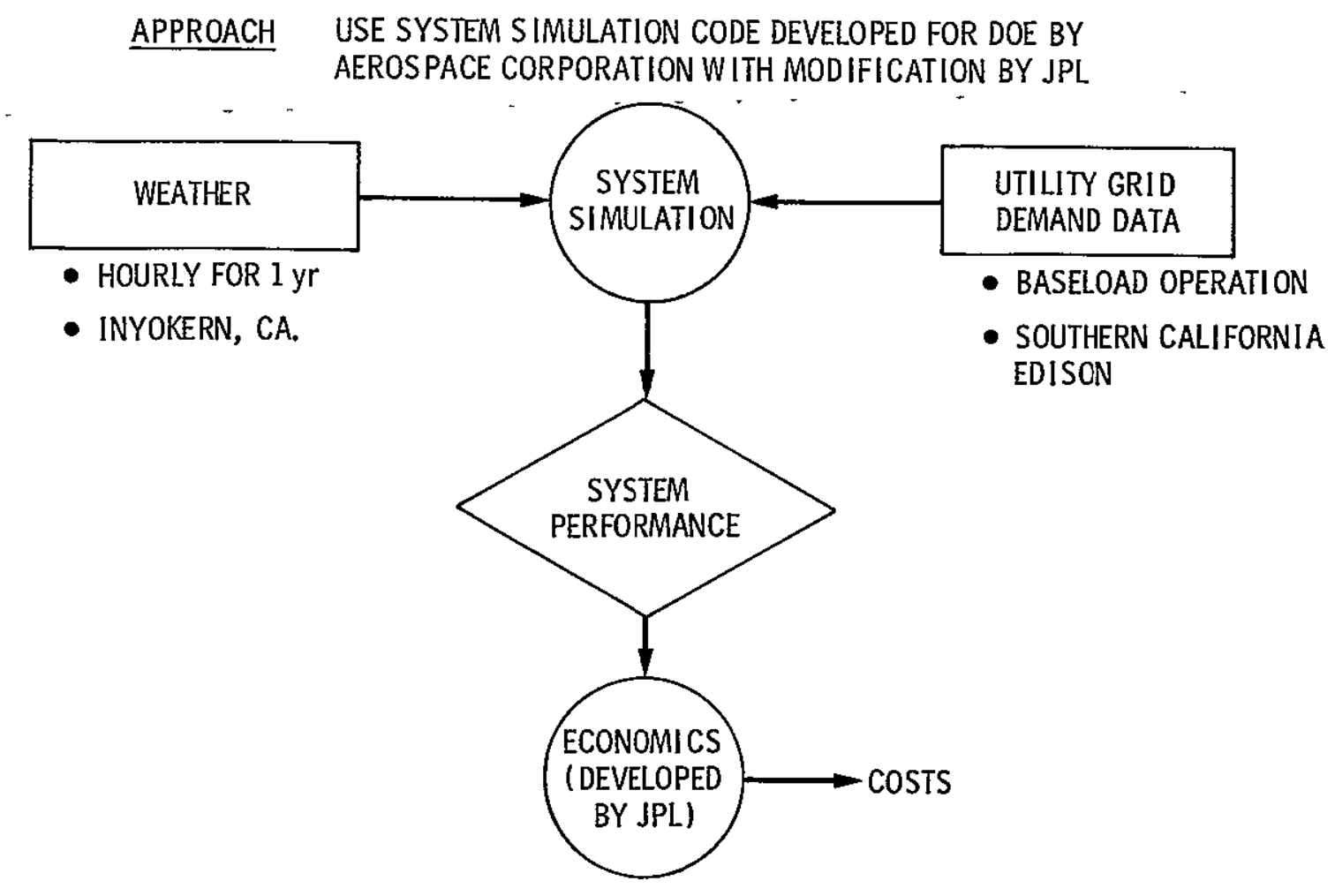

Figure 4-1. Solar Plant System Simulation Computer Code

insolation availability and store excess energy. The stored energy would then be delivered when insolation is insufficient. The total energy delivered during a year over the amount of energy that would have been delivered by continuous operation of the plant at the rated power is defined as the load factor.

For non-baseload operation, the demand characteristics of Southern California Edison are available in the computer code. However, the present study is limited to the baseload case corresponding to constant demand. The ability of a particular power plant configuration to satisfy this demand is measured by the load factor, where conventional nuclear and coal plants presently achieve load factors of $n 0.5$ to $\sim 0.7$ for baseload operation (Ref. 6). Investigation of utllity interfacing as a function of demand characteristics involves complex considerations beyond the scope of this study. Some of the utility interfacing issues are identified and treated in a preliminary manner in Refs. 6, 7, 29, and 30 , and this basic work has to be amplified and extended.

In operating the code, plant characteristics are first selected. These include collector type and area, plant rating, storage system size, and efficiencies of subsystems/components. The computer hour-byhour simulation then determines the corresponding load factor. By 
varying collector area and storage size a performance map for a given type of power plant can be generated.

\section{Economic Methodology}

The computer generated performance map and the subsystem unit cost data (Table 3-2) are employed in determining power plant economics as expressed by energy and capital costs. These power plant costs depend on cost escalation rates, discount rates, and the method of financing plant construction.

Therefore, an economic methodology is required so that comparisons can be conducted in a consistent manner. Such a methodology has been developed in Ref. 26 and implemented in Ref. 6. This same methodology is used in the present study. It involves consideration of factors such as:

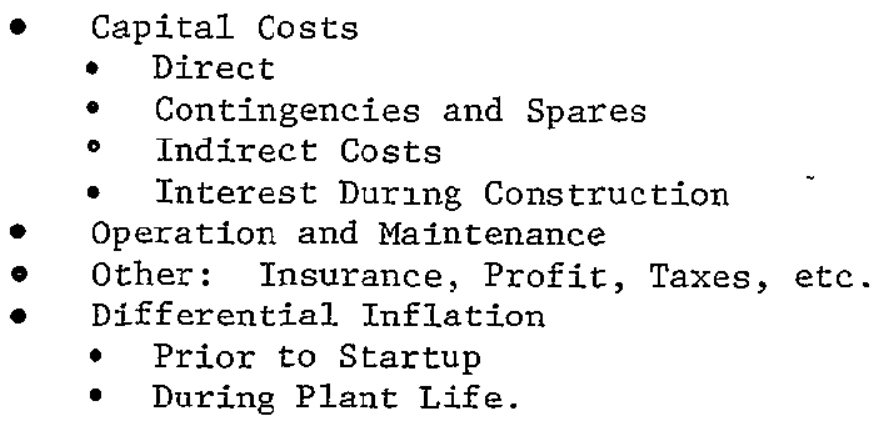

The methodology yields a levelized (average) energy cost over the plant life and allows the use of a constant dollar base. For the present study, 1975 dollars are used throughout since the data base from the comparatıve assessment study was in 1975 dollars. Due to differential inflation effects, costs are a function of the year of plant startup. For this study, all the plants have been analyzed on the basis of startup in the year 2000 with a plant construction period of 6 years. As a consequence of the assumed differential inflation rates (discussed in detail in Ref. 6), costs for year 2000 staxtup are $22 \%$ higher than costs for 1975 startup, where it is emphasized that all costs are in 1975 dollars. Also, the energy cost is calculated on the basis of $13.6 \%$ downtime for annual maintenance (scheduled and unscheduled).

\section{Example of Procedure}

The procedure involved in implementing the approach is explained by treating a specific example case. The parabolic dish-electric system is chosen for this purpose. Analysis of the other selected systems would inyolve the same basic steps. 
The first step involves the use of the performance simulation code to generate a performance map. The map for the parabolic dish-electric plant is shown on Fig. 4-2. The relationships among field size, storage capacity, and capacity factor are presented. Basically, to achleve a high capacity factor, Fig. 4-2 indicates that both storage capacity and collector fleld size must be increased. The larger field size

- result- in greater excess energy collection dưring iñsolation availability periods. This excess energy can be stored in higher capacity storage systems which are discharged during periods of insolation unavailability and this results in higher capacity factors.

For utility power plant systems, a major design consideration is to achieve the lowest energy costs for any given operating load factor. The energy cost for solar plants is given below:

$$
\mathrm{EC}=\frac{\mathrm{CRF}}{8760 \mathrm{PL}} \quad\left(\mathrm{hI}+\mathrm{f}_{1} \mathrm{O}+\mathrm{f}_{2} \mathrm{M}\right)
$$

- PLANT RATING: 100 MWe

- INSOLATI ON: HOURLY INYOKERN CA. DATA

- ADVANCED BATTERY STORAGE



"NO ANNUAL MAINTENANCE FACTOR

Figure 4-2. Parabolic Dish-Electric Plant Performance 
where

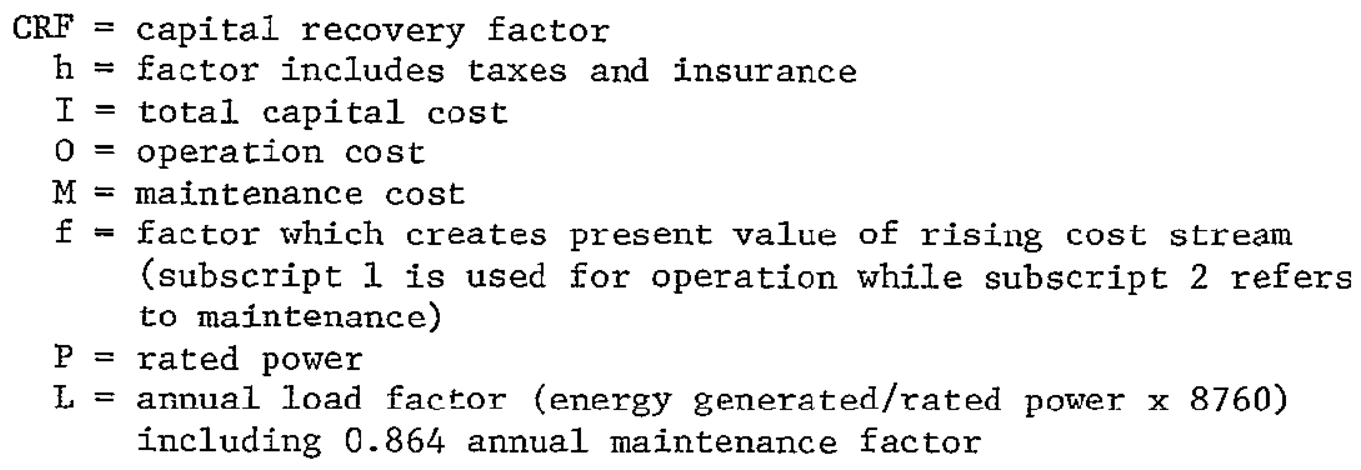

In both Ref. 6 and the present study, the weighted interest rate is $9.6 \%$, the cost of capital after taxes is $8 \%$, and the annualized fixed charge rate is $14.8 \%$ where capital costs, taxes, insurance, etc., are included.

The energy cost relation is essentially the ratio of annualized costs ovex the energy delivered. When the collector field size and storage capacity are increased, costs increase, but the energy delivery as denoted by the load factor also increases. In general, energy costs can be made to either decrease or increase depending on the combination of field area, storage, and load factor. The combination yielding the lowest energy cost is sought and the method for determining this combination is depicted on FIg. 4-3. For a chosen concentrator or collector field area, storage capacity is increased until the lowest energy cost is achieved. Annual load factor (which includes an 0.864 annual maintenance factor) also increases as storage capacity is increased, shown In Fig. 4-2. As storage size is increased beyond the value corresponding to minimum costs, energy costs rise rapidly while the load factor becomes essentially constant. This corresponds to the circumstance where the storage is being oversized in relation to the excess energy available for storage.

By considering a family of concentrator field sizes and determining the minimum energy cost for each size, an envelope curve (dashed line on Fig. 4-3) of minimum energy costs is constructed. This curve is relatively flat for load factors from 0.3 to 0.6 and thereafter tends to rise more rapidly. The knee in the curve occurs at a load factor of about 0.7 , and the curve becomes asymptotic to a load factor of 0.864 . which represents the maximum value possible in view of the assumed downtime for annual maintenance

The rapidly rising portion of the minimum energy cost curve corresponds to a zone of diminishing returns. If the solax plant is forced to provide energy on an essentially continuous basis except for maintenance downtime, large field areas and large storage capacities are required and costs will be high. The reasonable operating range for solar plants would appear to be for load factors $\leq 0.7$, which corresponds to the range of present conventional (coaí and nuclear) plants. 
For the dashed minimum curve line, all of the collected excess energy is not stored. When storage is full, energy is rejected. If no energy is to be rejected, the storage system must be sized to handle the peak excess insolation occurring during the year and for most of the year excess storage would be provided. Thus, under the ground rules of delivering a constant rated power level for baseload operation, minimum costs correspond to some energy rejection.

For external battery storage systems, it appears likely that the excess electrical energy over-rated power would be allowed to be fed into the utility grid. To compensate, fossil plants feeding the grid could back down slightly and conserve fuel. If this happened, the lower envelope curve of Fig. $4-3$ would prevail and a significant ( $25 \%)$ reduction in energy cost would result.

For thermal storage, the optimum baseload situation similarly results in some rejected thermal energy. Since this rejected energy is intermittent and highly variable in level, its use will require detailed tradeoff studies beyond the scope of this study. Thus, for thermal. storage systems, the rejected energy is considered to be lost.

In addition to energy costs, capital costs are an important consideration in the implementation of power plants. Availability of capital can dictate the feasibility of constructing a power plant. Both capital and energy costs are shown on Fig. 4-4 for the minimum life cycle energy cost designs so that cost trends can be compared. Capital costs increase rapidly with load factor since both field size and storage capacity must be increased. As noted previously, energy costs increase only slightly up to a load factor of 0.6 . Thus in this range, the price of achieving higher load factors is essentially manifest as higher capital costs.

\section{B. COMPARATIVE ECONOMICS}

Employing the basic procedure just described, the energy and capital costs of the selected systems have been determined. At a fixed plant rating of $100 \mathrm{MWe}$, the energy and capital costs of the systems are compared on Figs. 4-5 and 4-6. For distributed-collector systems, the two-axis tracking dish-Stirling arrangement has the lowest energy costs. The dish-Brayton is about $10 \%$ more expensive. The dish-steam and the one-axis tracking variable slat and parabolic trough are approximately comparable with an energy cost of $140 \%$ more than the dish-Stirling in the 0.3 to 0.6 load factor range. The fixed orientation (nontracking) Vee-trough is $280 \%$ higher.

At least part of this cost trend is due to the use of higher temperature $\left(\sim 1500^{\circ} \mathrm{F}\right)$ technology for the Stirling and Brayton systems. The dish-steam employs conventional $\left(\sim 1000^{\circ} \mathrm{F}\right)$ Rankine cycle technology. Use of advanced Rankine systems (e.g., topping cycles) could change the comparison. For one-axis tracking systems, either variable slats or parabolic trough, achievable temperatures appear to be limited to the level of conventional Rankine technology. But even for these systems, modifications such as the addition of a bottoming cycle could improve 


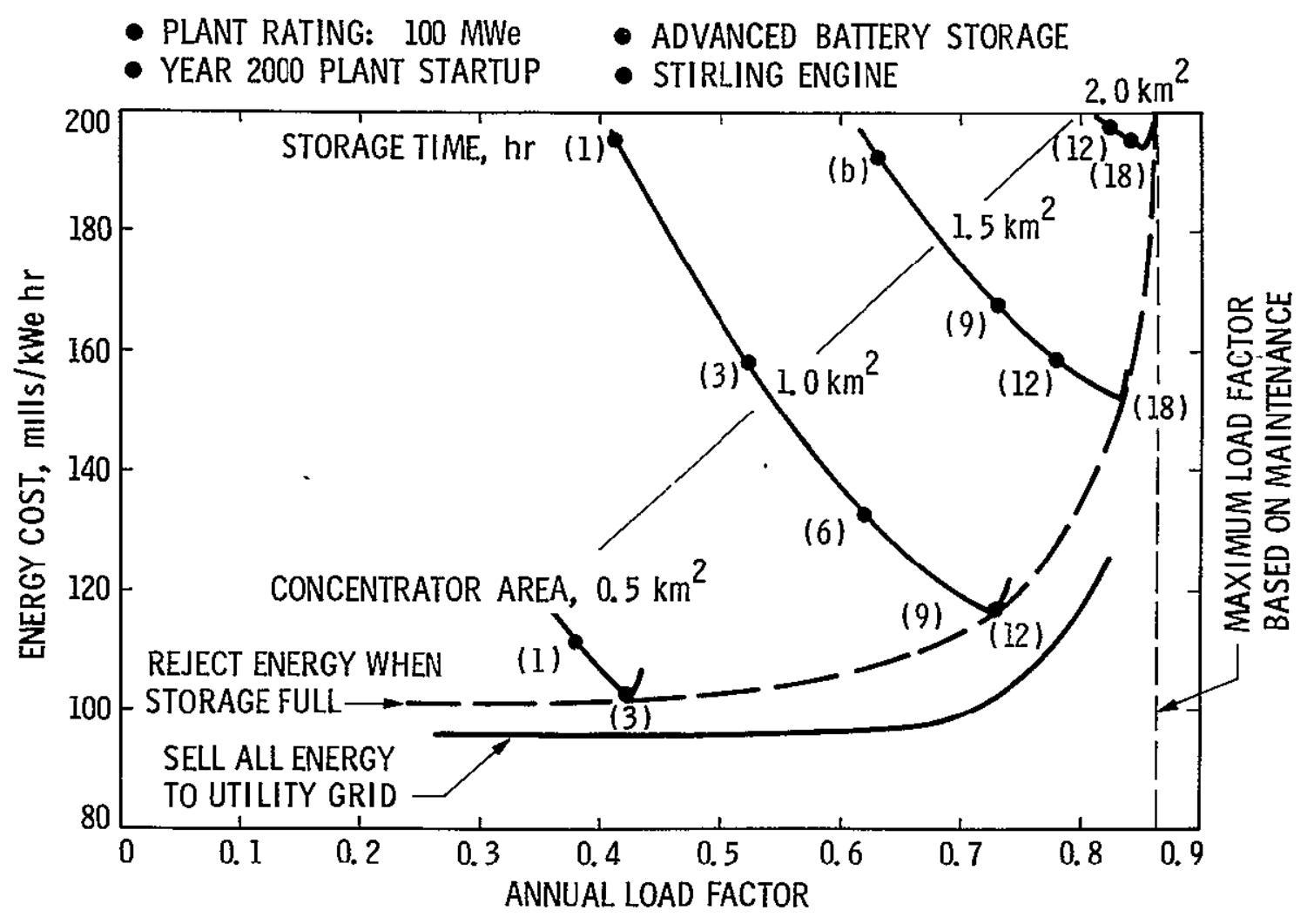

Figure 4-3. Parabolic Dish-Electric System Characteristics

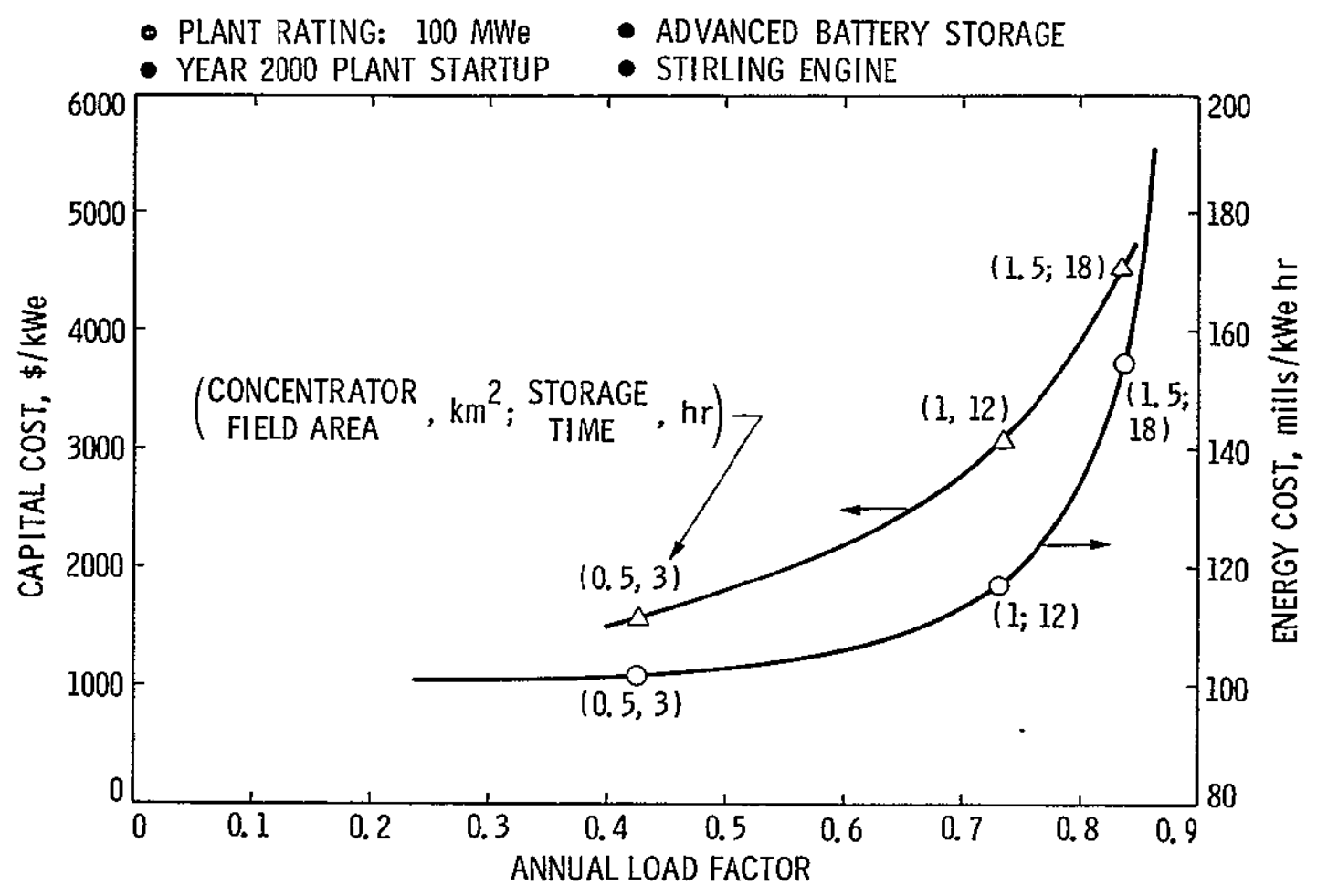

Figure 4-4. Parabolic Dish-Electric Capital and Energy Costs 


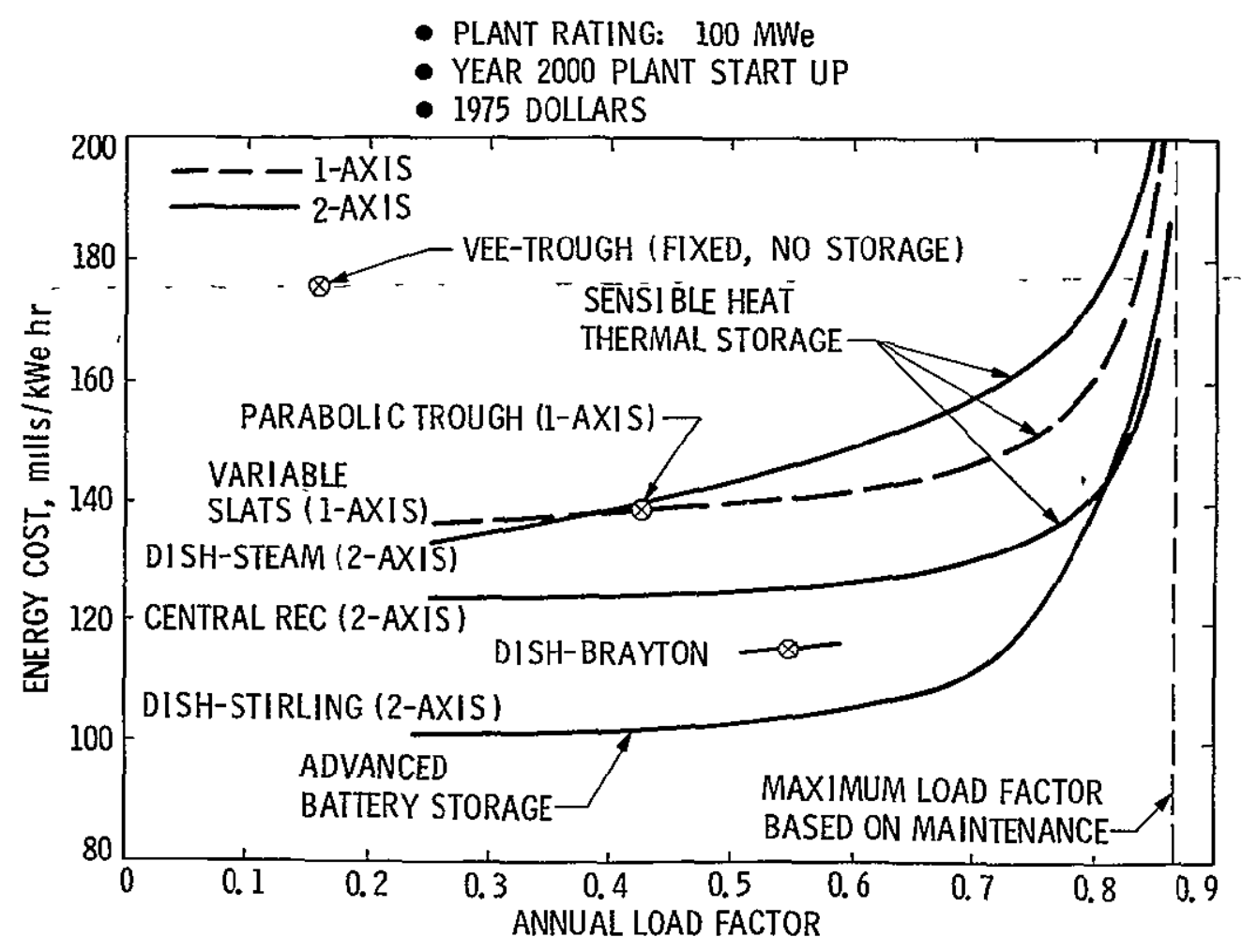

Figure 4-5. Solar Plant Energy Costs

- PLANT RATING: 100 MWe

- YEAR 2000 PLANT STARTUP
- 1975 DOLLARS

(YEAR 2000 STARTUP CAPITAL COSTS = 1221975 STARTUP CAPITAL COSTSI

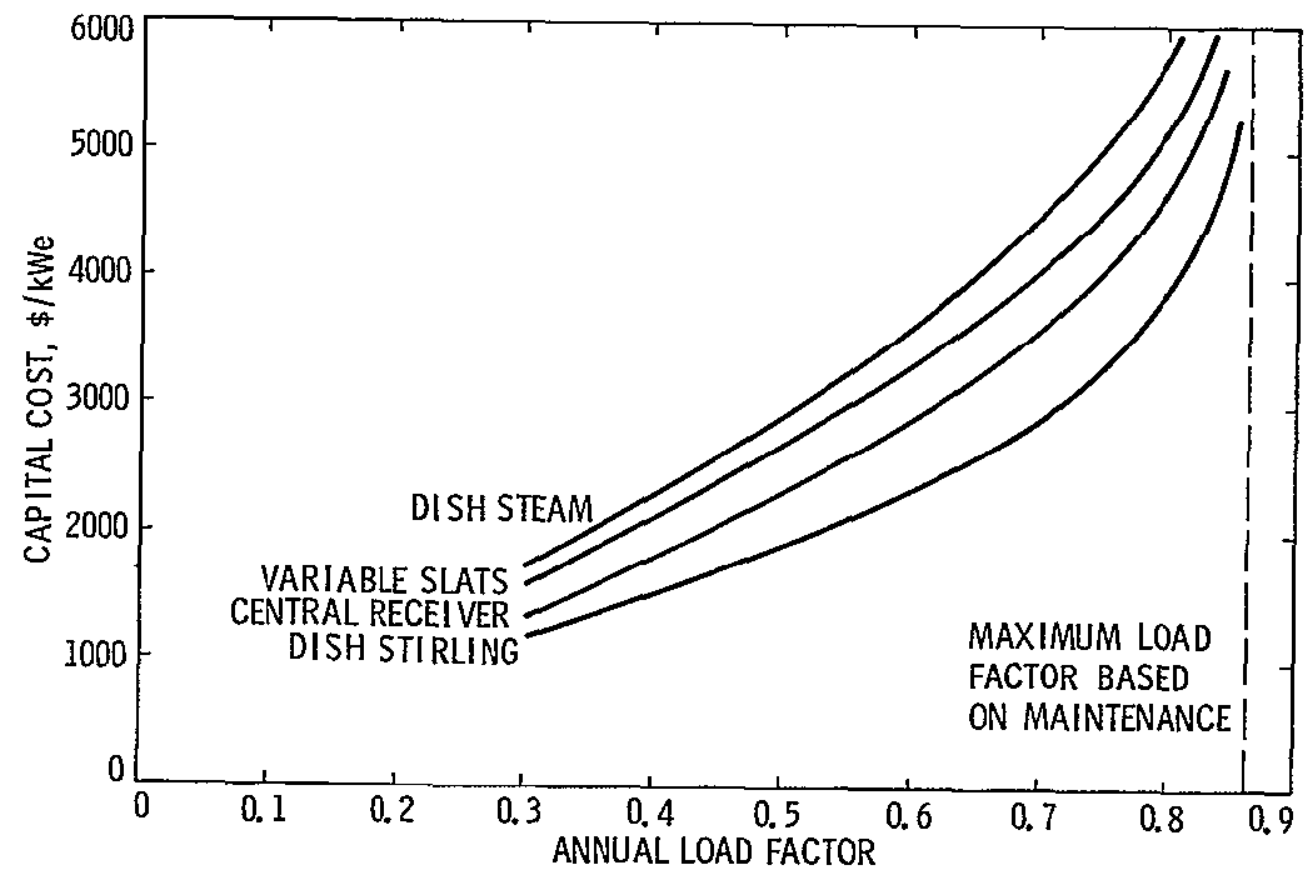

Figure 4-6. Solar Plant Capital Costs 
plant economics. Consideration of these possibilities is beyond the scope of the present study and it is emphasized that these limitations of the present effort should be recognized when Interpreting the results.

The baseline central receiver is between the dish-Stirling/Brayton systems and the dish-steam (Fig. 4-5), is based on conventional Rankine cycle technology, and is introduced here for reference purposes only. Since the dish-steam system based on comparable technology to the central receiver is projected to have a higher cost, and the dish-Stirling/Brayton systems based on higher temperature technology are projected to have lower energy costs, it appears that the central receiver (for the $100 \mathrm{MWe}$ size) is the best candidate when conventional Rankine conversion systems are-used. It is also noted that second and third generation central receiver systems will exhibit even higher performance than the baseline system.

The improved economics of the dish Stirling/Brayton systems indicate that advanced technology systems may be better than the reference baseline central receiver. Advanced technology/higher temperature central recelver systems are not considered in this study. It is therefore emphasized that Fig. 4-5 should not be interpreted to mean that dish-electric systems have higher performance capabilities than all central receiver systems. This comparison can only be made after an in-depth study of the advanced technology possibilities associated with each of the basic systems. These issues could not be addressed within the scope of this study.

The capital cost comparison of Fig. 4-6 shows that the dishStirling system has the lowest costs. Although unlt collector costs for two-axis tracking dish-electric systems are high (Table 3-2), these systems optically collect a higher percentage of incldent energy and are coupled to highly efficient cavity receivers and heat engines. This high overall system efficiency allows the use of a smaller collector field for a given output and these savings more than offset the highex unit collector cost.

The capital cost of the reference baseline central receiver is between the dish-Stırling and the varıable slat/dish-steam systems. Thus, capital and energy costs exhibit the.same relative rankings. The capital cost differences between systems is seen to be large; e.g., at a load factor of 0.5 the capital cost of the dish-steam system is more than $50 \%$ greater than the dish-Stirling. This indicates that substantial gains will result from technological advancement activities.

\section{SIZE EFFECTS}

The comparative economics of Figs. 4-5 and 4-6 involved a 100 MWe plant, which is representative of central power applications. Solar plants are being considered for a wide spectrum of applications involving a range of plant sizes. Thus, the variation of plant economics with size is an important consideration in planning a balanced R\&D program to meet application system requirements. 
Size trends for the selected systems are compared on Fig. 4-7. The dish-Stirling/Brayton systems are seen to be relatively insensitive to size. This follows because the arrangement is inherently modular with a single dish-receiver-engine/generator serving as the basic power unit which delivers only $\approx 25 \mathrm{kWe}$ at peak power rating. The slight increase in energy costs whth decreasing size shown on Fig. 4-7 is essentially due to the fact that indirect costs constitute a larger fraction of plant costs when sizes are small.

A11 of the other distributed-collector systems are based on conventional central Rankine cycle energy conversion plants. For these systems, costs increase with decreasing size, shown on Fig. 4-7. For steam Rankine systems, most of the development emphasis has been directed toward large size units for central power applications and, therefore. the performance of present smaller size Rankine systems will be higher if implemented for solar application in the 1990-2000 time frame. This technology development is accounted for in Fig. 4-7; e.g., although present prototype $100 \mathrm{kWe}$ Rankine engines have efficiencies of $\sim 20 \%$, it was projected that engines of $227 \%$ would be available.

The reference central receiver system is shown to have an even steeper rise in energy costs as plant size decreases. In addition to

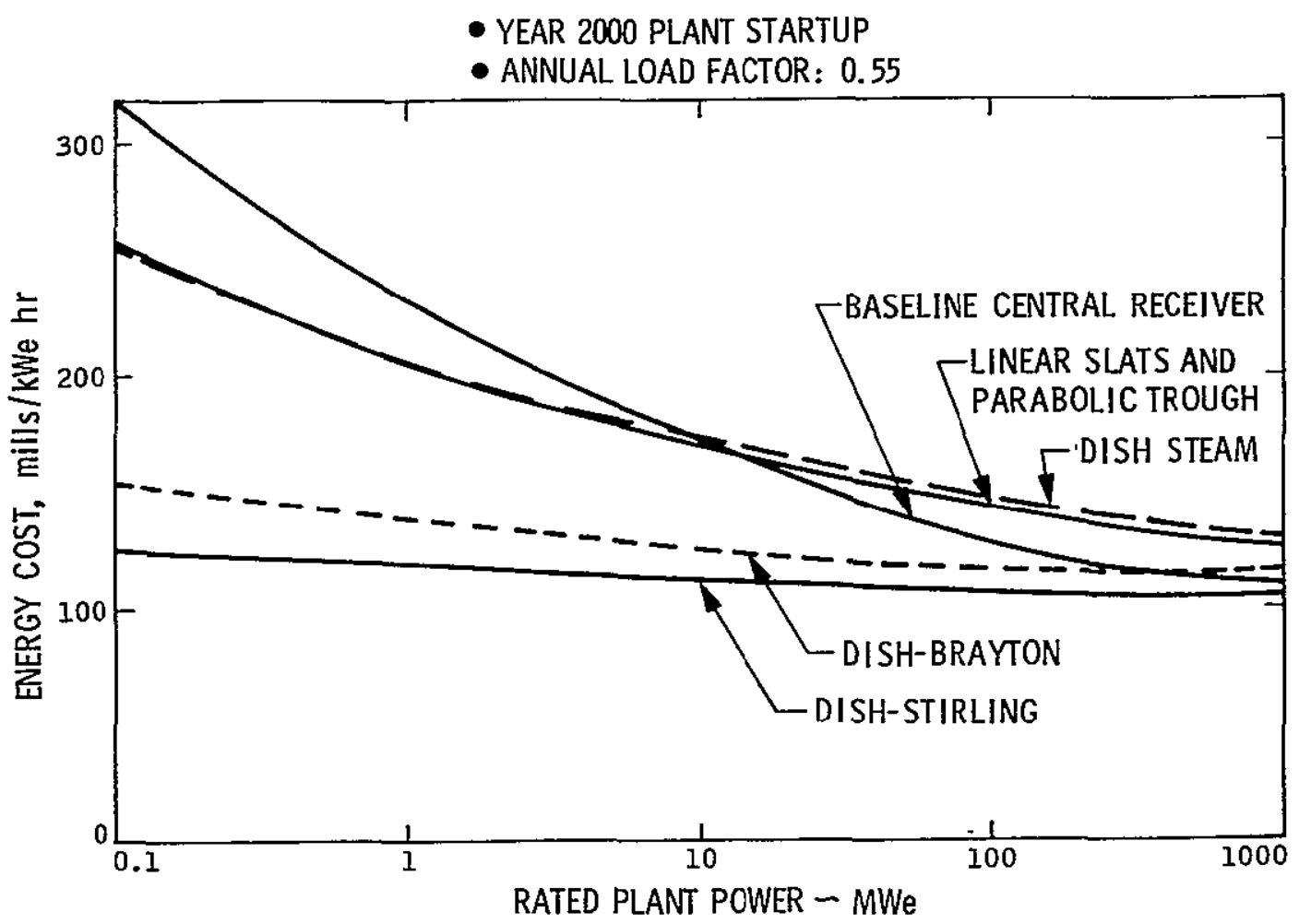

Figure 4-7. Effect of Plant Size 
higher Rankine engine costs, the heliostat field of the central recelver becomes more costly due to the need for smaller mirror facets and/or curving of the mirror surfaces. Thus, it appears that the dish-electric system is superior to all systems based on conventional Rankine technology for small power applications.

It is noted that an advanced small power central receiver system could be constructed with a tower-mounted Stirling or Brayton engine. This system would probably have lower energy costs than the small central receiver-Rankıne system of Fig. 4-7. Although an analysis of this possubility was not within the scope of this study, it should be kept in mind when interpreting results of this study.

Breakdowns of capital and energy costs are presented on Tables 4- 1 and 4-2, respectively, for four 100 MWe plants including dishStirling, dish-steam, variable slats, and the reference baseline central receiver. Similar breakdowns are given in Tables 4-3 and 4-4 for a 10 MWe size. A comparison of the total capital and energy costs for the systems conform with the size trends depicted on Fig. 4-7; e.g., at $10 \mathrm{MWe}$, all the systems, including the reference central receiver, have about the same energy cost except for the dish-Stirling which has lower costs.

The cost breakdown among subsystems shows that collectors (concentrators and receivers) dominate costs; e.g., from Table 4 - I it is seen that for the $100 \mathrm{MWe}$ dish-Stirling system, the collector subsystem cost of $\$ 139$ million comprises $64 \%$ of the total capital cost of $\$ 217$ million. In fact, for all the $100 \mathrm{MWe}$ and $10 \mathrm{MWe}$ systems, collectors constitute more than half of the total capital cost. The percent of energy cost contribution is slightly less (Tables 4-2 and 4-4) since energy costs include the effect of Operation and Maintenance (O\&M). However, the collectors still comprise $>45 \%$ of the energy cost for all the $10 \mathrm{MWe}$ and $100 \mathrm{MWe}^{-}$systems.

In terms of energy cost contribution, other capital and $0 \& M$ costs are comparable and are second only to collector costs (see Tables 4-2 and 4-4). Other capital includes charges for spares and contin. gencies, indirect costs, and construction interest (see Ref. 6). The O\&M contribution is the levelized energy cost due to O\&M costs which escalate during the life of the plant. The O\&M costs for the first year of commercial operation are shown in Tables 4-1 and 4-3 for the 100 MWe and 10 MWe plants, respectively.

Although subsystems of transport, conversion, and storage have relatively small contributions to capital and energy costs, it is emphasized that their efficiencies have a direct influence on the size and cost of the collector field. For example, unit parabolic dish concentrator costs (which comprise the bulk of the collector field cost) for the dish-Stirling and dish-steam systems are taken to be identical. However, as shown on Table 4-3, the collectors for a 10 MWe dish-Stirling plant cost $\$ 14$ million as compared to $\$ 21$ million for the dish-steam. This difference of $\$ 7$ million is primarily due to the high conversion efficiency of the dish-Stirling system (Table 3-1) 
Table 4-1. Capital Cost Breakdown, 100 MWe Plant

- anNual load factor $=0.55$ - year 2000 Start up $(1)$

- 1975 DOLLARS

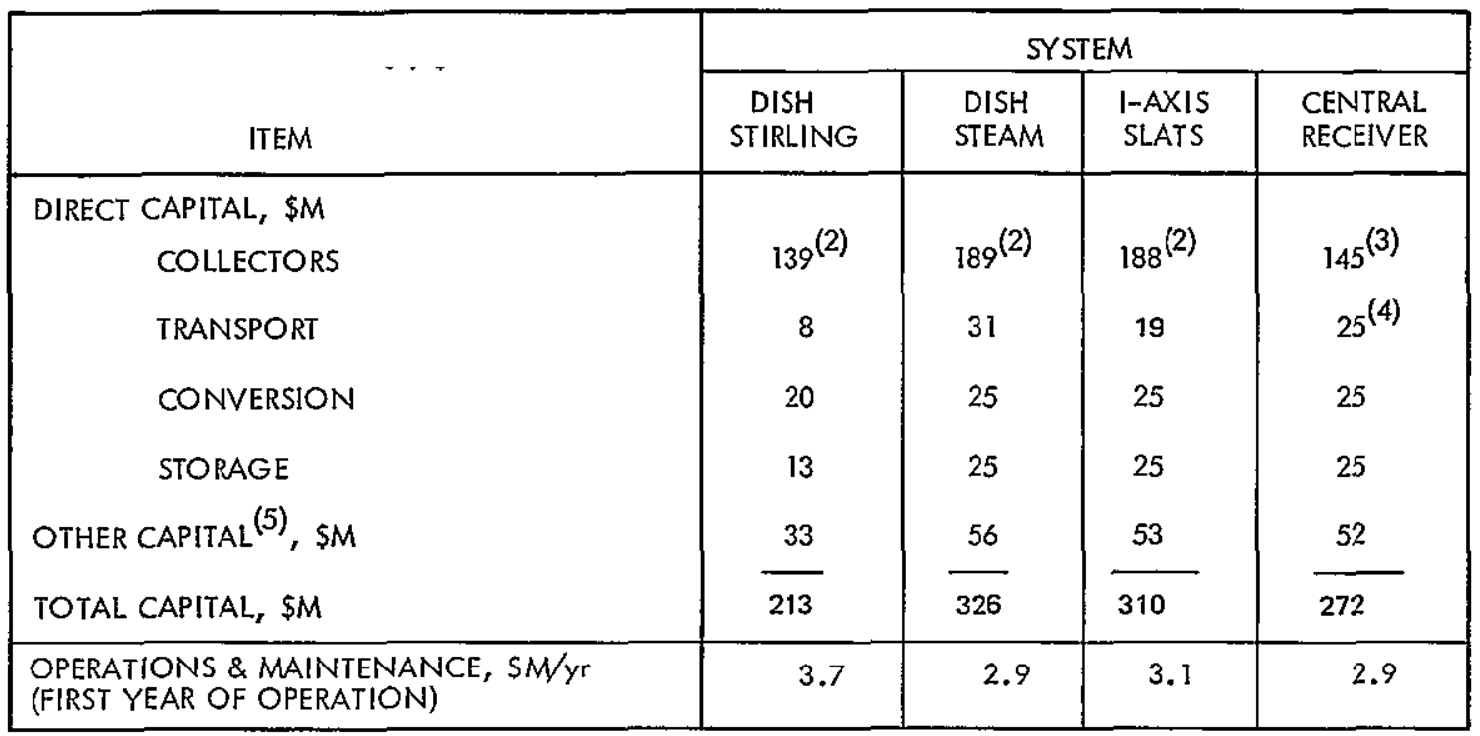

(1) YEAR 2000 START UP CAPITAL COST $=1.22 \times(1975$ START UP COST $)$

(2) INCLUDES RECEIVER

(3) HELIOSTATS ONLY

(4) INCLUDES TOWER, RECEIVER AND TRANSPORT

(5) INDIRECT, SPARES \& CONTINGENCY AND CONSTRUCTION INTEREST

Table 4-2. Energy Cost Breakdown, 100 MWe Plant

- - ANNUAL LOAD FACTOR $=0.55$

- year 2000 startup

- 1975 dollars

\begin{tabular}{|c|c|c|c|c|}
\hline \multirow{2}{*}{\multicolumn{1}{c|}{ ITEM }} & \multicolumn{4}{|c|}{ SYSTEM, - mills/kWe hr } \\
\cline { 2 - 5 } & $\begin{array}{c}\text { DISH } \\
\text { ELECTRIC }\end{array}$ & $\begin{array}{c}\text { DISH } \\
\text { STEAM }\end{array}$ & $\begin{array}{c}\text { I-AXIS } \\
\text { SLATS }\end{array}$ & $\begin{array}{c}\text { CENTRAL } \\
\text { RECEIVER }\end{array}$ \\
\hline DIRECT CAPITAL & & & & \\
COLLECTORS & 55.5 & 76 & 76 & 59 \\
TRANSPORT & 3 & 12 & 7.5 & 10 \\
CONVERSION & 9 & 10 & 10 & 10 \\
STORAGE & 5 & 10 & 10 & 10 \\
OTHER CAPITAL & 13.5 & 23 & 22.5 & 22 \\
O\&M & 20.5 & 16 & 17 & 16 \\
\hline TOTAL & 106.5 & 147 & 143 & 127 \\
\hline
\end{tabular}


Table 4-3. Capital Cost Breakdown, 10 MWe Plant

- anNual load factor $=0.55$ - year 2000 Startup $^{(1)}$

- 1975 dollars

\begin{tabular}{|c|c|c|c|c|}
\hline \multirow[b]{2}{*}{ ITEM } & \multicolumn{4}{|c|}{ SYSTEM } \\
\hline & $\begin{array}{c}\text { DISH } \\
\text { STIRLING }\end{array}$ & $\begin{array}{l}\text { DISH } \\
\text { STEAM }\end{array}$ & $\begin{array}{l}\text { 1-AXIS } \\
\text { SLATS }\end{array}$ & $\begin{array}{l}\text { CENTRAL } \\
\text { RECEIVER }\end{array}$ \\
\hline DIRECT CAPITAL,$\$ M$ & & & & \\
\hline COLLECTORS & $14.0^{(2)}$ & $21.0^{(2)}$ & $20.5^{(2)}$ & $20.0^{(3)}$ \\
\hline TRANSPORT & 0.5 & 3.0 & 1.5 & $3.0^{(4)}$ \\
\hline CONVERSION & 2.0 & 3.5 & 3.5 & 3.5 \\
\hline STORAGE & 1.0 & 2.5 & 2.5 & 2.5 \\
\hline OTHER CAPITAL ${ }^{(5)}, \$ M$ & 5.5 & 9.0 & 9.0 & 9.5 \\
\hline TOTAL CAPITAL, $\$ M$ & 23.0 & 39.0 & 37.0 & 38.5 \\
\hline $\begin{array}{l}\text { OPERATIONS \& MAINTENANCE, } \$ M / y r \\
\text { (FIRST YEAR OF OPERATION) }\end{array}$ & 0.37 & 0.32 & 0.34 & 0.32 \\
\hline
\end{tabular}

(1) YEAR 2000 STARTUP CAPITAL COST $=1.22 \times(1975$ STARTUP COST $)$

(2) INCLUDES RECEIVER

(3) HELIOSTATS ONLY

(4) INCLUDES TOWER, RECEIVER AND TRANSPORT

(5) INDIRECT, SPARES \& CONTINGENCY AND CONSTRUCTION INTEREST

Table 4-4. Energy Cost Breakdown, 10 MWe Plant

- ANNUAL LOAD FACTOR $=0.55$

- year 2000 startup

- 1975 DOLLARS

\begin{tabular}{|c|c|c|c|c|}
\hline \multirow[b]{2}{*}{ ITEM } & \multicolumn{4}{|c|}{ ENERGY COST, $\sim$ mills $/ \mathrm{kWe}$ hr } \\
\hline & $\begin{array}{c}\text { DISH } \\
\text { ELECTRIC }\end{array}$ & $\begin{array}{c}\text { DISH } \\
\text { STEAM }\end{array}$ & $\begin{array}{l}\text { I-AXIS } \\
\text { SLATS }\end{array}$ & $\begin{array}{l}\text { CENTRAL } \\
\text { RECEIVER }\end{array}$ \\
\hline \multicolumn{5}{|l|}{ DIRECT CAPITAL } \\
\hline COLLECTORS & 55.5 & 84 & 84 & 80.5 \\
\hline TRANSPORT & 2 & 11 & 7 & 31.5 \\
\hline CONVERSION & 9 & 14 & 14 & 13.5 \\
\hline STORAGE & 5 & 10 & 10 & 10 \\
\hline OTHER CAPITAL & 21 & 37.5 & 38 & 39.5 \\
\hline O\&M & 20.5 & 17.5 & 17 & 17 \\
\hline TOTAL & 113 & 174 & 170 & 172 \\
\hline
\end{tabular}


which results in a smaller collector field. This shows the importance of technology advances to improve the efficiencies of these subsystems.

\section{SYSTEM SENSITIVITIES}

The data base as given in. Tables 3-1 and 3=2, reflects nomina-1 values of projected efficiencies and costs. There are considerable uncertainties âssociated with many of these projections, particularly for those subsystems/components that are in early developmental stages. The effect of uncertainties in each subsystem is treated in the next section. In this section, the combined effect of the uncertainties on comparative system economics is examined.

In Fig. 4-8, the uncertainty ranges of the selected systems are compared for a plant rating of 100 MWe and a load factor of 0.55 . The low energy cost bound corresponds to all subsystems simultaneously achieving lowest projected costs and highest efficiencies, while the high bound results when highest projected costs and lowest efficiencies. occur. Neither of these extreme bounds is likely. but it is felt that the spectrum of possibllities is contained within these bounds.

As seen from Fig. 4-8, considerable overlapping occurs in the ranges. The dish-Stirling system, which has the lowest nominal energy

- PLANT RATING 100 MWe

- LOAD FACTOR: 0.55



Figure 4-8. System Sensitıvity Comparison 
cost, has the largest uncertainty range. It has high promise in terms of employing advanced technology. but if the technology development is not successful, it could be a poorer candidate than other systems. The nominal values for the one-axis tracking variable slat and two-axis tracking dish-steam systems are essentially identical but the dishsteam has a greater uncertainty range since the dish-collector is in an earlier stage of development.

The reference baseline central receiver also has a cost uncertainty range of the same order as the distributed systems due mainly to uncertainties in heliostat costs. Since the fixed collector Vee-trough system is not deemed to be attractive for electric power generation, a detailed sensitivity study for this system has not been conducted. However, it is noted that the nominal cost estimate for the Vee-trough system of $\approx 175 \mathrm{mills} / \mathrm{kWe}$ hr is within the uncertainty range of the other systems shown on Fig. 4-8. Thus, it is possible but not very likely that the Vee-trough or fixed systems could be competitive with tracking systems. As noted previously, projections for the Vee-trough system are considered to be optimistic.

The effect of system uncertainty ranges are shown over a range of power plant sizes on Figs. 4-9 and 4-10. The dish-electric Stirling system representing the lowest nominal cost distributed system is compared with the reference central receiver system on Fig. 4-9. There is a wide region of overlap with the central receiver having less uncertainty for large central power applications ( $>100 \mathrm{MWe}$ ). Even for small power levels there is considerable overlap, but the inherent modularity of the dish-electric system would give this system an advantage if projected technology development could be successfully accomplished.

On Fig. 4-10, the one-axis tracking variable slat system is compared with the two-axis tracking dish-electric Stirling system. These systems also exhibit considerable overlap with the variable slat system having lesser uncertainty for large central power applications. The variable slat system is based on using conventional centrally located steam Rankine conversion systems and scale effects associated with this conversion system tend to place the variable slat system at a disadvantage relative to the highly modular dishelectric Sirling system for small power applications. However, the overlap region Is large even for small sızes. The two-axis tracking dish-steam system has a projected nominal performance curve that Is essentially the same as the variable slat system curve shown on FIg. 4-10. However, it has a wider range of uncertainty (see Fig. 4-8) that persists over the entire size range.

Based on the system sensitivities to uncertainties in the data base, it is clear from Figs. $4-9$ and 4-10 that no defunitive conclusion can be drawn with regard to selecting a "best" system. Instead, it would appear that all of the systems should be pursued to reduce the level of uncertainty, while placing primary R\&D funding emphasis on candidates which appear to offer the greatest future promise. 
- year 2000 plant startup

- ANNUAL LOAD FACTOR: 0.55

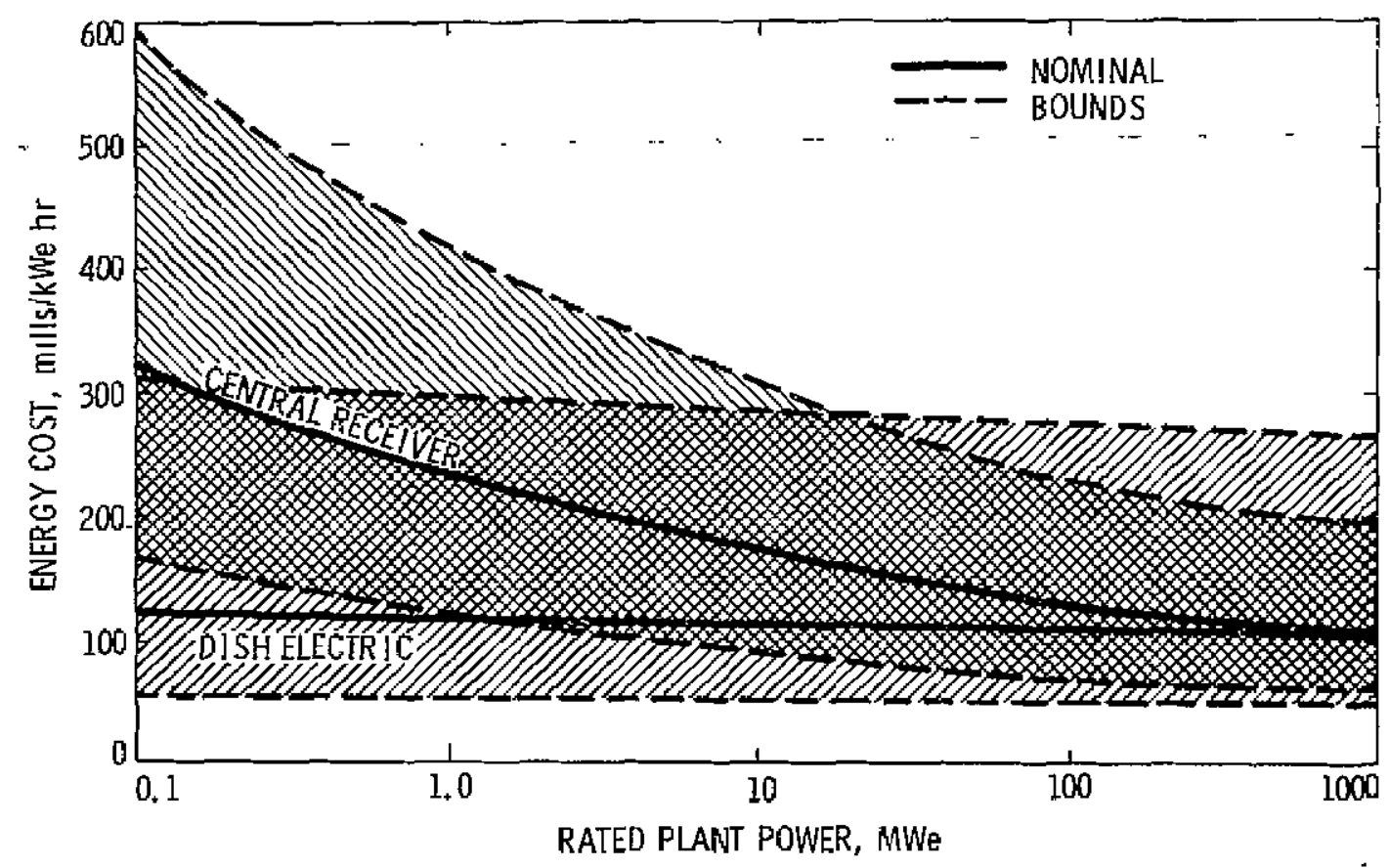

Figure 4-9. System Serlsitivitues: Central Receiver and Distributed Two-Axis Systems

- year 2000 PLANT STARTUP

- anNual lOAD factor: 0.55

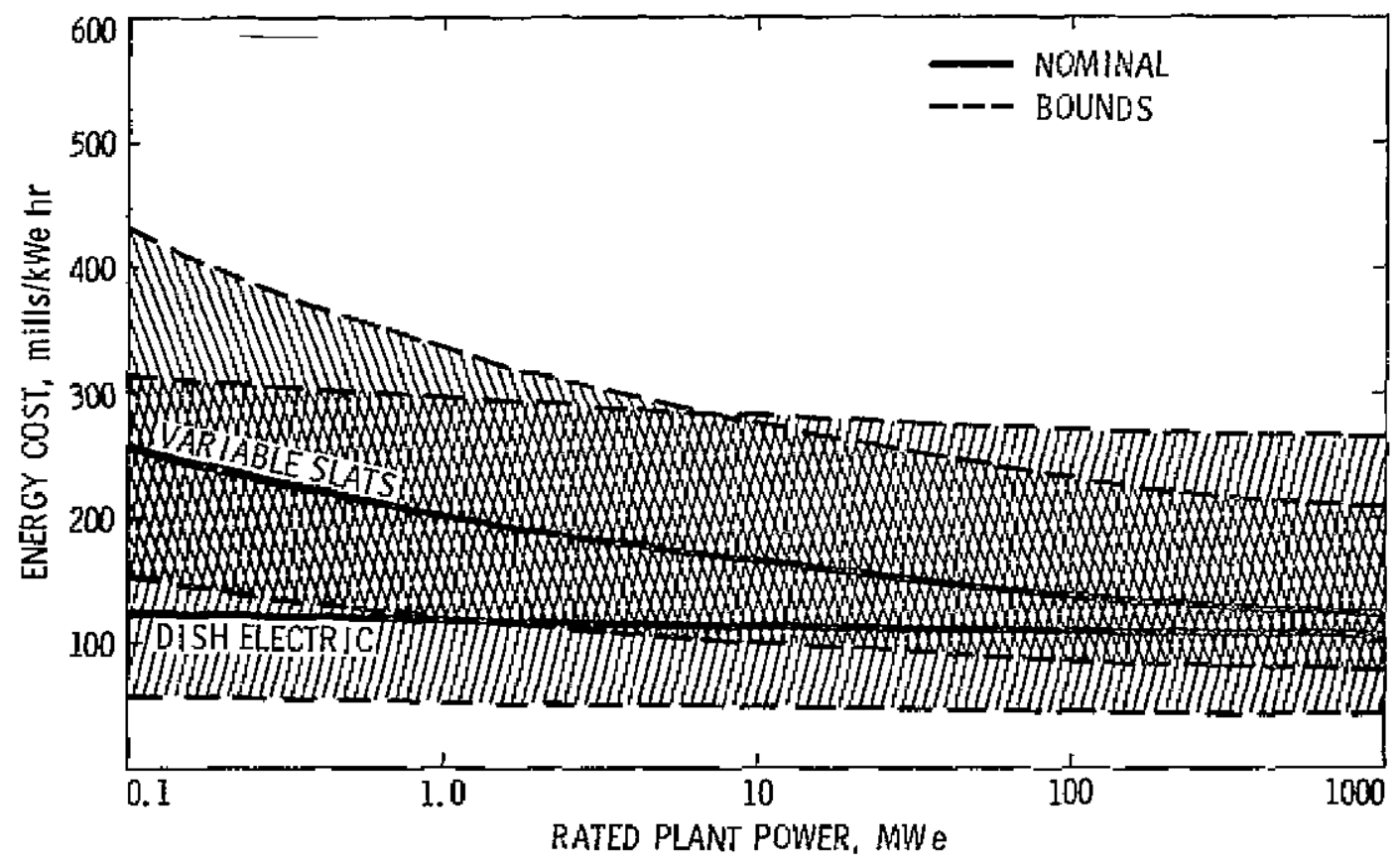

Figure 4-1.0. System Sensitivities: One-Axus and Two-Axis Distributed Systems 


\section{E. SUBSYSTEM SENSTTIVITIES}

The upper and lower system sensitivities, shown in Figs. 4-9 and 4-10, are the combined effect of subsystem sensitivities presented in this section. Upper and lower bound performance and cost sensitivities have been determined for each subsystem. Addıtionally, upper and lower bounds are estimated for operation and maintenance (O\&M) costs. Each of the individual sensitivities are discussed below.

\section{Collector Subsystem}

Cost and efficiency sensitıvities are shown in Figs. 4-11 and 4-12, respectively. The greater uncertainty of the two-axis tracking dish systems relative to the one-axis tracking variable slat system is clearly evident. The range of estimated collector cost variations for the variable slat system is $131 \$ / \mathrm{m}^{2}$ to $218 \$ / \mathrm{m}^{2}$ as compared to 12. $\$ / \mathrm{m}^{2}$ to $279 \$ / \mathrm{m}^{2}$ for the dish-electric system. The efficiency ranges are $52 \%$ to $60 \%$ and $60 \%$ to $85 \%$ for the variable slat (Iinear cavity receiver) and the dish-electric (point cavity receiver) systems. respectively.

\section{Energy Conversion Subsystem}

Sensitivities to cost and efficiency uncertainties are presented in Figs. 4-13 through 4-16 for both steam Rankine and Stirling engine systems. Additionally, sensitivity to Stirling engine life is shown on Fig. 4-I7.

For Rankine systems, the estimated cost range of $\pm 20 \%$ of nominal, as shown in Fig. 4-13, was inferred from Ref. 11. The cost uncertainty of the dish-electric conversion system was mainly due to the Stirling engine as indicated by the wide cost range shown on Fig. 4-14. The nominal efficiency levels for the Rankine system were based on intermediate term technology forecasts which were between the present and far term potential. For the results shown on Fig. 4-15, the upper uncertainty bound was estimated to be mid-way between the intermediate and far term potential; while the lower bound was mid-way between the present and intermediate term. The Stirling engine efficiency range is taken to be from $36 \%$ to $50 \%$ per Fig. 4-16, while engine life based on automotive engine developments is taken to be 2 to 10 years (Fig. 4-17). As shown by the dashed lines on Fig. 4-17, energy cost Increases rapıdly as engine life decreases below 2 years. Total replacement is assumed for initial estimating purposes. Some cost savings may be possible by overhauling engines as opposed to total replacement.

\section{Energy Storage Subsystem}

Cost and efficiency sensutivities for both sensible heat thermal storage and advanced batteries are presented on Figs. 4-18 and 4-19. The estimated cost ranges (Fig. 4-18) are from one-half to twice nominal for thermal storage, and two-thirds to twice nominal for advanced batteries. Since only a fraction of the collected energy is stored, the effect of storage efficiency is less important than for subsystems such as energy conversion. Estrmated efficiency ranges are shown on Fig. 4-19. 
- YEAR 2000 PLANT STARTUP

- anNUAL LOAD FACTOR: 0.55
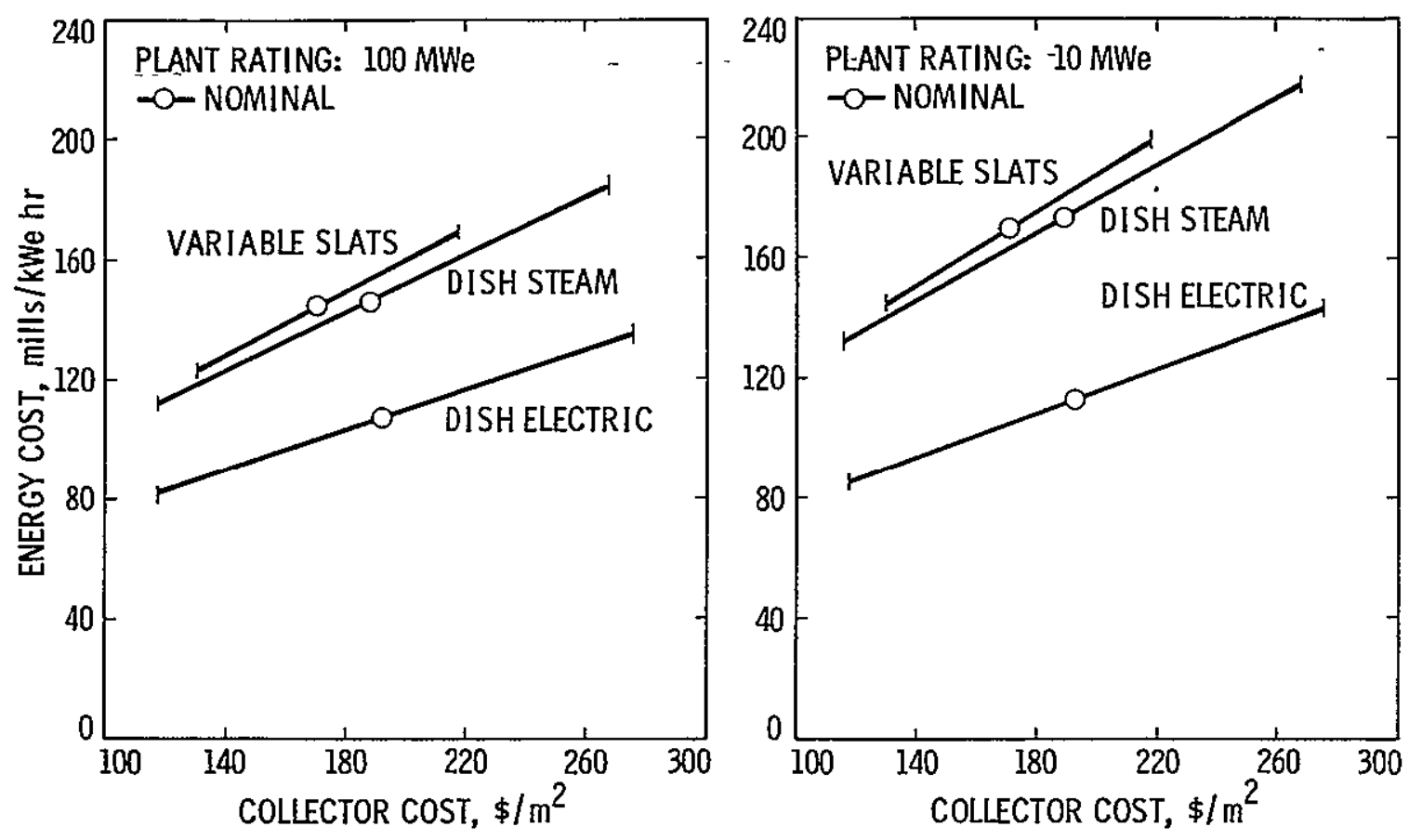

Figure 4-11. Sensitivity to Collector Cost

- YEAR 2000 PLANT STARTUP

- ANNUAL LOAD FACTOR: 0.55
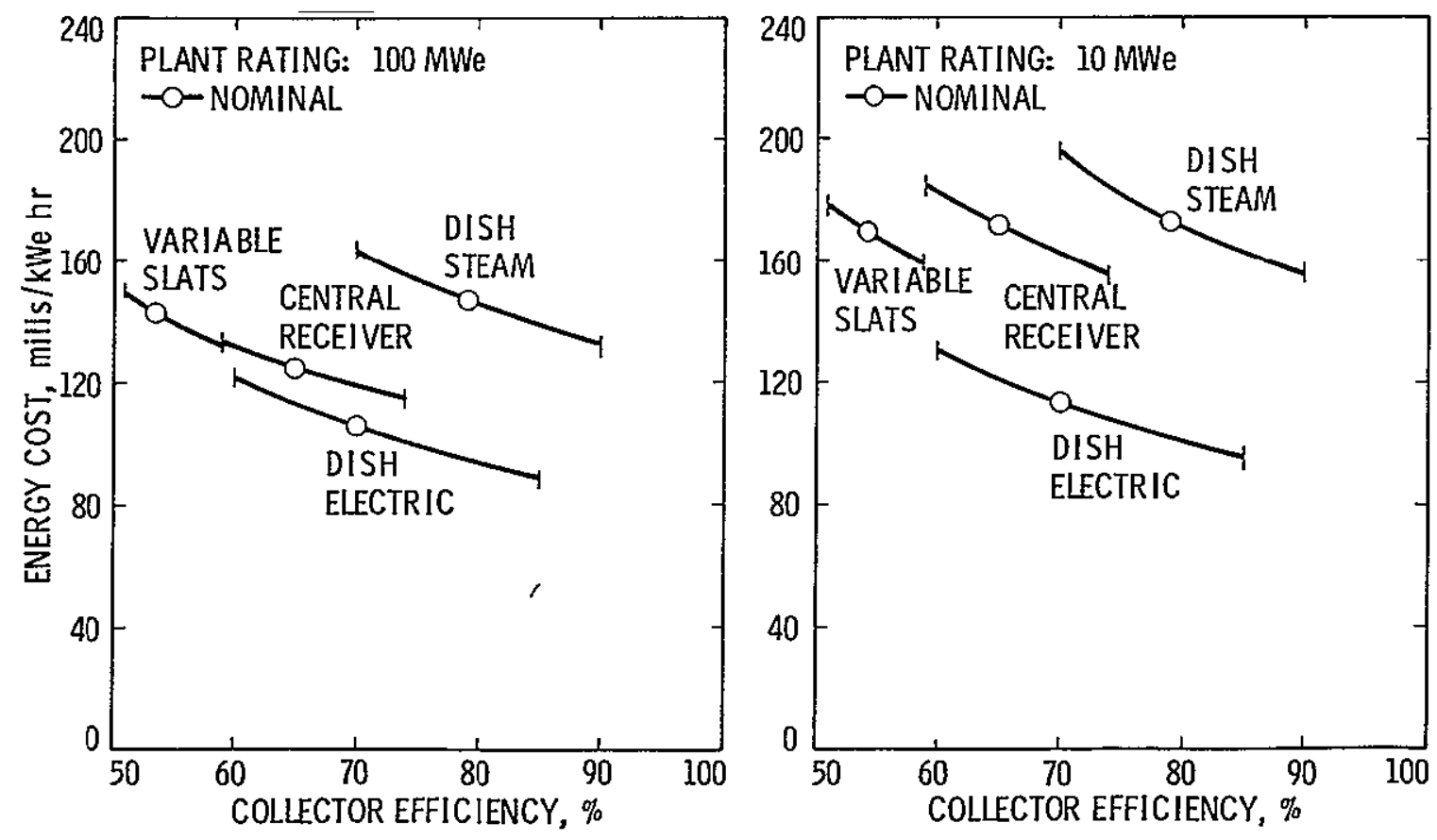

Figure 4-12. Sensitivity to Collector Efficlency 
- year 2000 PLANT STARTUP

- ANNUAL LOAD FACTOR: 0.55
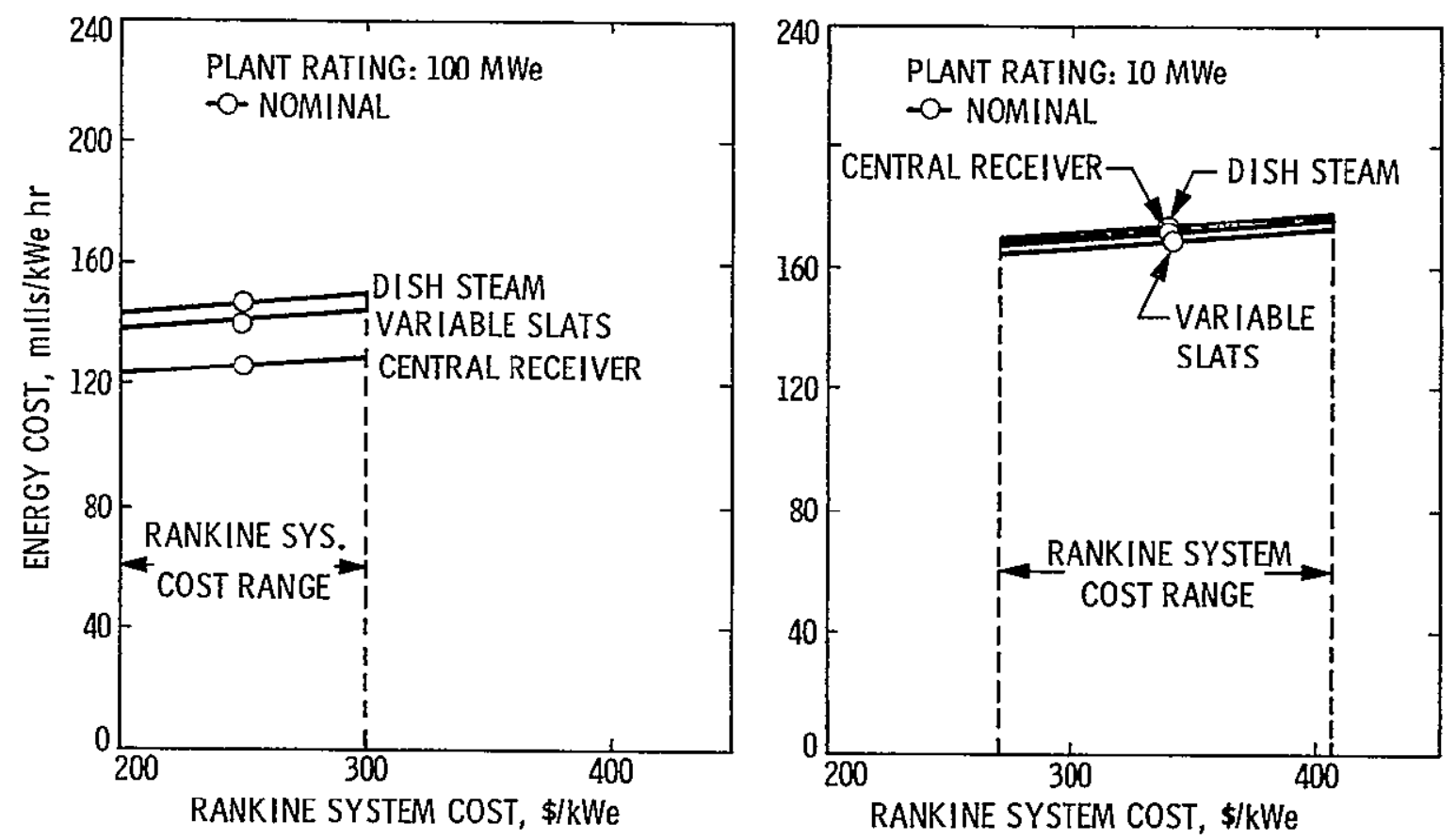

Figure 4-13. Sensitivity to Energy Conversion Cost:

Rankıne Cycle Systems

- yEAR 2000 PLANT STARTUP

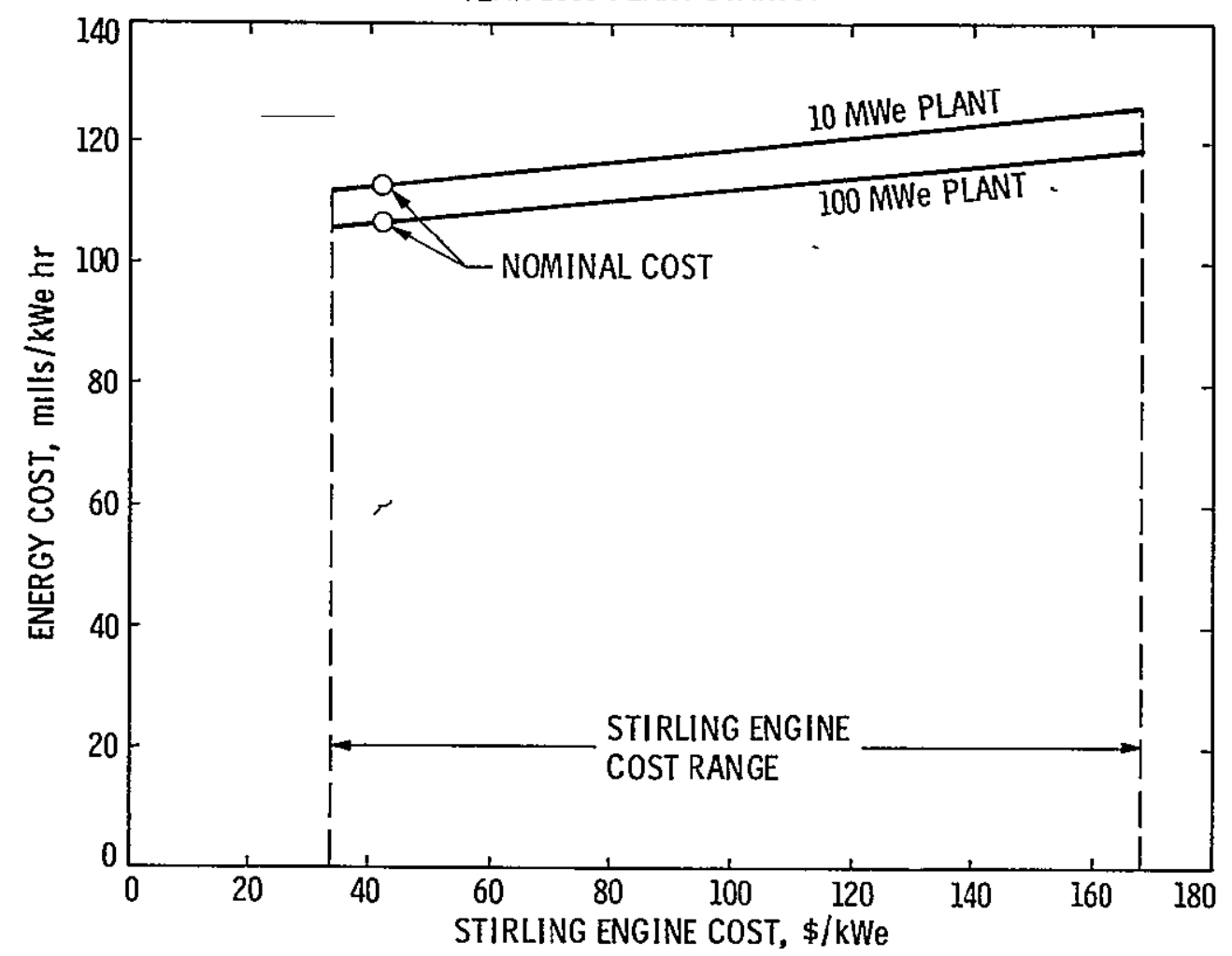

ORIGINAL PAGE IS

OF POOR QUALITY

Figure 4-1.4. Sensitivity to Energy Conversion Cost:

Parabolic Dish-Electric System 
- YEAR 2000 PLANT STARTUP

- ANNUAL LOAD FACTOR: 0.55
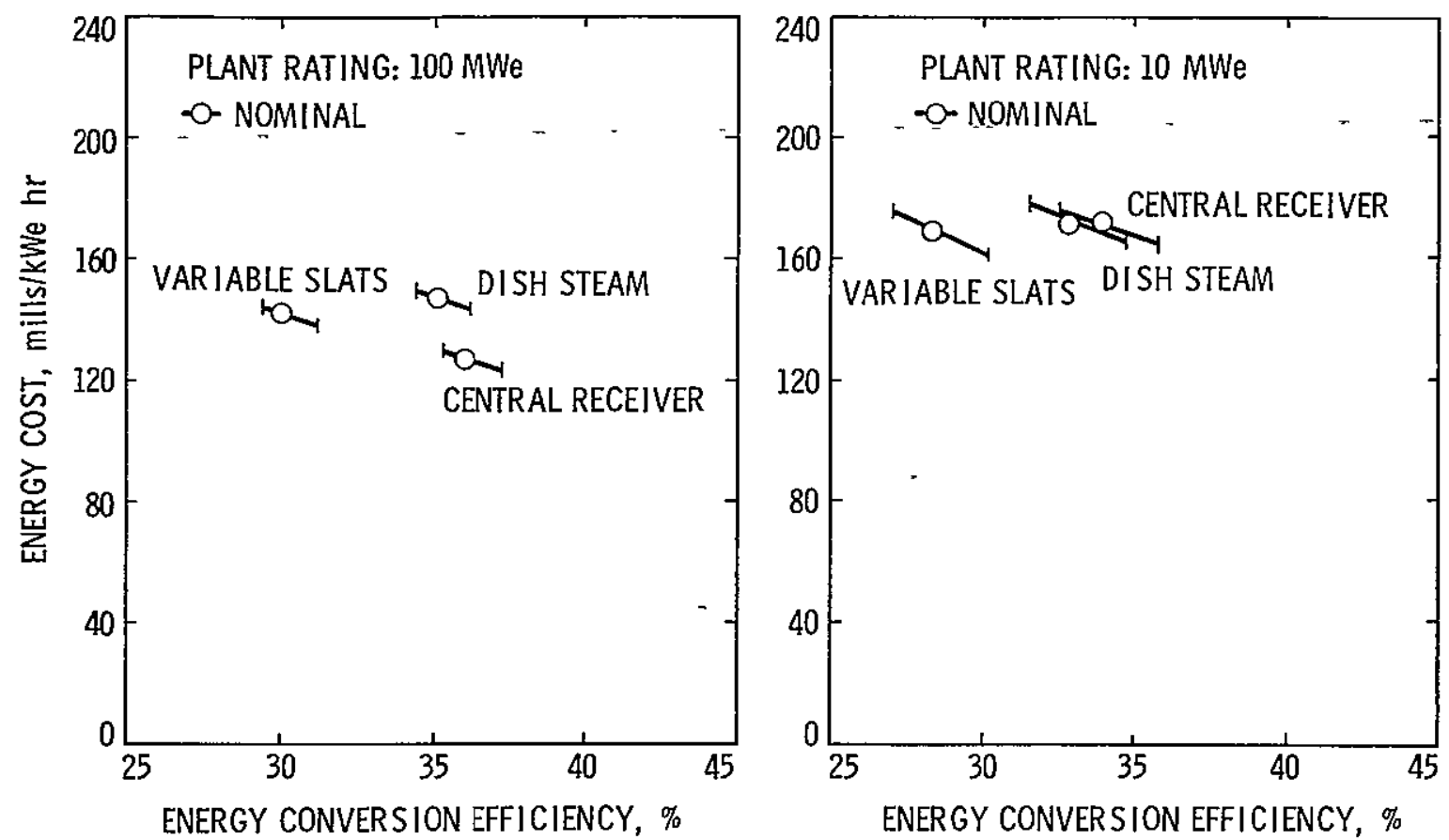

Figure 4-15. Sensitivity to Energy Conversion Efficiency: Rankine Cycle Systems

- YEAR 2000 PLANT STARTUP

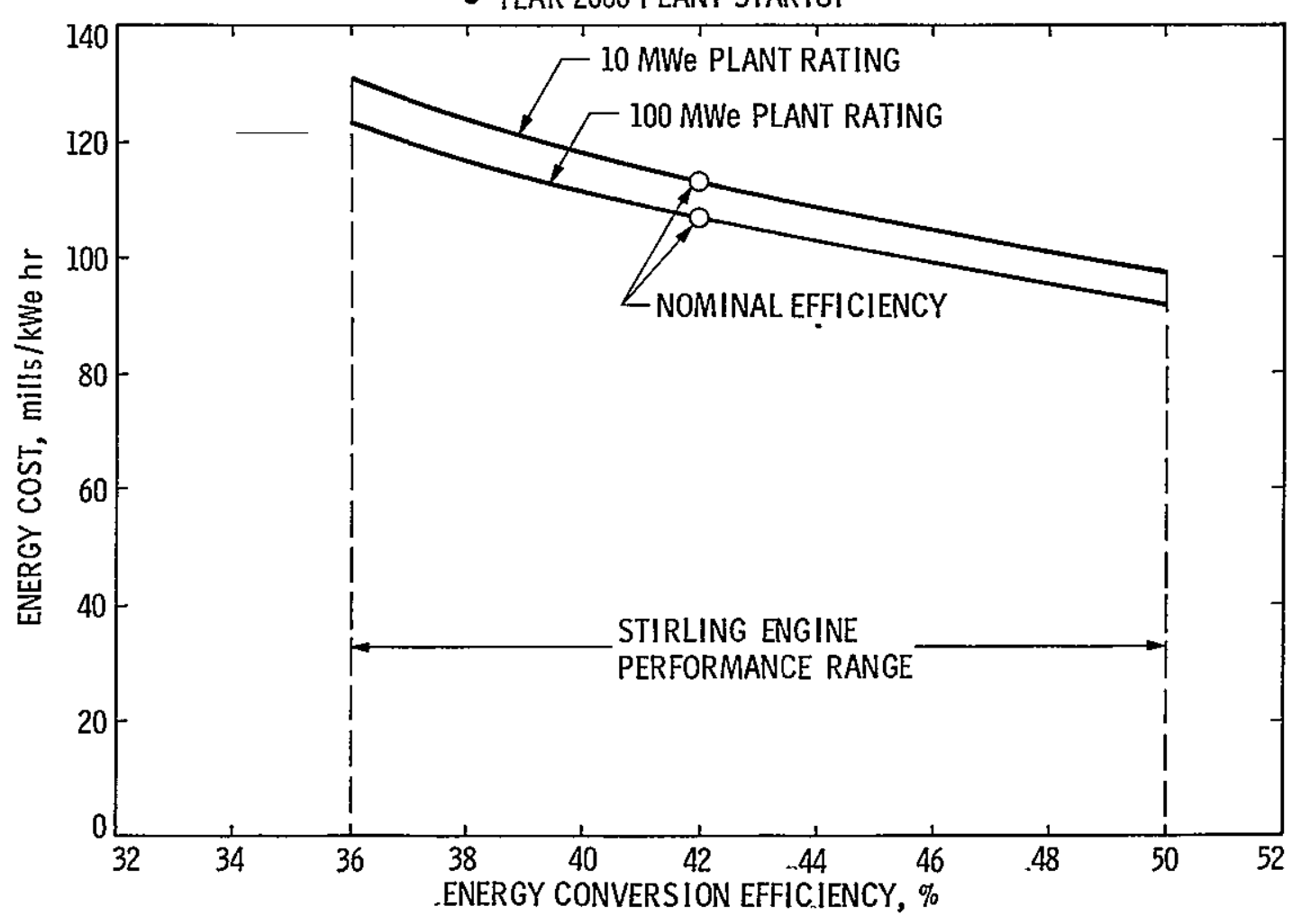

Figure 4-16. Sensitivity to Energy-Conversion Efficiency: Parabolic Dish-Electric System 


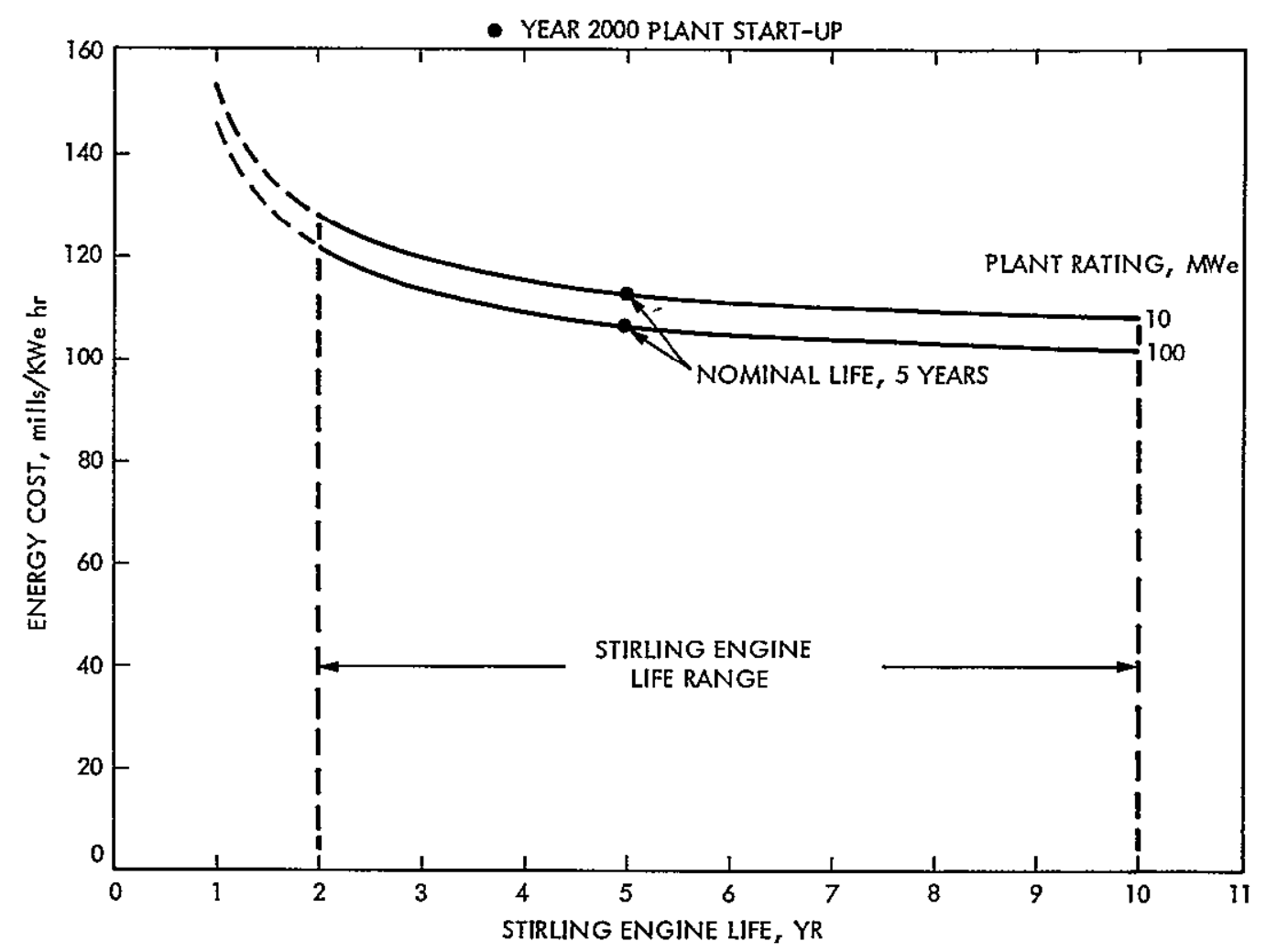

Figure 4-17. Sensitivity to Engine Life: Parabolic Dish-Electric System

- yeAR 2000 PLANT STARTUP

- ANNUAL LOAD FACTOR: 0.55


"NORMALIZED TO STORAGE OUTPUT OF $70 \mathrm{MWE}$

Figure 4-18. Sensitivity to Storage Cost 
- year 2000 PLANT STARTUP

- ANNUAL LOAD FACTOR: 0.55
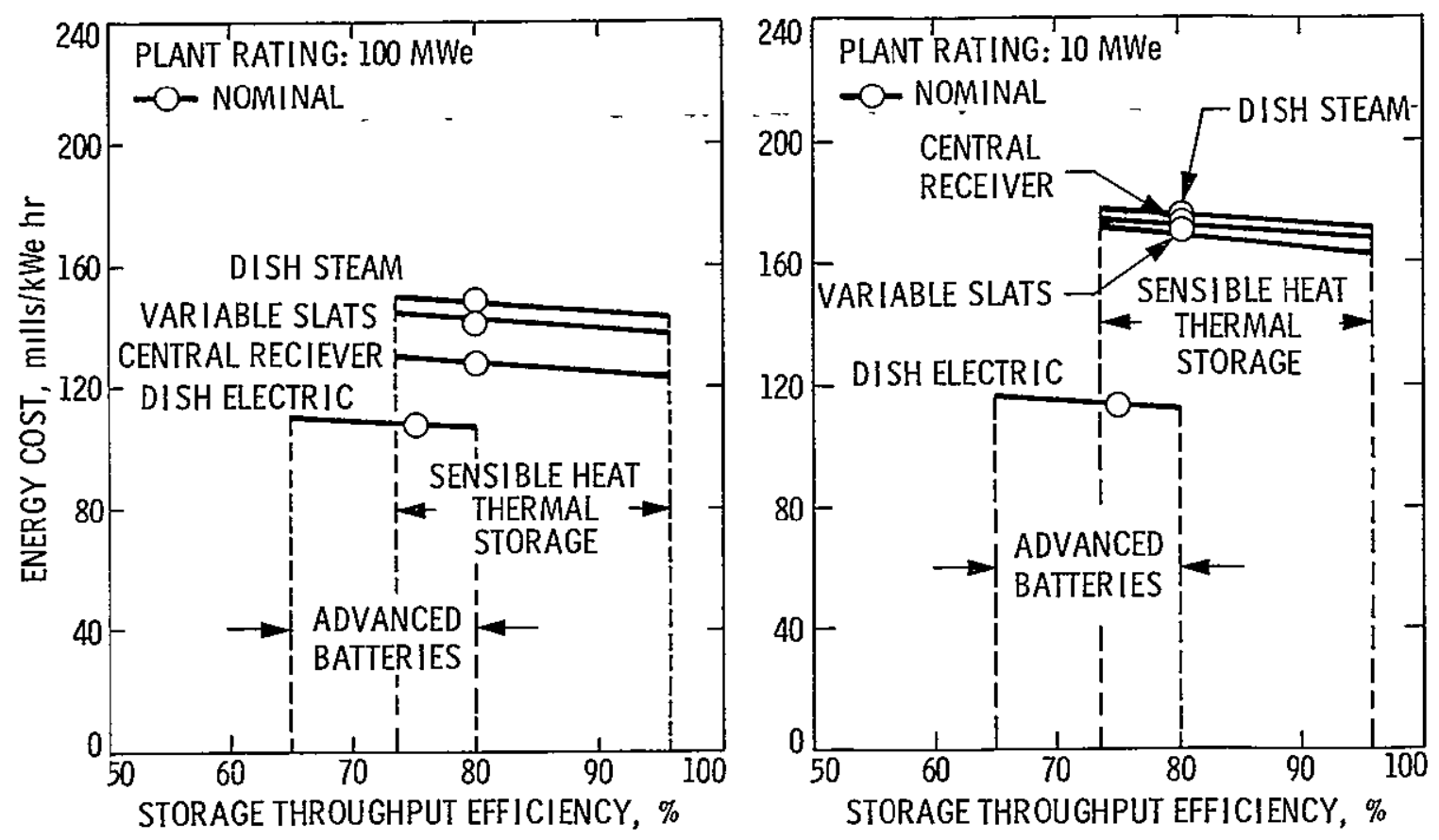

Fıgure 4-19. Sensitivity to Storage Throughput Efficiency

\section{Energy Transport Subsystem}

Sensitivities to both steam pipeline and electrical transport cost and efficiency uncertainties are depicted $1 n$ Figs. 4-20 and 4-21. For these systems, uncertainties do not arise as a result of technology projections, but relate to uncertaintıes in estimates based on very preliminary designs. The estimated cost range (Fig. 4-20) is from two-thirds to three-halves nominal. Transport efficiencies are governed primarily by design tradeoff considerations and the nominal. value is based on a preliminary optımization anlaysis (Ref. 24). Only small variations about this nominal are anticipated as reflected by the ranges shown on Fig. 4-21.

\section{Operation and Maintenance (O\&M) Costs}

Sensitivity to $0 \& M$ cost uncertainties is presented in Fig. 4-22. The estimates of $0 \& M$ costs are extremely uncertain and detall studies are needed. The nominal values used in this study correspond to the low bound determined in Ref. 27, since the low bound was interpreted to be appropriate for the type of activities associated with a large solar, power plant installation. A cost range involving a factor of five increase from the low bound to the high bound has been indicated in Ref. 27 , but by focusing on lower cost approaches it us believed that an appropriate uncertalnty range for systems considered in this study is from one-half to five-halves of nominal. 
- YEAR 2000 PLANT STARTUP

- ANNUAL LOAD FACTOR. 0.55
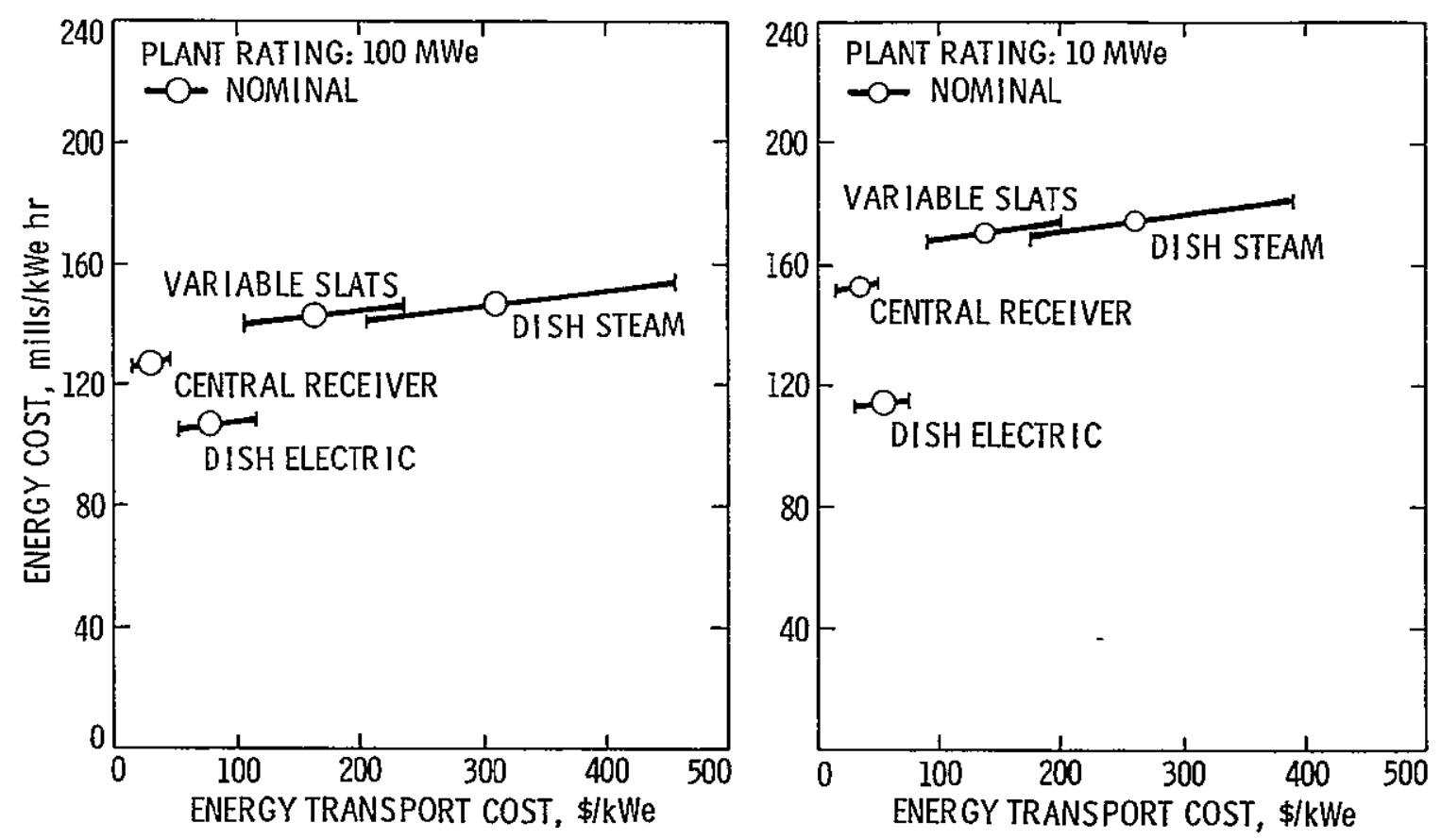

Figure 4-20. Sensitivity to Transport Cost

- year 2000 PLANT STARTUP

- anNual LOAD FActor 0.55
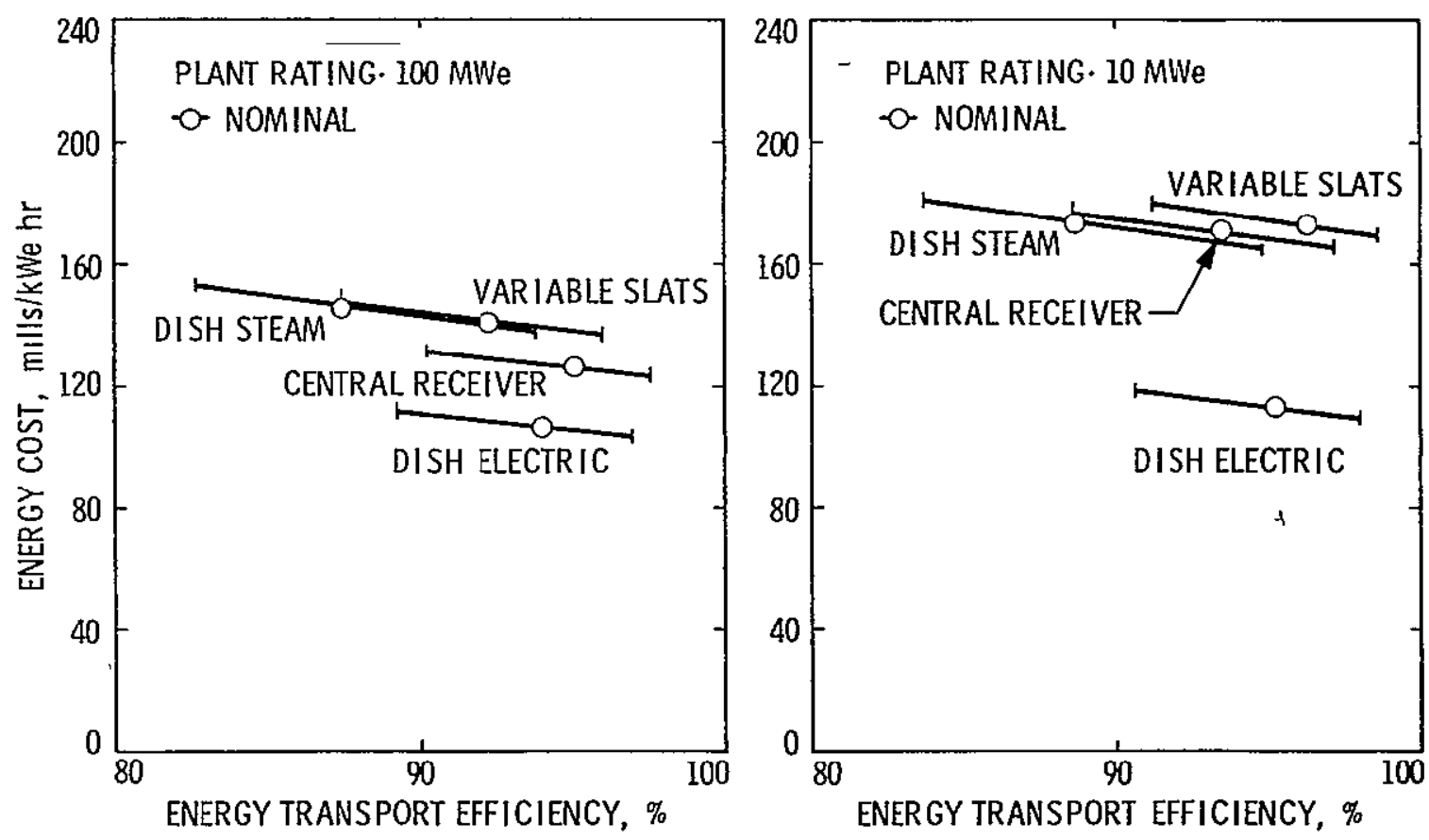

Figure 4-21. Sensitivity to Transport Efficiency 
- YEAR 2000 PLANT STARTUP

- ANNUAL LOAD FACTOR: 0.55


Figure 4-22. Sensıtivity to Operation and Maintenance Cost

Subsystem sensıtivity studies are useful in delineating domınant parameters that affect system performance and economics. As noted in an earlier preliminary parametric sensitivity study (Ref. 28). the cost of the collector field is a primary driver for all systems (see Fig. 4-11). Conversion system efficiency is also a major driver since achievement of high efficiencies will enable a reduction in the size and cost of the collector field for a given plant rating. The storage and transport subsystems can have a significant but not dominant effect.

The O\&M cost (Fig 4-22) has a sizeable Impact, and detailed studies should be conducted in parallel with subsystem/component development This is particularly needed sunce there is a direct tradeoff between capital costs and $0 \& M$; $i . e$. , a system designed for low maintenance will generally require higher capital costs. 
A major emphasis of this study was to compare distrubuted collector systems as a function of size or plant rating. In particular, a 100 MWe plant size representatıve of central station applications and a 10 MWe size corresponding to small power applications were investigated.

Conclusions pertaining to these two application categories are presented below:

- For Central Station Plant Size (100 MWe)

- Dish-Stirling/Brayton is projected as most attractive distrubuted solar system

$$
\text { - Others are } \simeq 40 \% \text { more expensıve }
$$

- Dish-steam and one-axis slats or parabolic trough systems are projected to have similar costs and are nearer term technologies than dish-Stirling

- Baseline central-recelver cost is projected to be between dish-Stirling/Brayton and other distributed solar approaches

- Advanced fixed systems are about $75 \%$ more even with optimistic cost estimates for collector

- The cost ranges of all five systems overlap.

- For Small Power Plants (10 MWe)

- Projected cost advantage of dish-Stırling/Brayton increases over other options

$$
\text { - Others } \simeq 55 \% \text { more expensive }
$$

- Dish-Stirling/Brayton costs are nearly constant over four orders of magnitude change in plant size

- Cost is within $\pm 10 \%$ as plant sıze goes from $100 \mathrm{kWe}$ to $1000 \mathrm{MWe}$

- Dish-steam and one-axis slats system costs "cross over" central receiver-steam system cost at 10 MWe

- Dish-Brayton costs are $\simeq 10 \%$ more than dish-Stirling over entire range of plant sizes. 
Broad general conclusions previously given are intended to provide guidance for preliminary planning of R\&D activities and are in concert with the scope and objectives of this study. Development of a detailed R\&D program plan must consider many factors beyond the scope of this study and is identified as a major element of future work. A basic consideration involves the weighing of potential gains from developing a particular technology against its projected R\&D.costs. A general procedure for analyzing this trade-off is presented in Appendix $B$ and is illustrated in terms of a preliminary comparison of the dish-Stirling system vis-a-vis the dish-Brayton.

Additionally, the study focused specifically on selected advanced distributed-collector concepts. Use of advanced central recelver concepts was not investigated and the present or first generation central receiver system was introduced in the study for reference purposes only. Since advanced versions of central recelver systems were excluded from the study, conclusions about the relative merits of distributed and central receiver systems cannot be drawn. Rather, the emphasis of the study is directed toward comparıng a selected number of distributedcollector concepts. 
SECTION VI

RECOMMENDATIONS

Based on the broad comparative analysis of distrubuted-collection solar thermal power plants as conducted in this study, the following recommendations are made:

- Pursue the technology for a point focusing dish combined with Stirling englne and electric transport as a most promising distributed solar electric plant.

- Pursue Brayton engine development as an impoxtant nearer term option and back-up to the Stirling englne until engine performance and cost uncertainties of both systems are reduced.

- Pursue dish-steam and one-axis slat/parabolıc trough as first generation systems and back-up to dish-electric systems until cost uncertainties are reduced and a more detailed comparatıve evaluation is performed.

- Do not pursue fixed orientation (non-tracking) solar systems for electric generation applications.

The rationale for the above recommendations is that a balanced $R \& D$ program should be undertaken. The effort should be directed toward ultimately achieving the performance of the most promising candidate whlle minimizing risks by encompassing back-up systems. The activity should progress systematically fxom first generation systems based on present technology to the advanced technology systems offering greater promise; i.e., Improvements to or replacements of components should be accomplished in a stepwise manner as the technology develops.

CAVEAT: The recommendations given above to pursue partıcular developments are to be strictly regarded as applicable to early activities concerned with reducing uncertaintles. After uncertainties are reduced and the systems are better understood, studies in much greater depth will be required before recommendations can be made regărding provision of large funding levels necessary to develop any specific technology to the point where it can be commercially implemented. These later in-depth studies must address issues such as relative technical risks versus benefits, amount of $R \& D$ funding required, payback period for the R\&D investment, the match between required technology development time and anticipated technology need dates, and socio-environmental considerations (see Ref. 6). 


\section{REFERENCES}

1. Selcuk, M. K., "Prelımınary Assessment of Flat Plate Collector Solar Thermal Power Plants," Internal Report 900-692, Jet Propulsion Laboratory, Pasadena, CA, March 1975.

2. Caputo, R. S., "Solar Power Plants Using Vee-Trough Concentrators," preliminary draft EM 341-0060B dated December 1976, Jet Propulsion Laboratory, Pasadena, CA, (to be published).

3. Selcuk, M. K., "A Prelimınary Technical and Economic Assessment of Solar Power Plants Using Line Concentrators," Internal Report 900704, Jet Propulsion Laboratory, Pasadena, CA, July 1975.

4. Caputo, R. S., "An Initial Study of Solar Power Plants Using a Distributed Network of Foint Focusing Collectors," Internal Report 900-724, Jet Propulsion Laboratory, Pasadena, CA, July 1975.

5. Selcuk, M. K., et al, "Preliminary Evaluation of a Parabolic DishSmall Heat Engine Central Solar Plant," Internal Report 900-749, Jet Propulsion Laboratory, Pasadena, CA, (to be published).

6. Caputo, R. S., "An Initial Comparative Assessment of Oribtal and Terrestrial Central Power Systems," Final Report 77-44, Jet Propulsion Laboratory, Pasadena, CA, March 1977.

7. Manvi, R., "Terrestrial Solar Power Plant Performance," preliminary draft dated March 1977, Jet Propulsion Laboratory, Pasadena, CA, (to be published).

8. Bartel, J., Prıvate Communication, Sandıa Laboratories, Livermore, CA, February 1977.

9. Gintz, J. R., "Technical and Economic Assessment of Phase Change and Thermochemical Advanced Thermal Energy Storage (TES) Systems," EPRI EM-256 (four volumes), prepared by Boeing Engineering and Constructıon Co., Seattle, Wash., for EPRI, Palo Alto, CA, December 1976.

10. Selcuk, M. K., "Survey of Several Central Receiver Solar Thermal Power Plant Design Concepts," Internal Report 900-714, Jet Propulsion Laboratory, Pasadena, CA, August 1975.

11. Bailey, M., "Near Term Engine Review," Briefing Document 5102-11, A Presentation to ERDA Thermal Power Systems, NASA LeRC/JPL, April 28, 1977.

12. Elliott, D., Private Communication, Jet Propulsion Laboratory, Pasadena, CA, February 7, 1977.

13. Stearns, J., "A Comparative Review of Thermionic Power Conversion For Application to Space and Terrestrial Power," Internal Report 
900-723, Jet Propulsion Laboratory, Pasadena, CA.

14. Merril1, 0., Private Communicatıon, Energy Research and Development Administration, Thermionic Program Manager, January 12, 1977.

15. Britt, N., Private Communication, Rasor Assocıates, January 14, 1977.

16. Huffman, F., Private Communication, Thermo-Electron Corp., January $20,1977$.

17. Shimada, K., "Prospects of Thermionlc Duodes for Space Power Appllcations," AIAA Paper 77-500 presented at the AIAA Conference on the Future of Aerospace Power Systems, St. Louis, MO, March 1-3, 1977.

18. Cole, T., Private Communication, California Institute of Technology, -Falrchild Fellow, January 10, 1977.

19. Hunt, T. K., Weber, N., and Cole, T., "Output Power and Efficiency For a Sodıum Thermoelectric Heat Engıne," Ford Motor Co., Dearborn, MI.

20. Manvi, R., and Fujita, T., "Economics of Internal and External Energy Storage in Solar Power Plant Operation," Jet Propulsion Laboratory, Pasadena, CA (to be published in the 12th IECEC Proceedings).

21. Turner, R., "Thermal Energy Storage for Solar Power Plants," Internal Report 900-754, Jet Propulsion Laboratory, Pasadena, CA, July 1976.

22. Fujita, T., "Preliminary Data on Electrical Energy Storage Systems for Utillty Applıcations," Internal Report 900-738, Jet Propulsion Laboratory, Pasadena, CA, April 1976.

23. Schneider, T. R., (Project Manager), "An Assessment of Energy Storage Systems Suitable for Use by Electric Utilities," EM-264, EPRI Project 225/ERDA E (11-1) - 2501, Public Service Gas and Electric Company, Newark, NJ, July 1976.

24. Turner, R. H., "Economlc Optimization of the Energy Transport Component of a Large Distributed Collector Solar Power Plant," presented at the 11th IECEC, State Line, Nevada, Sept 12-17, 1976.

25. Awaya, H., "Energy Transport Costs for Linear Focusing Distributed Receiver Solar Collection Systems, "Internal JPL IOM 非41-NSTE-77124, May 2, 1977.

26. Doane, J. W., et a1, "The Cost of Energy from Utility-Owned Solar Electric Systems, a Required Revenue Methodology for ERDA/EPRI Evaluations," Internal Report 5040-29, ERDA/JPL-1012-7613, Jet Propulsion Laboratory, Pasadena, CA, June 1976.

27. Herrera, J. G. (Editor), "Assessment of R,D\&D Resources, Health and Environmental Effects, O\&M Costs, and Other Social Costs for Conventional and Terrestrial Solar Electric Plants," Internal Report 900-782, 
preliminary draft dated January 1977, Jet Propulsion Laboratory (to be published).

28. El Gabalawi, N., et al, "Preliminary Parametric Study of Solar/Thermal Power Plants," Engineering Memo 341-014-B, Jet Propulsion Laboratory, Pasadena, CA, May 31, 1977.

29. "Solar Thermal Conversion Mission Analysis, Comparative System/ Economics Analyses," Vo1. IV, Report No. ATR-74 (7417-16)-1, The Aerospace Corporation, E1 Segundo, CA., November 15, 1974.

30. "Solar Thermal Conversion Mission Analysis, Midterm Report," Report No. ATR-76 (7506-05)-1, The Aerospace Corporation, E1 Segundo, CA., September 1, 1975.

31. Gutstein, M., Furman, E. R., and Kaplan, G. M., "Liquid Metal Bınary Cycles for Stationary Power," NASA TND-7955, Lewis Research Center, Cleveland, Ohio, August 1975. 


\author{
APPENDIX A* \\ DISTRIBUTED COLLECTOR SURVEY
}

This appendix summaxizes findings regarding the status of distributed collectors obtained by a survey of industry and government laboratories. The survey was predicated on a screening procedure to first delineate the on-going research and development actlvities within government laboratories and private companies which could contribute information regarding performance and costs of distributed collector systems. Then, discussions were held to ascertain all available and pertinent data.

The survey was implemented by conducting the followng steps:

1) A literature search was undertaken.

2) The names of companies were obtained from:

a) Western Regional Solar Energy Directory.

b) National Solar Heating and Cooling Information Center.

c) Active prime contracts in solar energy programs as of November 30, 1976 furnished by ERDA (now DOE).

d) Technology Applications Center, Unıversity of New Mexıco.

e) Solar Energy Industries Association.

f). Conversations with technical personnel at JPL and outside contacts.

3) Letters were sent to 44 companies requesting: collector description (photos, etc.), performance, capital costs for prototypes and mass-produced units and service/maintenance costs.

4) Based on the company responses, further inquiries were made via telèphone about their concentrators and to make appointments for visits to the plant.

The results of the literature search, letter responses and telephone conversations revealed the following:

1) 14 companies responded and have significant involvement in the development and testing of solar concentrators.

2) 3 companies responded and are just getting started with solar concentrators.

3) 4 companies responded, but are not engaged in the development of solar concentrators.

4) 23 companies did not respond. 
Out of the fourteen companies already involved with concentrators, eight are listed below. These companies responded to the initial requests, provided data and information, and have solar concentrators undergoing testing and evaluation. The eight companies are:

- AAI Corporation.

- Acurex Córporation.

- Del Manufacturing Company.

- General Atomic Company.

- Hexce1.

- Honeywe11, Inc.

- Sheldah1, Inc.

- Raytheon Company.

The followlng information was acquired durıng February September, 1977:

A. AAI CORPORATION, BALTIMORE, MARYLAND

1. General Description

AAI Corporation is developing and testing three different linear focusing solar concentrators:

1) Modular cylindrical roof concentrator, $8 \mathrm{ft}$ aperture by $32 \mathrm{ft}$ long.

2) Venetian blind, strip-mirror concentrator, 8 ft aperture by $32 \mathrm{ft}$ long.

3) Fixed parabolic roof concentrator, $20 \mathrm{ft}$ aperture by $60 \mathrm{ft}$ long.

\section{Cylindrical Concentrator}

This concentrator has a reflective surface composed of glass strıps 2 inch wide by 5 ft long. The concave surface is made of 0.065 inch thick aluminum and the glass strups are cemented to the metal. A metal. framework serves as support structure for the $8 \mathrm{ft}$ by $32 \mathrm{ft}$ concentrator. Orientation for the longitudinal axls of the reflective surface is in an east-west direction. The receiver assembly is remotely actuated and transcrubes an arc as it tracks the sun (Fjg. A-1). Concentration ratio is 8-10 and fluid temperature of approximately $300^{\circ} \mathrm{F}$ at the recelver can be achieved. Sixteen cylindrical concentrators will be utilized to provide the majority of heating and alr conditıoning for Disney World's Central Energy Plant. This concentrator-roof assembly replaces the usual trusses, corrugated decking and concrete roof. For new construction, this concept reduces the costs associated with conventional roofing if solar concentrators are to be part of the design. Each $8 \mathrm{ft}$ by $32 \mathrm{ft}$ modular collector consists of a concave cylindrucal reflective surface and a receiver. The receiver uses water as a heat transfer medium and is kept focused with a linear actuator controller by a sun sensor focusing device. System will be operational in the summex of 1977. 


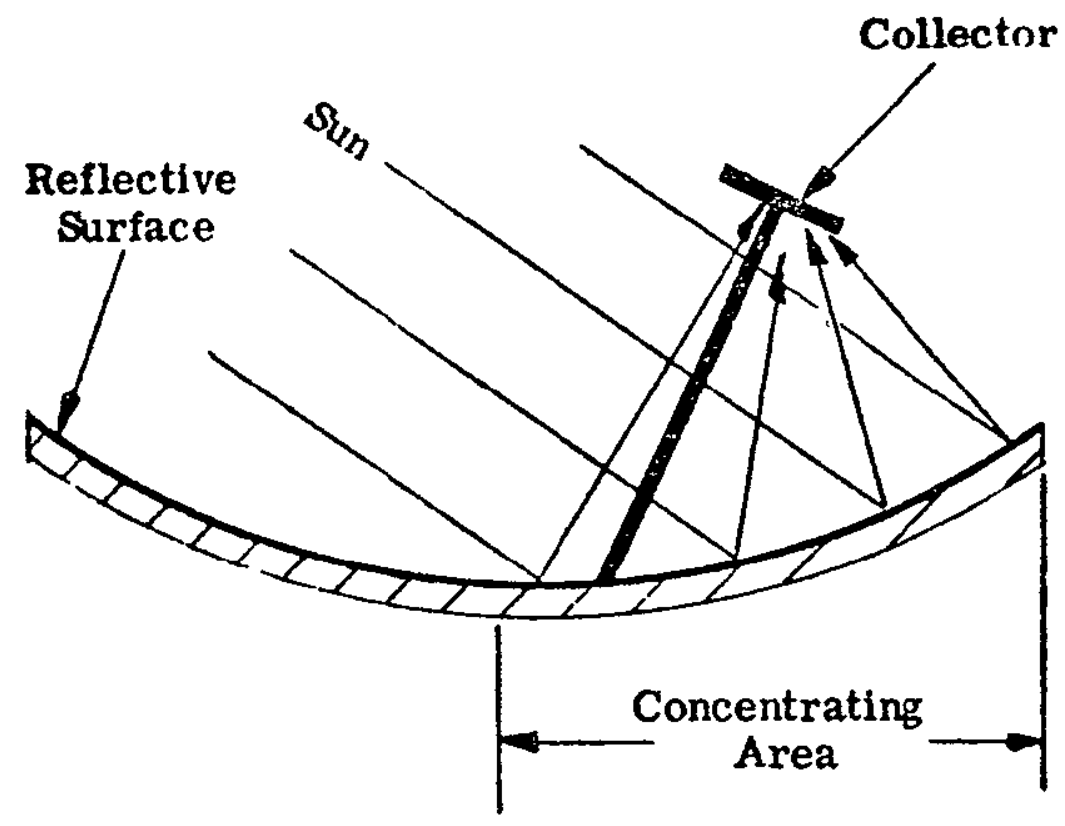

Winter Operation

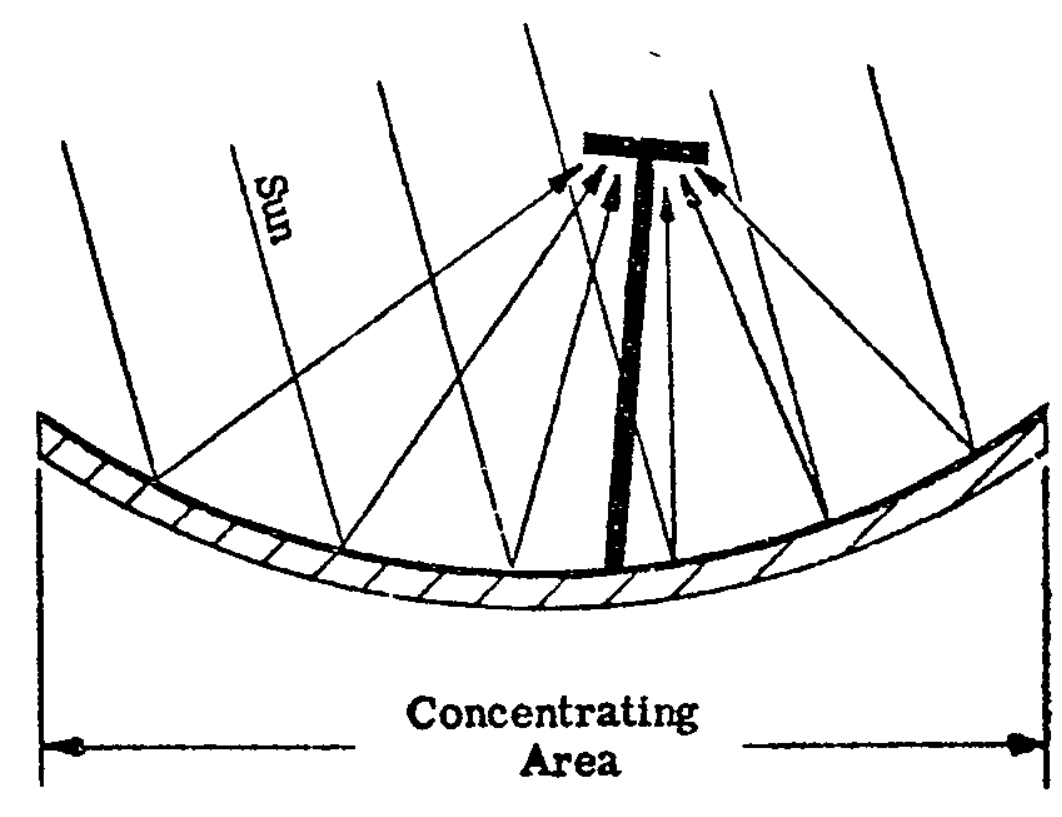

ORIGINAL PAGE IS OF POOR QUALITY

Summer Operation

Figure A-I. Cylindrical Concentrator

A-3 
3. Venetian Blind, Strip-Mirror Concentrator

This concentrator consists of eight mirrors (slightly concave), $1 \mathrm{ft}$ wide by $8 \mathrm{ft}$ long that are motor actuated. Four units comprise the $8 \mathrm{ft}$ by $32 \mathrm{ft}$ concentrator. The fixed receiver is built of 304L stainless steel pipe 3.5 inch 0.D. A metal framework is used to support the mirror assembly and receiver pipe. Rotation axis of the mirrors is oriented in an east-west direction (Fig. A-2).

\section{The Fixed Parabolic Roof Concentrator}

The parabolic roof concentrator utilizes a reflective surface consisting of $3 \mathrm{ft}$ by $5 \mathrm{ft}$ sections of glass, 0.1 inch thick that are curved in-place by means of a metal molding that bolts down. The receiver is movable and tracks the sun with the aid of a sensor and an electric motor (Fig. A-2). This parabolic roof concentrator will be included in a retrofit installation on the one-story Padonia Elementary School, MD. Most of the heating and cooling required for the cafetorium, library and administratıve suite will be provided by the concentrator. The concentrator system consists of fixed parabolic reflector mirrors mounted on the south end of the school with an electronic sun-sensing control mechanism, hot/cold water storage and an absorption chlller. Expected operational date is August 1977.

\section{B. ACUREX CORPORATION, MOUNTAIN VIEW, CALIFORNIA}

\section{General Description}

The parabolic trough concentrators designed and built by Acurex have the receiver tube positioned east-west, and remote tracking takes place in a north-south direction. The $6 \mathrm{ft}$ aperture by $10 \mathrm{ft}$ long collectors are designed to be coupled together to form a Iine of eight units, driven by a single-motor. This arrangement can be modifled and the number of collectors can vary to accommodate the application. Figure A-3 shows the parabolic concentrators and corresponding performance data.

\section{Collector}

The collector frame is constructed of moderate-weight painted metal and the reflecting surface is aluminum lighting sheeting 0.038 inch thick (Alzak). Metal brackets are used at the edges of the Alzak to firmly press the sheets against paraboluc-shaped metal ribs that form the contour of the trough. Neither adhesives nor cements are used to bond the sheets to the metal frame.

\section{Receiver Assembly}

Each collector is equipped with a 1.25 inch diameter mild steel receiver tube. The receiver tube is coated wtih either black paint or selective black chrome over nickel plate (for applications over $250^{\circ} \mathrm{F}$ ). A pyrex glass tube encloses the receiver tube. Up to this time Acurex has not seriously considered using an evacuated tube to enhance performance. Fluids that may be used in the receiver tube are water, organic 


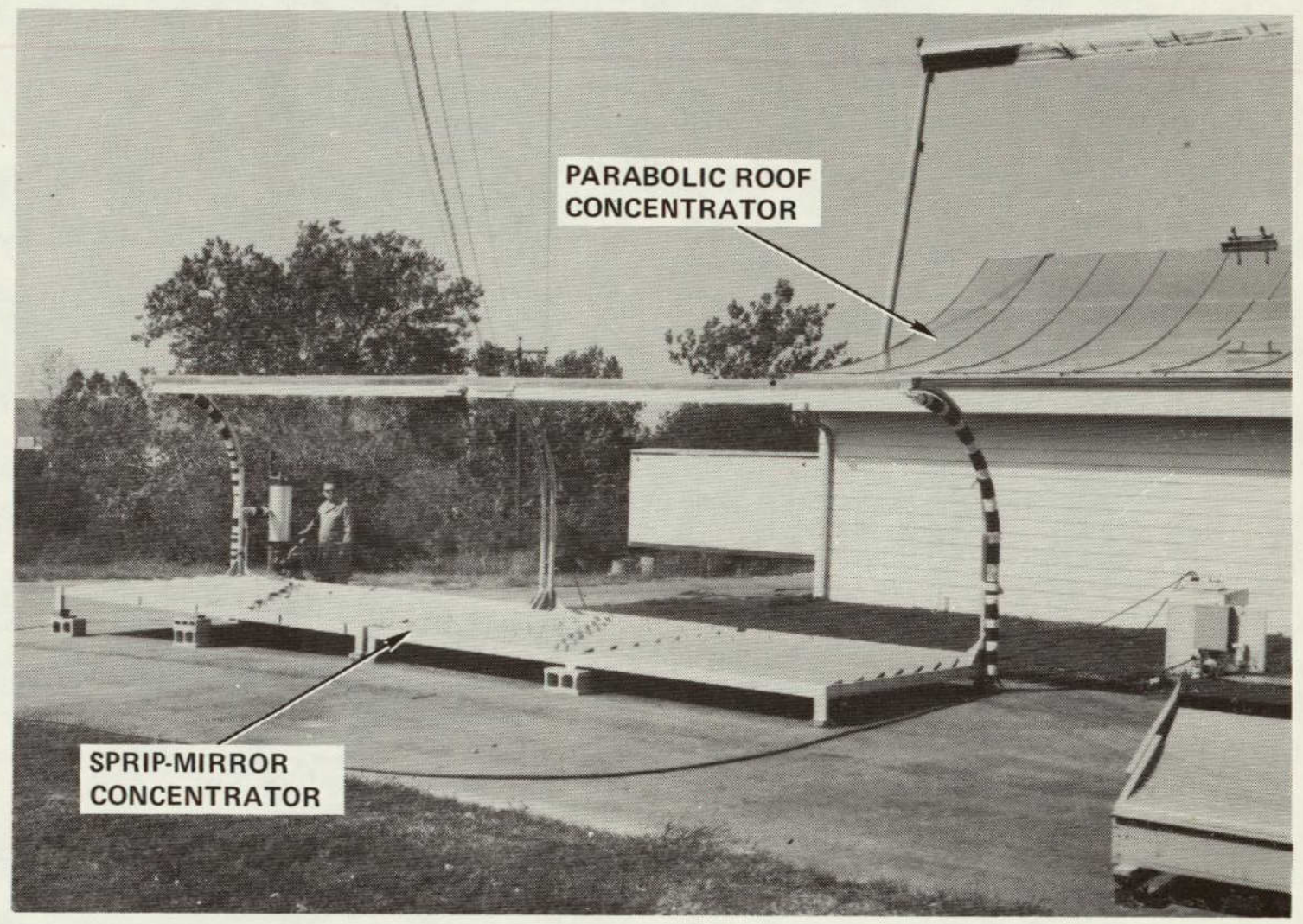

Figure A-2. Solar Concentrators

ORIGINAL PAGE IS
OF POOR QUAITIY 

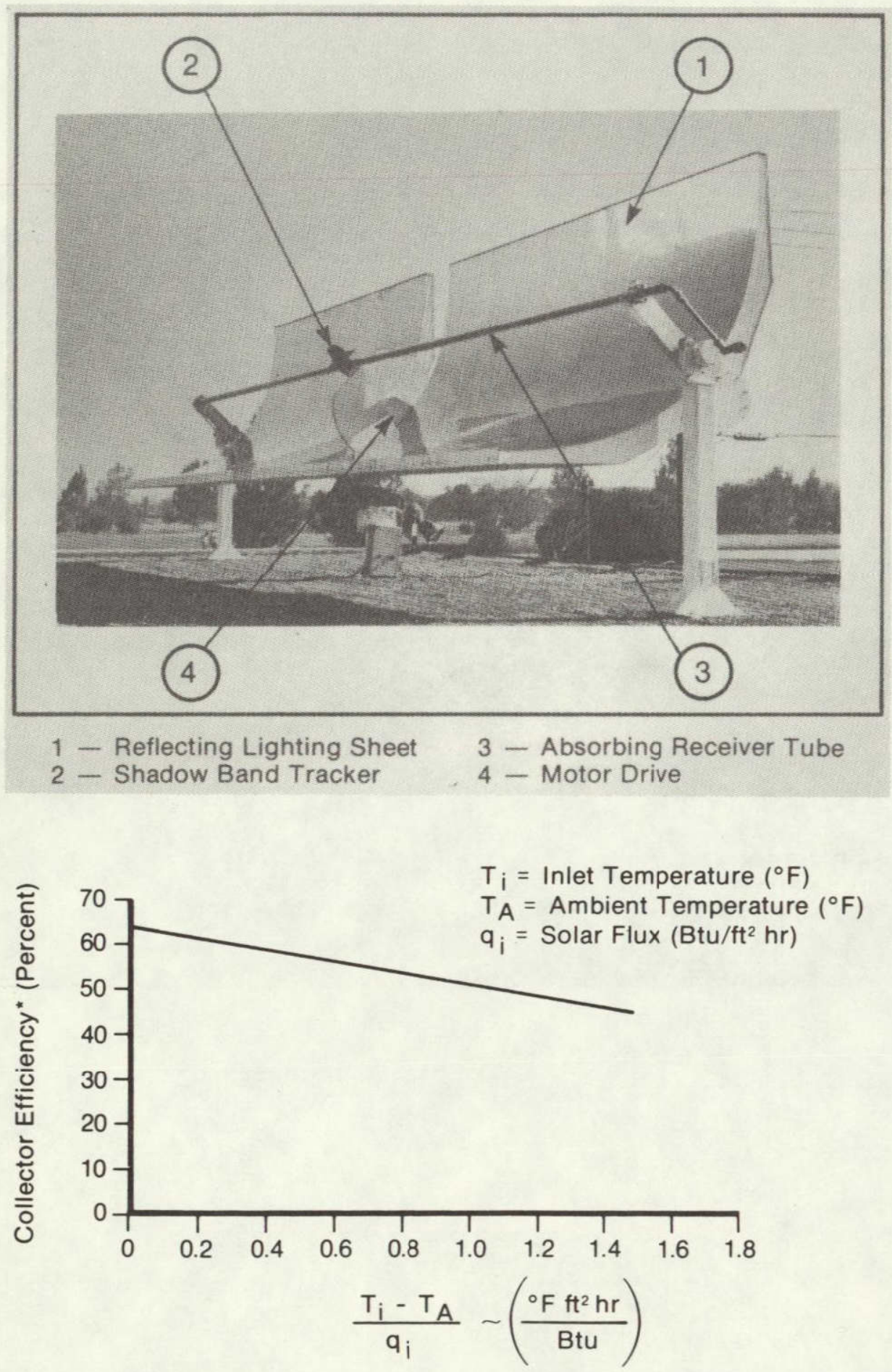

"Based on experimental data for a clear day, normal incidence, and no dust loss.

Figure A-3. Parabolic Trough Concentrator and Performance Data 
liquids, or air. The receiver tube is equipped with a central orifice that produces the proper convective coefficients with an acceptable fluid pressure drop. The size of the orifice is based on the specifications of the overall system.

\section{Tracking and Control System}

Tracking of the sun and trough rotation is accomplished by means of of a motor/chain drive system and associated silicon photocells. Acurex developed and built their own tracking system prior to the time when commercial units were readily available. The bridge circuit connected to the photocells is imbalanced by shading one of the photocells. Balance is restored when the drive system seeks the sun and rotates the parabolic troughs. No provisions are available for automatically going to the store position due to undesirable climatic or hazardous conditions (rain, hail, etc.).

\section{Comments}

Approximately $7,000 \mathrm{ft}^{2}$ of parabolic troughs are scheduled to be installed at a New Mexico farm for irrigation purposes. Another project at the Campbel1 Soup Company, Sacramento, CA, will utilize 3,000 $\mathrm{ft}^{2}$ for the company's canning/washing operation. During the development of the parabolic troughs, Acurex has lowered their cost for the collector unit (reflector, receiver, and tracking system) to $\$ 14.50 / \mathrm{ft}^{2}$ for production runs of $10,000 \mathrm{ft}^{2}$. The company is quoting $\$ 10.40 / \mathrm{ft}^{2}$ for orders of 50,000

$\mathrm{ft}^{2}$. Future mass production costs are estimated in the range of $\$ 6-8 / \mathrm{ft}^{2}$.

C. DEL MANUFACTURING COMPANY, MONTEREY PARK, CALIFORNIA

1. General Description

De1 has designed and is testing/evaluating their linear focusing parabolic trough concentrators. Each collector module is $2 \mathrm{ft}$ by $8 \mathrm{ft}$ long and eight can be grouped together and be driven by a single motor. The parabolic troughs are constructed such that the longitudinal axis is east-west oriented (Figs. A-4 and A-5). Figure A-5 shows steam being produced by the concentrators and results of performance computations. A unique feature of this design is the glass mirror segments used as a reflective surface.

\section{Collector}

The parabolic trough's reflective surface is composed of eight curved, glass mirror segments. Each second-surface mirror segment is $1 \mathrm{ft}$ wide and $2 \mathrm{ft}$ long and back-silvered to provide protection from the environment. Design and construction of the collector permits replacement of individual mirror segments for cleaning, replacement, or inspection in the field. The glass mirror provides a stable, lasting surface 




Figure A-4. Parabolic Concentrator Test Site 

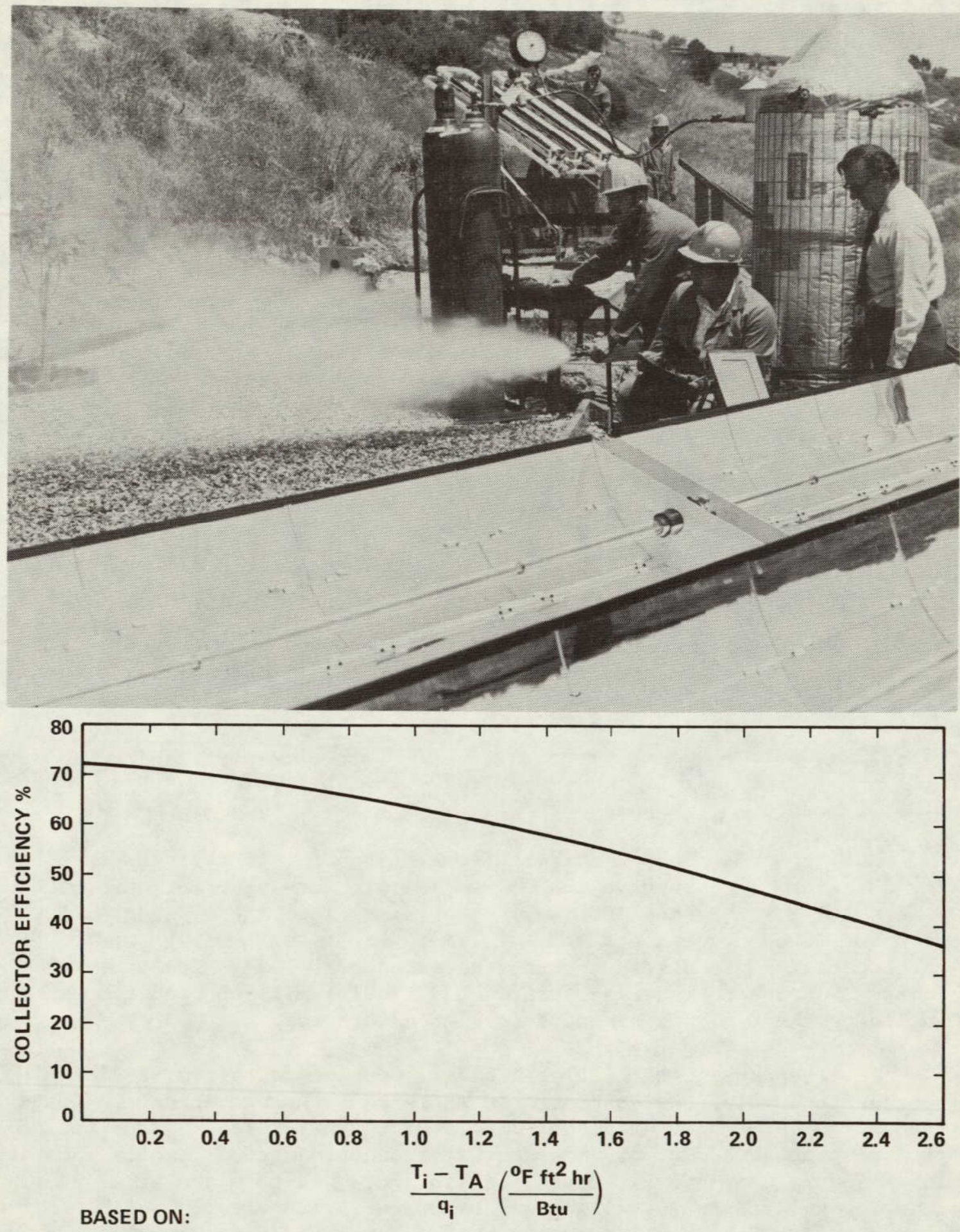

- INSOLATION VALUES FROM 200 TO 300 Btu/hr-ft2

- NO WIND CONDITION

- $\mathrm{T}_{\mathbf{i}} \sim$ INLET TEMPERATURE

- TA AMBIENT TEMPERATURE

- $\mathrm{q}_{\mathrm{i}} \sim$ INSOLATION

Figure A-5. Parabolic Trough Concentrator and Performance Computations 
that will not scratch or mark during cleaning. Reflective efficiency for these mirrors is in excess of $90 \%$. A rigid metal framework comprises the structure that supports the mirror segments and bearings utilized during the tracking mode.

\section{Receiver Assembly}

A stationary steel tube, 0.5 inch 0.D., plated with a selective black chrome coating over dull nickel comprises the receiver. Since the receiver tube is fixed, leaks from pipe joints transporting hot water, air or steam are minimized. Each receiver tube is surrounded by a 1.5 inch O.D. pyrex glass tube to reduce convection losses and protect the selective surface from the environment. The system has been designed such that the stationary receiver is on the center of gravity of the rotating system, thus minimizing motor drive requirements and cost. Evacuation of the space between the steel and glass tube has been considered but has not taken place at this time.

\section{Tracking and Control System}

Tracking is accomplished by means of a reversible electric motor and related photoelectric sensor. A commercially available sensor produced by Delavan Corporation is used to provide the electrical signal to the 24 volt dc motor. Up to eight parabolic troughs connected together can be driven with one motor. The system control logic will place the reflecting surfaces face down at night and during undesirable climatic or hazardous conditions (rain, hail, etc.).

\section{Comments}

Del has developed a number of mass production techniques in producing a variety of aerospace and commercial products. Formation of the Jacobs-Del Solar Systems Company to act as exclusive worldwide distributors for the concentrators and to serve a broad range of industrial and commercial processes was announded in August 1977. The parent company, Jacobs Engineering, represents a multi-million dollar operation including the U.S. and numerous foreign countries.

At the present time Del has a $\$ 113,000$ contract from Sandia, Albuquerque to develop the concentrator and extend the operating temperature from $400^{\circ} \mathrm{F}$, presently attainable, to $600^{\circ} \mathrm{F}$. They recently received an ERDA contract award to provide hot water and steam to a laundry, American Linen Supply Company, E1 Centro, California. Due to a number of uncertainties related to installing solar concentrators (i.e., possible increases in real estate taxes, required service and maintenance, etc.), the owner decided not to participate in the project. As an outgrowth of that project, negotiations are taking place with DOE to install Del concentrators at a Home Laundry in Pasadena, California to provide hot water and steam. The cost estimates for $1 \times 10^{6} \mathrm{ft}^{2}$ of concentrators is $\$ 10-12 / \mathrm{ft}^{2}$. 
D. GENERAL ATOMIC COMPANY, SAN DIEGO, CALIFORNIA

The fixed mirror linear focusing solar concentrator developed and built by General Atomic is approximately $5 \mathrm{ft}$ (aperture) by $10 \mathrm{ft}$ long. Surface of the concentrator where the mirrors are located is basically a concave cylindrical contour with built-in steps to accommodate the reflective surface (Fig. A-6). Reflective surfaces consist of glass mirror strips approximately 2 inch wide cemented to the cylindrical contour. The entire base where the mirror strips are placed is made of cement.

A movable receiver tube tracks the sun by means of an actuator. To accommodate the motion, flexible hoses that carry the fluid are utilized at each end of the concentrator. Orientation of the concentrator's longitudinal axis is east-west. The program has consisted of: 1) preparation of a dynamic computer model to predict performance, 2) preliminary engineering design of system components, 3) testing and evaluation of concentrator, and 4) preparation for testing the proposed construction method. General Atomic personnel indicate that their concentrator is applicable not only for total energy applications but also for process heat and electric power generation. Present unit cost is in excess of $\$ 20 / \mathrm{ft}^{2}$ corresponding to $200,000 \mathrm{ft}^{2}$ being manufactured.

This program was initiated by EPRI (Electric Power Research Institute) and the testing will be conducted with joint EPRI/DOE sponsorship.

E. HEXCEL, DUBLIN, CALIFORNIA

1. General Description

Hexcel has designed, developed, and constructed tracking parabolic trough linear focusing concentrators. The receiver tube is oriented east-west and remote tracking occurs in a north-south direction. They are producing a $9 \mathrm{ft}$ aperture by $20 \mathrm{ft}$ long (complete parabola) with concentration ratios of 60-80. Testing is taking place on a $5 \mathrm{ft}$ aperture by $10 \mathrm{ft}$ long, termed half parabola (from an end view only one-half of the parabola is utilized). Concentration ratio of this latter configuration is about 34. One of the unique features of their design is the lightweight aluminum honeycomb sandwich used for the parabolic section. Figure A-7 shows the parabolic concentrators and performance data.

\section{Collector}

Hexcel's collector panels are constructed of an aluminum honeycomb sandwich. Three elements make up a sandwich panel: face sheet, adhesive and honeycomb core. The face sheet is typically 0.020 inch thick, and the core is a corrosion-resistant treated aluminum honeycomb. The reflective surface material is an aluminized acrylic film. Weight of the collector panels is approximately $71 \mathrm{~b} / \mathrm{ft}^{2}$ or $32 \mathrm{lb}$ per trough. 

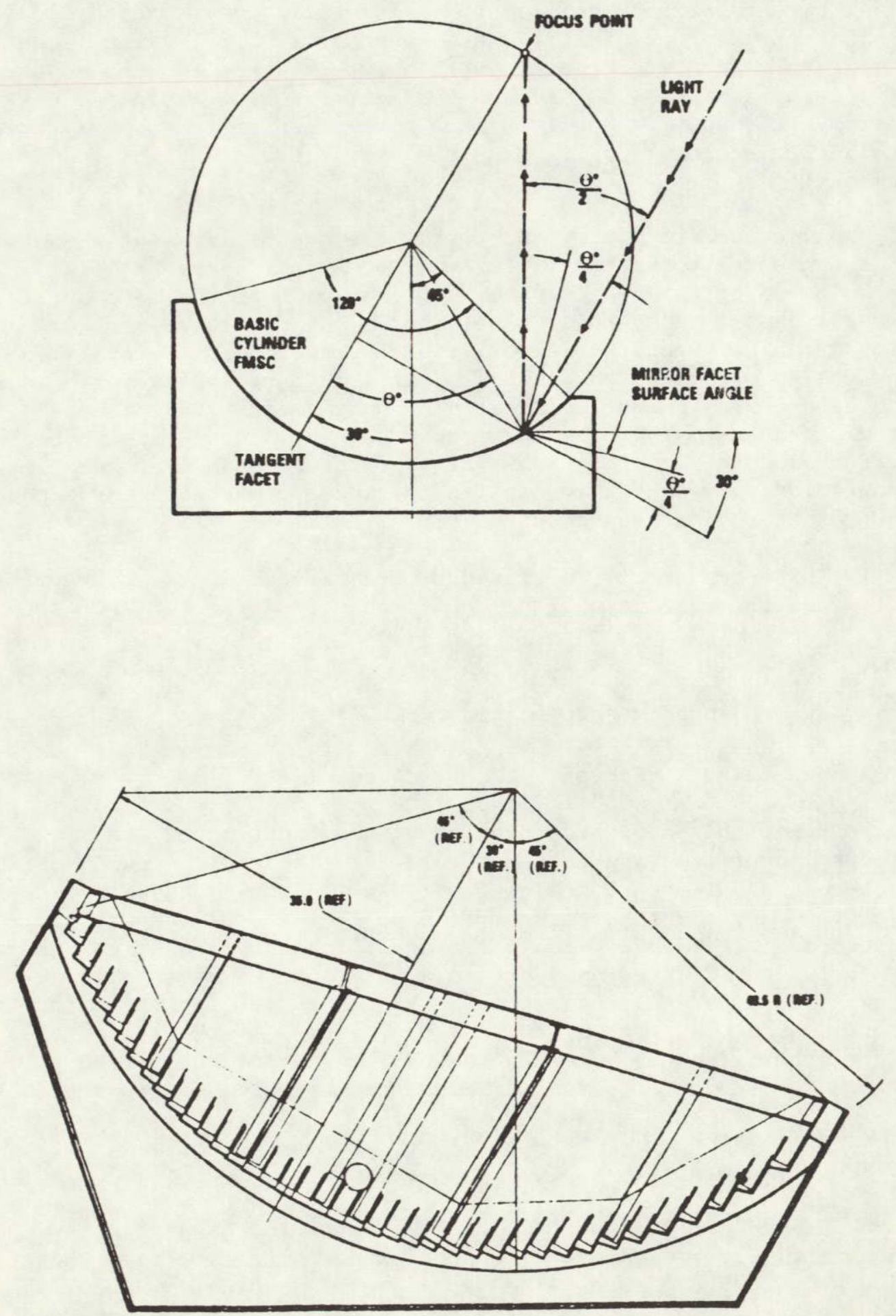

Figure A-6. Fixed-Mirror Solar Concentrators (Sideview) 



Figure A-7. Parabolic Trough Concentrator and Performance Data 


\section{Receiver Assemb1y}

The receiver, which is supported in an insulated casing, can be copper, steel, or glass depending on the chemistry and operating temperature of the working fluid. Their present configuration consists of a pyrex half cylinder, to reduce convection losses, covering a selectively coated copper pipe encapsulated with an insulated galvanized sleeve. Another receiver design they have developed includes a back-up secondary reflector. Estimated costs for the receivers are approximately $\$ 4 / \mathrm{ft}^{2}$ of aperture area.

\section{Tracking and Control System}

The parabolic trough tracks the sun with the aid of photo transistor sensors and an electro-mechanical drive. The associated bridge circuit is imbalanced by shading one of the transistors and balance is restored as the drive mechanism seeks the sun and rotates the parabolic trough. The system is designed to sense undesirable climatic or hazardous conditions (rain, hail, etc.) and rotates the trough to the store position until conditions have cleared. Additional features include a standby $24 \mathrm{Vdc}$ power supply that will maintain or store the trough in the event of a utility power failure.

\section{Comments}

The $9 \mathrm{ft}$ by $20 \mathrm{ft}$ parabolic troughs have achieved receiver temperatures of $800^{\circ} \mathrm{F}$ at its plant at Casa Grande, Arizona. About $1200 \mathrm{ft}^{2}$ of concentrators heat air that is used to generate heat for manufacturing processes. Hexcel is utilizing this type of trough with a modified Rankine cycle engine for an irrigation project in Gila Bend, Arizona. Private funding for this demonstration project was obtained from Northwest Mutual Insurance Company and Battelle Institute. Hexcel is projecting commercial costs of $\$ 15-20 / \mathrm{ft}^{2}$ for $40,000-50,000 \mathrm{ft}^{2}$ production runs. In addition, estimated installation costs are about $\$ 2 / \mathrm{ft}^{2}$. Anticipated service and maintenance involves hosing reflective surfaces with high pressure water, and final rinse once every 3-4 weeks with water containing surfactants.

\section{F. HONEYWELL, INC., MINNEAPOLIS, MINNESOTA}

\section{General Description}

Honeywell has been a pioneer in the field of tracking parabolic trough linear focusing concentrators. In cooperation with the University of Minnesota, Honeywell has designed, developed and extensively tested the concentrators. Initial work on the parabolic trough, started approximately four years ago, has a $3.7 \mathrm{ft}$ aperture and is $12.7 \mathrm{ft}$ long (Fig. A-8). A $4 \mathrm{ft}$ aperture by $20 \mathrm{ft}$ long unit (collector consists of half parabola) is being tested at the Minneapolis plant. Both troughs have their longitudinal axes oriented in an east-west direction. 


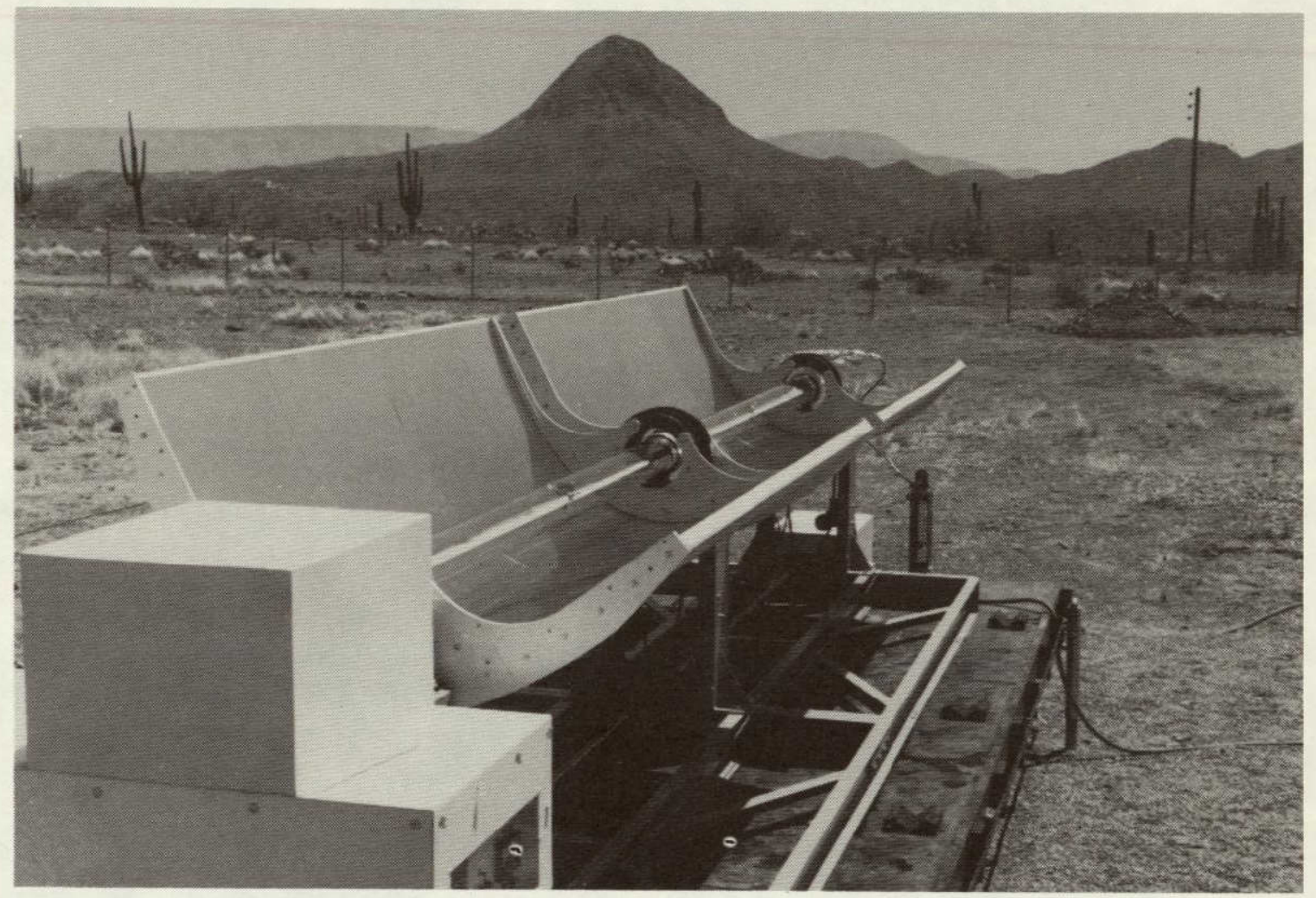

Figure A-8. Parabolic Trough Concentrator

ORIGINAL PAGE IS

OF POOR QUAIII'A 


\section{Parabolic Trough Concentrator}

The $3.7 \mathrm{ft}$ by $12.7 \mathrm{ft}$ long trough has undergone continued exposure testing at Phoenix, Arizona. Reflective surface material used on the trough is first surface anodized aluminum (Alzak). Samples of a number of different types of reflecting surfaces have been subjected to solar exposure. Some of the samples include: 1) first surface aluminized fiberglass with protective coating, 2) second surface aluminum and silver mirrors on acrylic, teflon, and glass, and 3) first surface anodized aluminum. Concentration ratio for the trough is about 41 , and $300^{\circ} \mathrm{C}$ working fluid temperature has been achieved at the receiver. The receiver consists of a 1-inch diameter tube enclosed by a glass cylinder. A vacuum is maintained in the space between the tube and the glass cylinder to reduce heat loss from the receiver and to protect the high absorption material deposited on the tube. In this design the receiver tube remains fixed and the parabolic trough, as it tracks the sun, rotates around the receiver.

\section{Half-Parabolic Trough Concentrator}

Honeywell is developing and testing a half-parabolic concentrator. The collector panel is constructed of honeycomb and Sotchcal 500 (supplied by Minnesota Mining and Manufacturing Company) which is used as the reflective surface. A stainless steel receiver is enclosed by a 1.0 inch diameter glass tube covered with insulation on the back side. They are in the process of acquiring data and evaluating performance.

\section{Comments}

Honeywell plans to install $20,000 \mathrm{ft}^{2}$ of parabolic troughs to be used for air conditioning one of their buildings in Minneapolis, Minnesota. The troughs will be mounted on the roof of an existing building. The target date for installation and operation is May 1978. In regard to costs, the prototypes are running approximately $\$ 35 / \mathrm{ft}^{2}$ and corresponding installed system costs for typical applications will be in the range of $\$ 60-100 / \mathrm{ft}^{2}$.

\section{G. SHELDAHL, INC., NORTHFIELD, MINNESOTA}

Sheldah1 has been performing tests on a linear focus solar concentrator (Fig. A-9). Their system consists of a field of slightly curved rectangular mirrors reflecting sunlight onto a fixed receiver tube. Ten mirrors ( $1 \mathrm{ft}$ wide, $20 \mathrm{ft}$ long and resembling venetian blinds) comprise half of the system. An identical set of mirrors is linked adjacent to the first group to include a total of $400 \mathrm{ft}^{2}$ of mirror surface. The drive system that adjusts the mirror position consists of a $24 \mathrm{Vdc}$ motor with an accompanying auxiliary battery system. Reflective surfaces that they have tested are aluminized film with plastic or teflon coating and 
glass with a silvered second surface. Sheldahl is well known for their flexible composite materials and they have developed and produced reflective surfaces for solar applications. The maximum fluld temperature achievable at the receiver is $630^{\circ} \mathrm{F}$ using water as the working fluid. Tests at a recelver temperature of $300^{\circ} \mathrm{F}$ reveal that the absorptivity is 0.95 and emittance is 0.2. A limited amount of performance data- is

- available at this tēmperature.

Sheldahl has installed a total of $400 \mathrm{ft}^{2}$ of solar concentrators that have been operational for approximately one year in an apartment complex at the Bahama Islands. One of their concerns is the moisture/ humidity content of the islands and its adverse effect on the aluminized film. Sandia, Albuquerque reported that an aluminized film with tefion coating degraded about 5\% reflectivity in one year. SheldahI has been working on three contracts from the following organizations: 1) American Technological University, Texas, 2) Sandia, Albuquexque, and 3) DOE. The first contract is to fabricate a solar concentrator module $\left(400 \mathrm{ft}^{2}\right)$ for testing, evaluation, and delivery to the University. The second contract includes evaluation of the design both technically and economically as applied to large-scale applications. The last contract includes delivery of a solar concentrator, installation, and limited test support at Sandia, Albuquerque.

\section{H. RAYTHEON COMPANY, BEDFORD MASSACHUSETTS}

\section{General Descruption}

The Raytheon Company is participating in the DOE/Sandia Laboratories total energy systems development program by designing and fabricating a parabolic, point concentrator solar collector. Current program planning is to-demonstrate the collector at Sandia Albuquerque in the fall of 1977. In the following year Raytheon will construct, install, and operate a three-collector field at the same location.

The point concentrator designed and under construction is a toric parabola of $22 \mathrm{ft}$ diameter. Azimuth and elevation drive systems are computex controlled and provide maximum aperture utılization over a course of the year. Mirxors are curved glass, hard-mounted on an aluminum substructure, concentrating the solar energy into a cavity receiver located on the collector's optical axis.

Figure A-I0 is an artist's concept of the point concentration collector. The receiver material is zirconuum copper, plated with Harshaw black chrome selective coating. Recelver efficiencies of 90 percent are expected, attalned by the relatively high energy concentration, the selective coating, minimization of reflected radiatıon leaving the cavity, and the convection suppression effect of the cavity design. 


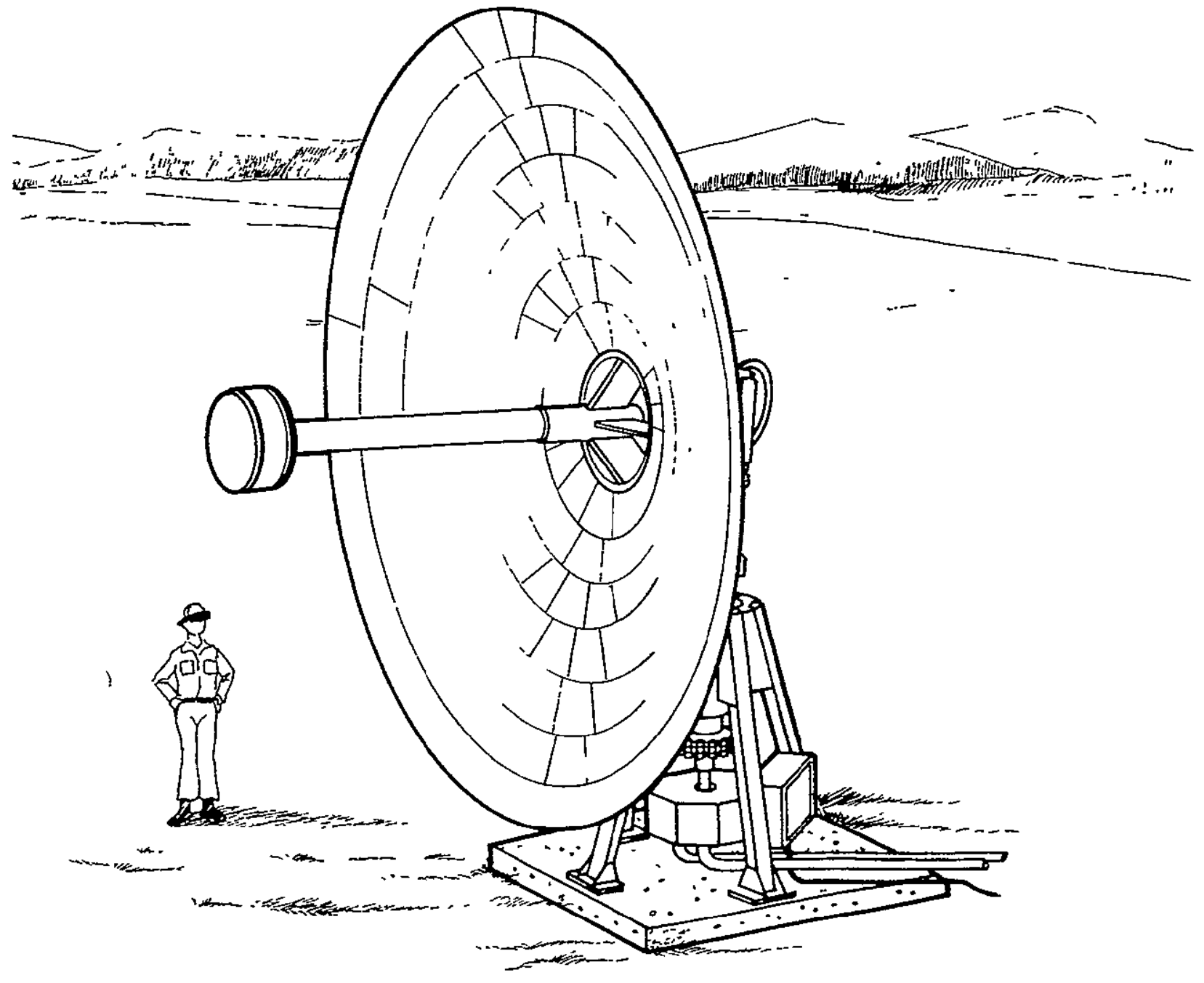

Figure A-10. Point Concentrator Collector

The reflective parabolic design is implemented by spherical mirror segments hard-mounted on an aluminum substructure. The mirrors are curved, water white crystal glass, back silvered to provide maximum reflectance over the course of an expected twenty year life. Specular reflectance values on the order of 0.9 are expected from the mirrors. This parabolic dish is approximated by 228 spherical mirrors in seven rings (Fig. A-11). Mirror rings are made with a slight overlap to minimize mirror mechanical tolerance problems. The collector is driven in azimuth and elevation by dc stepping motors. These drives are computer controlled in an open loop incremental manner. 


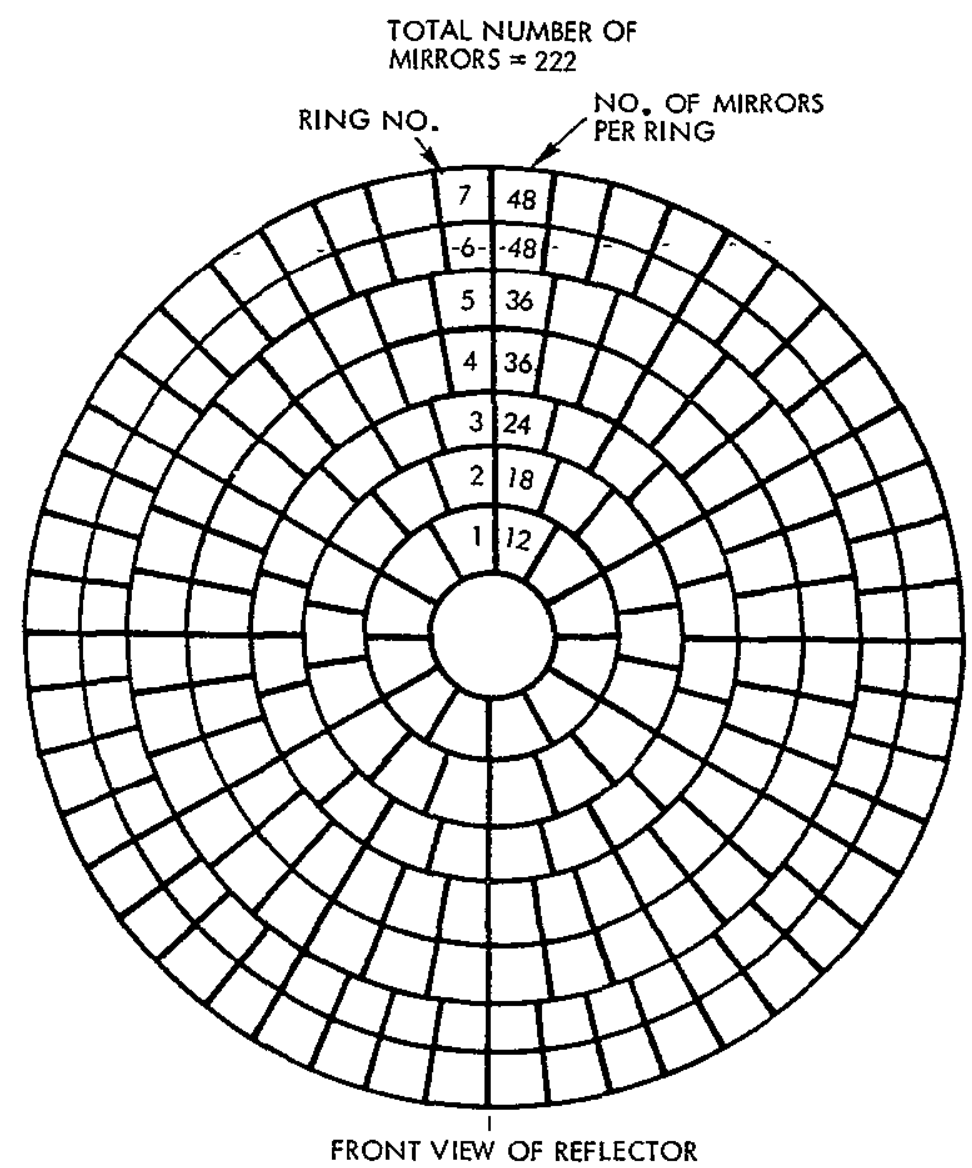

Figure A-11. Reflector Mirror Layout

\section{Comments}

The contract Raytheon is engaged in, calls for delivery of heated Therminol from the parabolıc dish at approximately $600^{\circ} \mathrm{F}$. Sunstrand Corporation will supply the turbine that will be used in conjunction with the dish for Sandia's total energy project. They plan to deliver one dish to Sandia by the end of summer 1977. Upon delivery, testung and evaluation will continue for about a year with Sandia and Raytheon personnel cooperatively takıng data and analyzing results. 


\author{
ISSUES INVOLVED \\ IN \\ DETERMINATION OF R\&D FUNDING LEVELS
}

What level of R\&D funding Is justified in pursuing a particular technology development that promises to achieve a certain projected commerclal energy cost reduction over other alternatives? This question can be addressed in a 1imited fashion based on work in Refs. 6 and 27. The approach is illustrated in terms of the following example involving the dish-Brayton and Stirling systems.

A successful Stixling engine development program appears to offer a $10 \%$ reduction in commercial energy cost compared to a Brayton engine. This reduction corresponds to an $\simeq 10 \mathrm{mills} / \mathrm{kWe}-\mathrm{hr}$ savings. What is this worth to society?

Using analysis developed in Ref. 6 , the equivalent energy cost of an $R \& D$ expenditure can be estimated by treating the R\&D cost as a capital investment to be spread out over the energy generated. The independent variables are:

1) Discount rate to be applied to this investment. In this case, it is a social discount rate and $10 \%$ Is used.

2) The amount of future energy to be generated using the results of this R\&D program. This depends on the rate of introduction of new plants, and the payback perzod over which energy generation occurs.

Using the information developed in Ref. 6, the rate of power capaclty introduction is shown In Fig. B-1 based on a successful development program. It closely follows the nuclear precedent and has $50 \mathrm{GWe}$ installed in 20 years after commercial demonstration.

Figure B-2 shows the equivalent energy cost surcharge to pay back the $R \& D$ investment at $10 \%$ interest. This is the levelized R\&D energy cost as a function of allowable time to generate power. At 20-year payback time, a $10 \mathrm{mllls} / \mathrm{kWe}-\mathrm{hr}$ energy surcharge (corresponding to the projected savings of the Stirling system over the Brayton) will pay back about $\$ 10$ billion dollars to $R \& D$ investment.

The Ford Motor Company recently estimated that $\$ 164$ million would be required to develop an automotive Stirling engine. Allowing for some margin of error, this estimate can also be applied to solar Stirling engines since it is easier to develop an engine for stationary solar applications than for mobile automotive uses. Using $\$ 164$ million as a rough estimate, it 15 found that this amount is only $\approx 2 \%$ of the $\$ 10$ bil1zon amount that a 20-year payback period would indicate as reasonable. The amount of tıme for the payback is a social decision. This is only one way to look at the value of $R \& D$ to society and Is offered here as a numerical approach that may be of some value to the reader. 


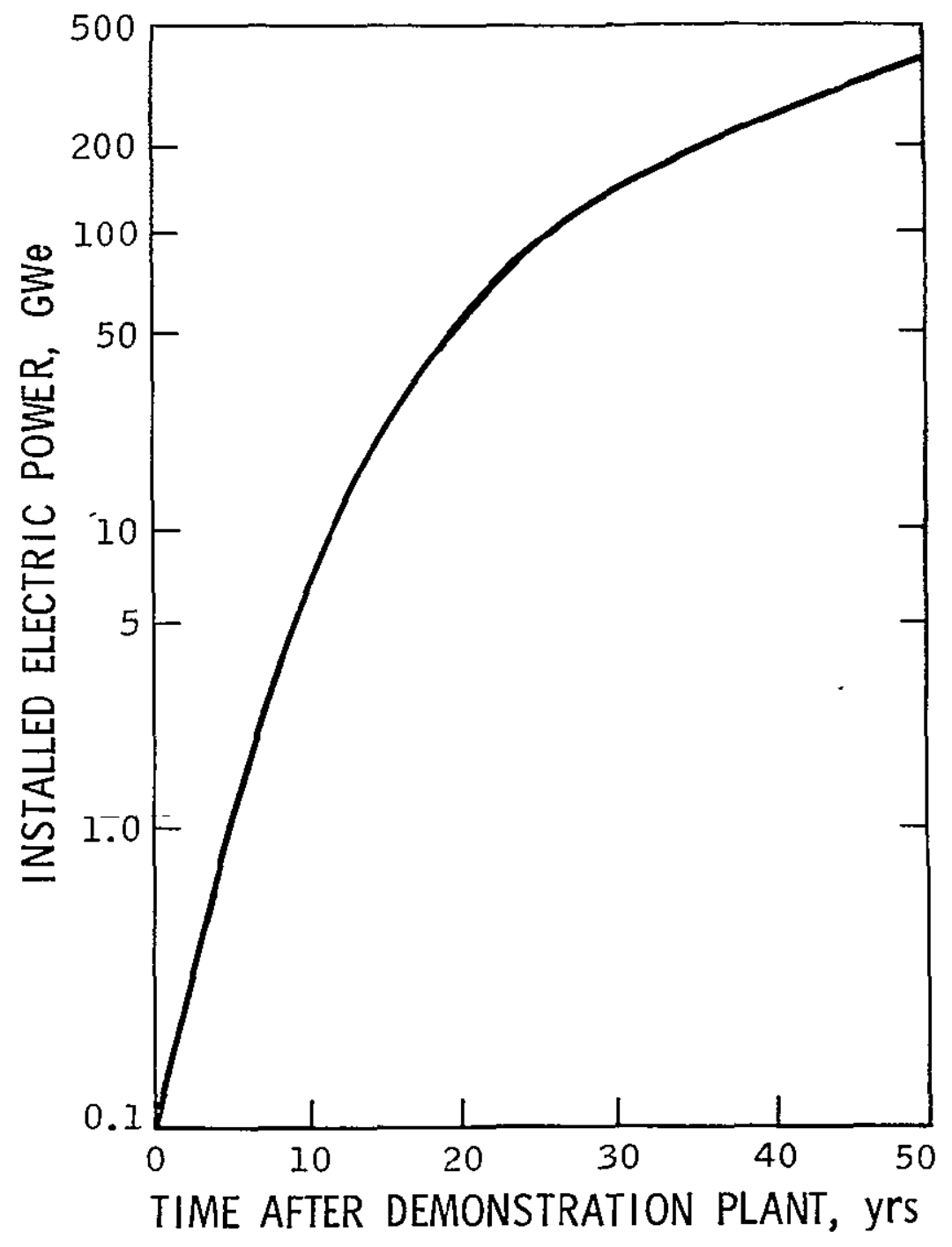

Figure B-1. Projection of New Plant Installation 


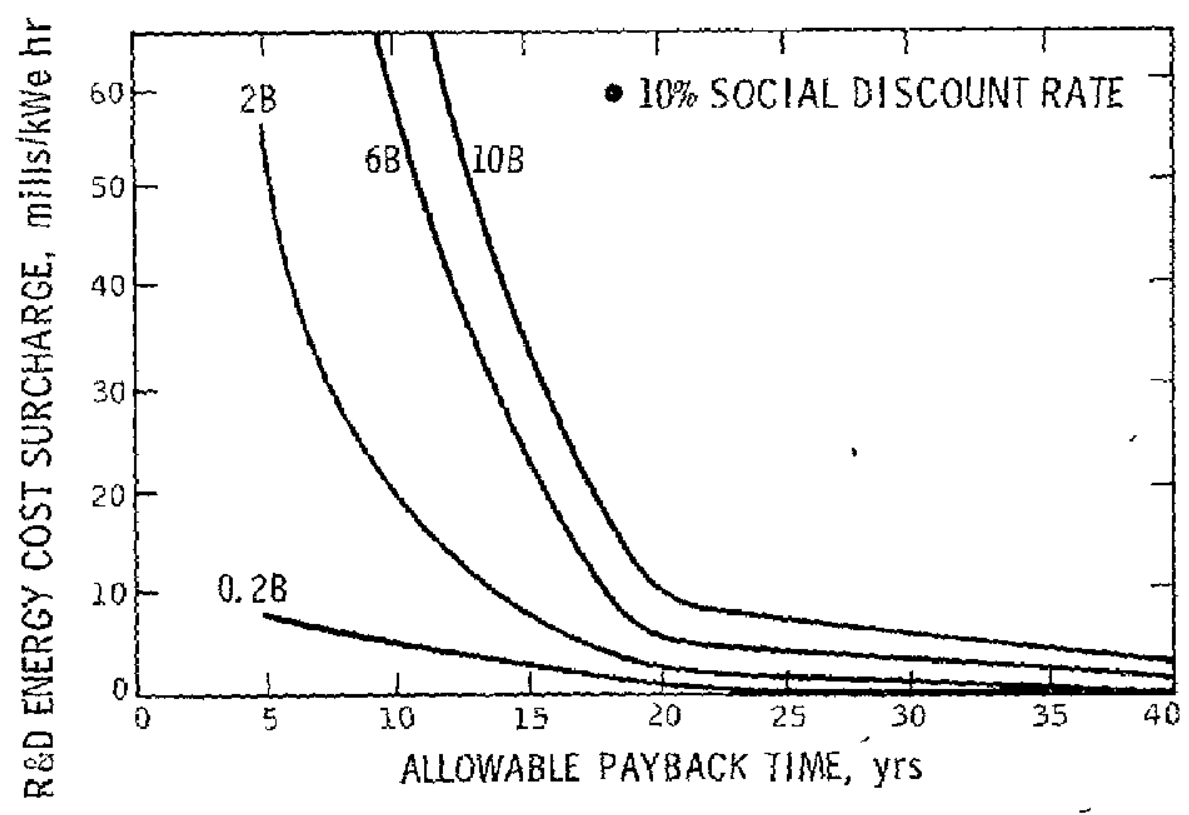

Figure B-2. Payback of Ró Energy Costs 
$-\mathrm{jp} \longrightarrow$ PUBLICATION 77-79 